Illinois State University

ISU ReD: Research and eData

Theses and Dissertations

3-7-2017

\title{
Characterizing Exceptional Superintendent Leadership in Ethnically and Economically Diverse School Districts
}

Nicholas Henkle

Illinois State University, nhenkle@gmail.com

Follow this and additional works at: https://ir.library.illinoisstate.edu/etd

Part of the Educational Administration and Supervision Commons

\section{Recommended Citation}

Henkle, Nicholas, "Characterizing Exceptional Superintendent Leadership in Ethnically and Economically Diverse School Districts" (2017). Theses and Dissertations. 680.

https://ir.library.illinoisstate.edu/etd/680

This Dissertation is brought to you for free and open access by ISU ReD: Research and eData. It has been accepted for inclusion in Theses and Dissertations by an authorized administrator of ISU ReD: Research and eData. For more information, please contact ISUReD@ilstu.edu. 


\title{
CHARACTERIZING EXCEPTIONAL SUPERINTENDENT LEADERSHIP IN ETHNICALLY AND ECONOMICALLY DIVERSE SCHOOL DISTRICTS
}

\begin{abstract}
Nicholas Henkle
173 Pages

This study examined 'exceptional' superintendent leadership in ethnically and economically diverse school districts. The purpose of the study was to use comparative case studies to better understand the beliefs and strategies these proven leaders employ to positively impact achievement and close the opportunity gap for students in ethnically and economically diverse school districts. The study examined three superintendents from the state of Illinois with respect to their philosophy, identified district strengths, culturally responsive attitudes and actions, leadership style, core beliefs, direct impact on students, and decision-making process to identify commonalities and differences that exist.
\end{abstract}

Culturally responsive leadership was the theoretical lens for this study. The research questions reflected this framework and provided a focus for the study. Evidence was collected through individual interviews with each superintendent and members of his or her administrative team and by collecting and examining observation data and artifacts. After collecting and analyzing the data, patterns, and themes were identified and analyzed to develop superintendent portraits. These portraits illuminated the characteristics of exceptional superintendents, including: (a) The Superintendent Recognizes Culture as Paramount to Effective Instruction; (b) The Superintendent Has a Deep Understanding of What Quality Instruction Looks Like; (c) The Superintendent Effectively Engages the Community; (d) The Superintendent Hires Educators Who Believe Culture and Language is Essential to Learning; (e) The Superintendent Articulates 
a Vision that Denies Deficit-Thinking; (f) The Superintendent Innovates to Ensure Equity and Excellence for Every Child.

One essential theme was identified much more frequently in the context of serving in ethnically and economically diverse school districts. The theme was that of the Superintendent as a Culturally Responsive Leader. This characteristic was identified in the leadership of all three identified superintendents.

The findings from this study generated recommendations for practicing administrators, academic research, superintendent preparation programs and policy that may have significant implications for schools that are working to close the opportunity gap in a similar context. Specifically, these recommendations should focus on the identified Characteristics of Exceptional Superintendents with an emphasis on culturally responsive leadership. Recommendations for future research include additional studies on: exceptional superintendents serving in other geographical regions, the impact of culturally responsive leadership at the district-level, and the impact of school boards hiring from within the community.

KEYWORDS: Culturally Responsive Pedagogy, Educational Leadership, Exceptional Superintendents 
CHARACTERIZING EXCEPTIONAL SUPERINTENDENT LEADERSHIP IN

ETHNICALLY AND ECONOMICALLY DIVERSE SCHOOL DISTRICTS

\author{
NICHOLAS HENKLE
}

A Dissertation Submitted in Partial

Fulfillment of the Requirements

for the Degree of

DOCTOR OF EDUCATION

Department of Educational Administration and Foundations

ILLINOIS STATE UNIVERSITY

2017 
(C) 2017 Nicholas Henkle 
CHARACTERIZING EXCEPTIONAL SUPERINTENDENT LEADERSHIP IN ETHNICALLY AND ECONOMICALLY DIVERSE SCHOOL DISTRICTS

NICHOLAS HENKLE

COMMITTEE MEMBERS:

Beth Hatt, Chair

Guy Banicki

Brad Hutchison

Dianne Renn 


\section{ACKNOWLEDGMENTS}

Love is patient, love is kind. It does not envy, it does not boast, it is not proud.

It does not dishonor others, it is not self-seeking, it is not easily angered, it keeps no record of wrongs. Love does not delight in evil but rejoices with the truth. It always protects, always trusts, always hopes, always perseveres.

1 Corinthians 13:4-8

This is a study rooted in love. Jesus Christ provides the perfect example of love through authentic social justice. Thanks to God, the Creator of love and the Architect of the incredible diversity in this world.

This work is dedicated to my amazing wife, Annie, the greatest educator I know. You are my best friend and my rock. Thank you for supporting my personal and professional growth throughout this process and for sacrificing to make it possible for me to achieve this goal. You have given us the most beautiful life and I love you, Annie.

To my daughters, thank you for bringing so much joy to my life. You have been an encouragement to me every step of the way. God could not have given me two more incredible children. I hope that I was able to model for you the importance of pursuing higher education and working hard to achieve your dreams. I love you both with all of my heart.

To my mother, thank you for instilling in me the importance of education and to never question my ability to achieve a goal if I set my mind to it. To my father, thank you for teaching me so much about faith and about being better tomorrow than I am today. Thank you to my stepparents for raising me with values and loving me as one of your own. I love you all.

To my beloved family, friends, and the incredible mentors I have had along the way, thank you for the encouragement and support. God has blessed me with an incredible journey, and I am so glad that you have been a part of it. 
Thank you to Dr. Beth Hatt for developing me as a student and for emphatically supporting this important research. I could not have achieved this goal without your leadership. Finally, thank you to my committee members who continue to provide insight, support, and enthusiasm for this research.

N. H. 


\section{CONTENTS}

\section{Page}

ACKNOWLEDGMENTS

CONTENTS

iii

TABLES

viii

FIGURES

ix

CHAPTER

I. INTRODUCTION

Research Statement

Purpose of Study

Research Questions

10

Relationship of Study to Personal Experiences and Knowledge

Type of Study

Summary

II. REVIEW OF THE LITERATURE

What Do We Know About Exceptional School District Leadership?

What Do We Know About Exceptional Leadership in

Ethnically and Economically Diverse School Districts?

What Do Experts Say are the Most Effective Ways for

District Leaders to Improve Learning for all Students,

Particularly Students in Ethnically and Economically

Diverse School Districts?

Kowalski

Summary and critique

Marzano

Summary and critique

The Superintendent's Fieldbook

Summary and critique

Comparison of approaches to district leadership 
What is Culturally Responsive Pedagogy and Why Should

School Leaders Care?

What Do We Know About Culturally Responsive Pedagogy

from Existing Research?

Ladson-Billings

Summary and critique

Gay

Summary and critique

Irvine, Armento, Causey, Jones, Frasher and Weinburgh

Summary and critique

Hanley and Noblit

Defining success in a culturally responsive classroom

Culturally Responsive Leadership

Summary of findings

What Would a Culturally Responsive Superintendent Do Differently?

Summary

III. RESEARCH METHODOLOGY

Introduction

Research Questions

Research Methods

Research Paradigm

66

Participants

67

Data Collection Techniques

Contributions of Pilot Study to Current Thoughts and Proposed Approaches

Data Analysis Procedures

Consideration of Possible Ethical Issues

Trustworthiness/Reflexivity

Implications, Significance, and Contributions

Policy

Practice

Benefit to Participants

Summary of Study 
Introduction $\quad 76$

$\begin{array}{ll}\text { Superintendent Portraits } & 76\end{array}$

Portrait 1: Dr. Paul James $\quad 76$

$\begin{array}{ll}\text { Superintendent leadership philosophy } & 79\end{array}$

$\begin{array}{ll}\text { Identified strengths of district } & 79\end{array}$

$\begin{array}{ll}\text { Culturally responsive attitudes and actions } & 82\end{array}$

Leadership style $\quad 84$

Core beliefs $\quad 86$

$\begin{array}{ll}\text { Direct impact on students } & 87\end{array}$

Decision-making process $\quad 89$

$\begin{array}{ll}\text { Portrait 2: Dr. Mary Jacobs } & 91\end{array}$

Superintendent leadership philosophy $\quad 93$

Identified strengths of district $\quad 95$

Culturally responsive attitudes and actions $\quad 96$

Leadership style $\quad 99$

$\begin{array}{lr}\text { Core beliefs } & 101\end{array}$

Direct impact on students $\quad 102$

$\begin{array}{ll}\text { Decision-making process } & 103\end{array}$

Portrait 3: Dr. Thomas Matthews 105

Superintendent leadership philosophy 107

$\begin{array}{ll}\text { Identified strengths of district } & 108\end{array}$

Culturally responsive attitudes and actions 111

Leadership style $\quad 114$

Core beliefs $\quad 116$

Direct impact on students $\quad 117$

$\begin{array}{ll}\text { Decision-making process } & 118\end{array}$

$\begin{array}{ll}\text { Summary } & 119\end{array}$

V. RESEARCH FINDINGS 122

The Key Characteristics of Culturally Responsive Superintendents

Serving in Ethnically and Economically Diverse School Districts

Characteristic 1: The Culturally Responsive Superintendent

Recognizes Culture as Paramount to Effective Instruction 
Characteristic 2: The Culturally Responsive Superintendent Has a

Deep Understanding of What Quality Instruction Looks Like

Summary of characteristic 2

128

Characteristic 3: The Culturally Responsive Superintendent

Effectively Engages The Entire Community

Summary of characteristic 3

132

Characteristic 4: The Culturally Responsive Superintendent Hires and Develops Educators Who Understand Culture and Language are Essential to Learning

Summary of characteristic 4

Characteristic 5: The Culturally Responsive Superintendent Articulates a Vision that Denies Deficit-Thinking

Summary of characteristic 5

Characteristic 6: The Culturally Responsive Superintendent Innovates to Ensure Equity and Excellence for Every Child

Summary of characteristic 6

Other Superintendent Commonalities

Superintendent Differences

Summary

VI. CONCLUSIONS AND SUGGESTIONS FOR FUTURE RESEARCH

Research Question 1

Research Question 2

Research Question 3

Implications for Policy and Practice

Policy

Practice

Epiphany

Critique of the Study

Recommendations for Future Research 
APPENDIX A: Interview Guides

APPENDIX B: Data Accounting Log

APPENDIX C: Observational Protocol

APPENDIX D: Letters of Consent

APPENDIX E: Superintendent Identification Tool 


\section{TABLES}

Table

Page

1. Traditional Superintendent Approach to Responsibilities and Meetings

2. Culturally Responsive Superintendent Approach to Responsibilities and Meetings

3. Data Accounting Log

4. The Key Characteristics of Culturally Responsive Superintendents Serving in Ethnically and Economically Diverse School Districts

5. Best Practices of Culturally Responsive Teachers 


\section{FIGURES}

Figure

Page

1. ISAT Achievement Gap Between Black and White Subgroups in

Reading and Math from 2010 through 2014

2. ISAT Achievement Gap Between Latino and White Subgroups in Reading and Math from 2010 through 2014

3. ISAT Achievement Gap Between Low Income and Non Low Income Subgroups in Reading and Math from 2010 through 2014 


\section{CHAPTER I}

\section{INTRODUCTION}

The highly-demanding and ever-evolving responsibilities of the school district superintendent ensure that the position is one in constant flux. Since the introduction of No Child Left Behind Act (2001), the demands and the pressure of the position have increased significantly (Cowan, 2003). In Illinois, school districts, and subsequently the superintendents who lead them, are asked to do much more despite a substantial annual decrease in state funding. This is particularly true in districts serving low-income neighborhoods that rely heavily on a reduced state aid and dwindling categorical grants. Meanwhile, the evolving political landscape has increased the accountability of the position. Superintendents must be highly motivated, well-trained, and have an understanding of how to employ strategies to increase student achievement. District leaders must accomplish this within a highly constructive budget while serving in an increasingly volatile political and financial environment.

\section{Research Statement}

The purpose of this study was to investigate the leadership approaches of exceptional superintendents in ethnically and economically diverse school districts to better understand how individual characteristics might be emulated by other district leaders and put into practice. Additionally, the study aimed to identify best practices for superintendents attempting to close the opportunity gap and raise student achievement in districts identified as economically and ethnically diverse.

Given the continued opportunity gap that exists in Illinois, data suggests that we need stronger leaders and a new approach to leadership in ethnically and economically diverse school districts. Therefore, to better understand the purpose of this study, the context of leadership in 
public school districts needs to be explored and better understood. According to Pascopella (2011), in a national study on longevity published in District Administrator magazine, tenure in larger, often ethnically and economically diverse school districts has only improved from 2.3 years in 1999 to 3.6 years in 2010. Pascopella (2011) argues that the school superintendent struggles with numerous roles including: hiring and retaining effective teachers, ensuring positive student growth, managing dwindling resources, implementing excessive mandates, and closing the opportunity gap in schools serving an ethnically and economically diverse community. Libka (2012), in his research study examining the relationship between superintendent longevity and student achievement in Illinois, determined that there are a number of factors that lead to the excessively high turnover of Illinois superintendents including: entering the superintendency later in one's career, changing school boards, and increased pressure on closing the opportunity gap. Interestingly, Libka (2012) also determined that there is a positive correlation between superintendent longevity and student achievement.

Furthermore, it is necessary to examine student achievement data in Illinois, specifically the performance of students of color compared to their white peers. Data collected from the Illinois State Board of Education (ISBE) and provided on the Illinois School Report Card website indicates that in 2010 the statewide achievement gap ${ }^{1}$, or opportunity gap, in reading between white and black students was $24 \%$ as measured by the ISAT. Concerningly, the opportunity gap in reading widens over the next 4 years to $31 \%$. In math, the gap widens from $22 \%$ to $32 \%$ over the same period.

${ }^{1}$ The term achievement gap will be referred to as an "opportunity gap" and is explained in greater detail later in the paper. 


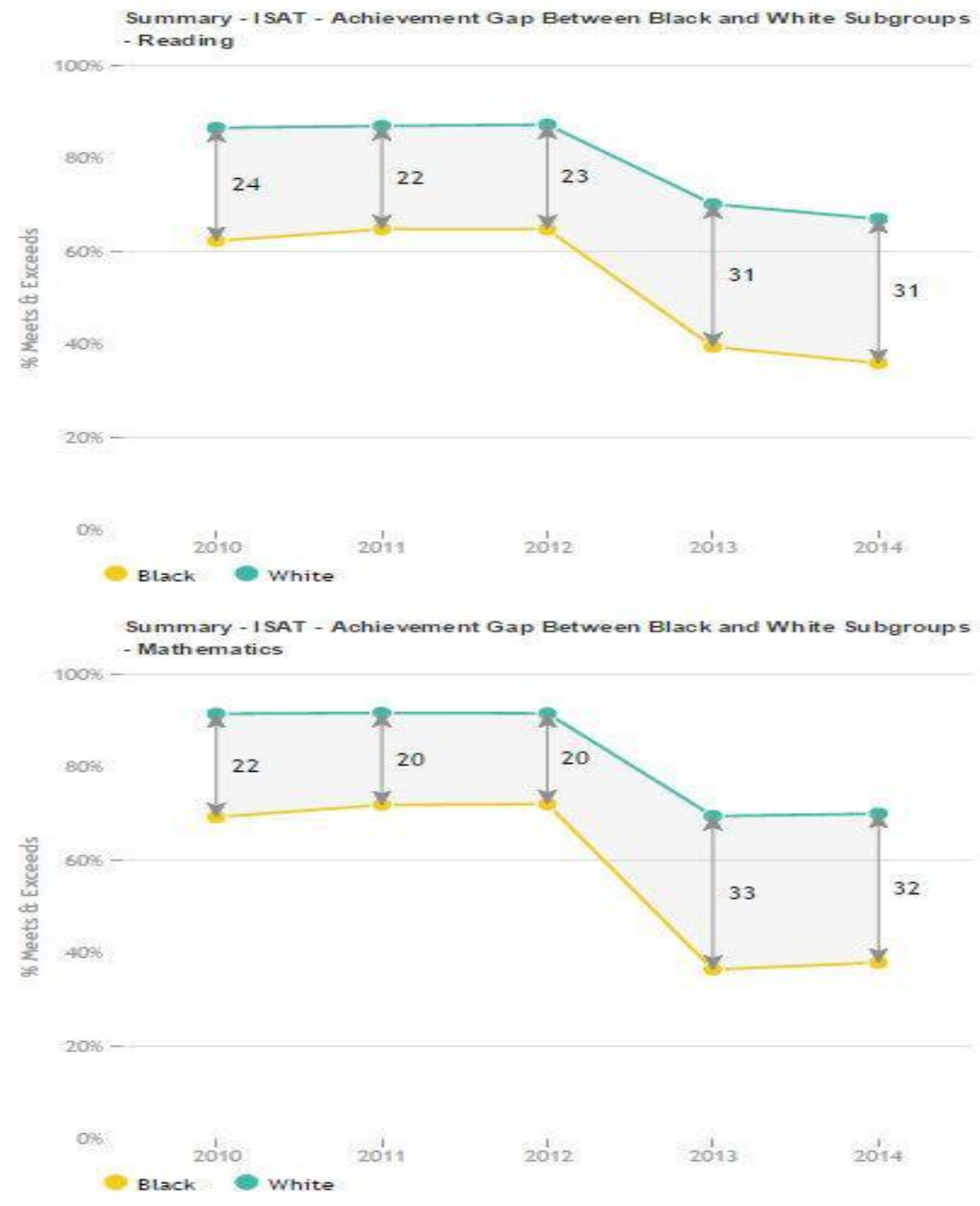

Figure 1. ISAT Achievement Gap Between Black and White Subgroups in Reading and Math from 2010 through 2014

Similarly, the statewide opportunity gap in reading between white and Latino students was $22 \%$ as measured by the ISAT in 2010 , and widens to $24 \%$ in 2014 . In math, Latino students were performing $13 \%$ below their white counterparts in 2010 . That number balloons to $21 \%$ by the year 2014. 


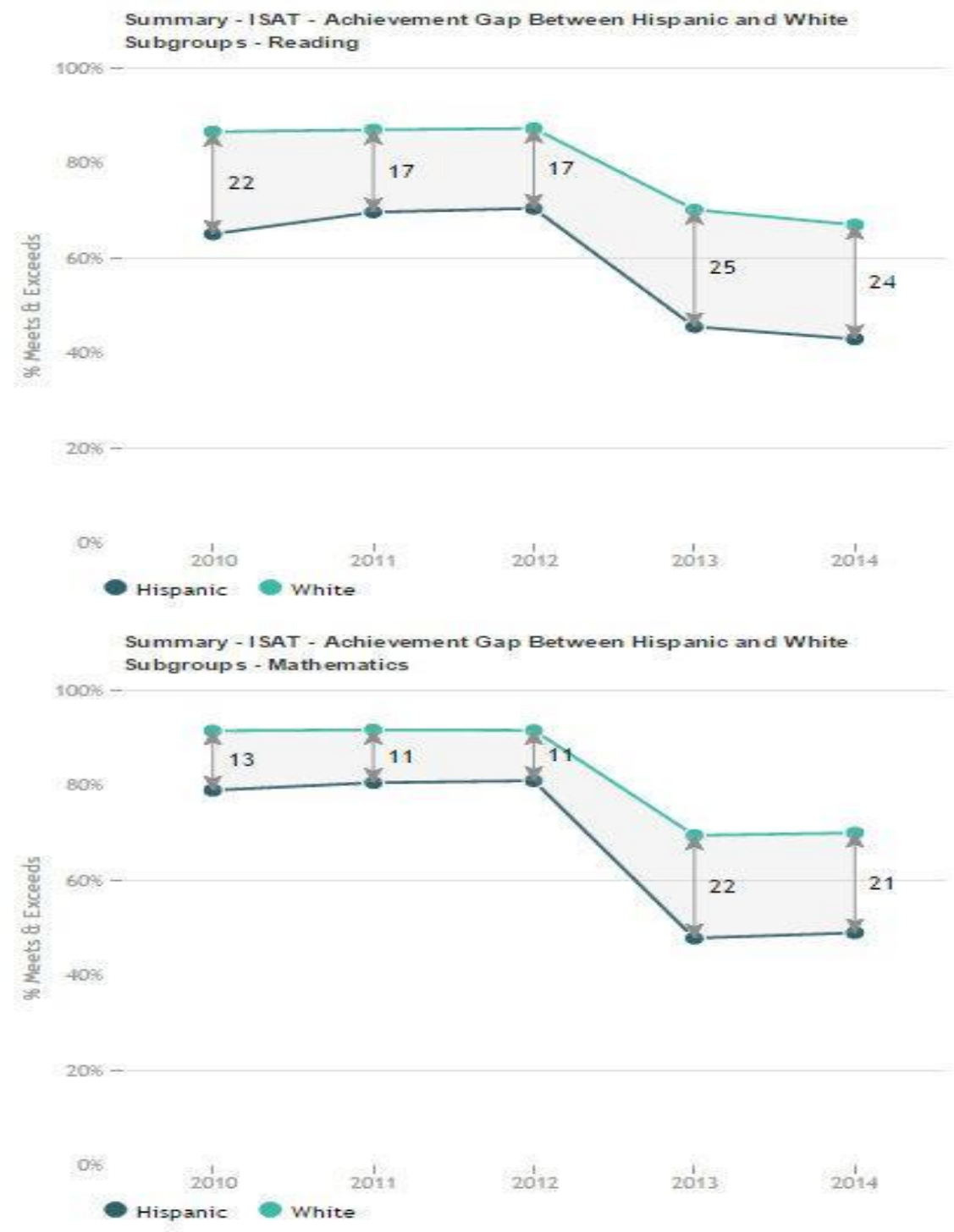

Figure 2. ISAT Achievement Gap Between Latino and White Subgroups in Reading and Math from 2010 through 2014

Not only are students of color not performing as well as their white counterparts, they also see the gap widen over time. Similar gaps are identified when examining the scores of nonlow-income students and their economically disadvantaged peers. The school report card reveals that this gap is widening for these students as well. There is a significant and growing disparity between low-income and non-low income subgroups. 


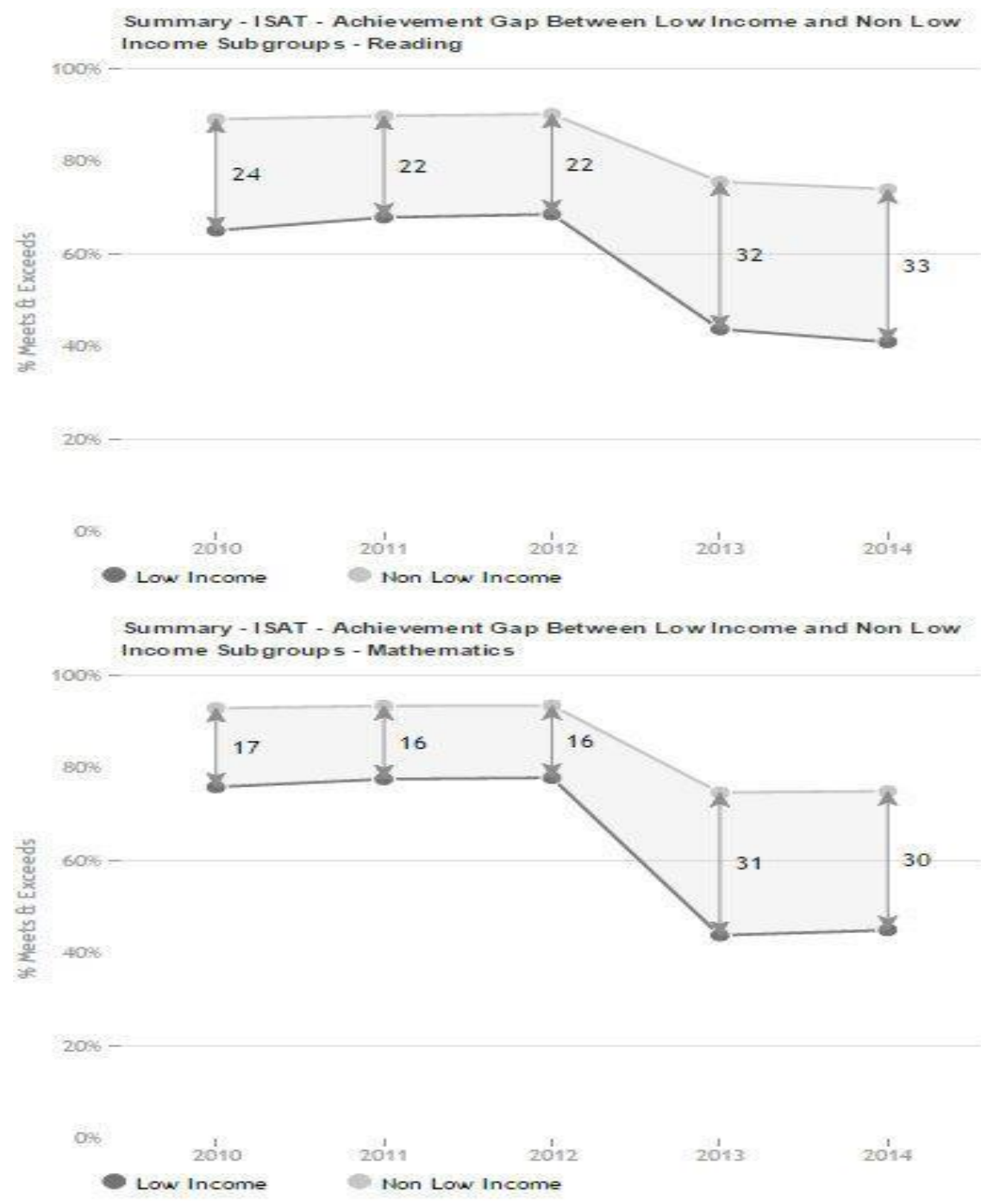

Figure 3. ISAT Achievement Gap Between Low Income and Non Low Income Subgroups in Reading and Math from 2010 through 2014

One argument for this discrepancy could be the significant funding gap that exists in Illinois. According to Phil Kadner (2015) of the Chicago Tribune, "The state's school districts with the greatest number of students living in poverty receive substantially fewer state and local dollars than their more affluent counterparts." Kadner cites a report from The Education Trust. The report (2015) indicates that, "by far, the largest gap [in the nation] is in Illinois, where the highest poverty districts receive nearly 20 percent less state and local funding than the 
lowest poverty districts." Kadner (2015) goes on to call Illinois the "most unfair school funding system in the nation." Moreover, the state has a constitutional obligation to fund its schools, but Illinois has never even funded $50 \%$ of the bill (Kadner, 2015). Illinois' contribution to funding education has fallen below $30 \%$, which has caused schools to both increase local property taxes and cut programs (Kadner, 2015).

To compensate for the inadequate funding in Illinois' schools, communities must increase property taxes to fund their operation; however, this is much more difficult in poorer districts with lower property values and will likely result in cuts to quality and quantity of programs (Kadner, 2015). This presents a challenge to any school district losing much needed resources, but it has the greatest impact on high-poverty districts (Kadner, 2015). Proposed solutions to overcoming these limited financial resources include recommendations for school leaders to recognize assets and resources available in the community (parents and community members) and develop opportunities for the inclusive engagement of these stakeholders (Comer, 2006). Jane Graves Smith (2006), in a case study, Parental Involvement in Education Among LowIncome Families, explains that this is easier said than done. Smith (2006) determined that there is a significant correlation between parental involvement and poverty and a continued decline in parental involvement in economically and ethnically diverse school districts. However, Smith (2006) also recognized that this might be drastically improved if schools would engage in intentional planning and relationship building with the community. However, it is significant to recognize that parent engagement is regularly conceptualized from the traditional middle-class definition (Baquedano-Lopez, Alexander, \& Hernandez, 2013).

Baquedano-Lopez, Alexander, and Hernandez (2013), in their research review Equity Issues in Parental and Community Involvement in Schools: What Teacher Educators Need to 
Know, counter the perception that parents from 'non-dominant' backgrounds are apathetic or complacent and suggest that school efforts and constructed norms must be expanded and redefined. A review of research revealed that social capital applied by parents of 'non-dominant' race and class were not accepted in the school context (Baquedano-Lopez et al., 2013). Baquedano-Lopez et al. (2013) suggests that deficit-thinking must be examined and eliminated, which will require schools to view students and parents as assets and advocates who can break down barriers and help close the opportunity gap. Families with a low SES simply face challenges that middle-class and upper middle-class families do not face making it difficult to spend time during the school day; therefore, school personnel must recognize alternative approaches to engaging parents in the school (Smith, 2006). A culturally responsive approach to involvement requires schools to explicitly re-define parent involvement by recognizing the assets in the community and allowing those agents to become leaders and transformers of schools, which will empower students and families (Baquedano-Lopez et al., 2013; Comer, 2006). Economic and ethnic diversity should be viewed as an asset that can enhance the academic, social and civic opportunities for all students (Latham, 1997).

Another barrier to student learning and possible causes of the widening opportunity gap is the concept of 'smartness' (Hatt, 2012). Unfortunately, students of color often develop poor self-concepts, discipline problems and poor academic performance early in life as a result of classroom experiences and perceptions of deficits versus assets (Hatt, 2012). Rather than 'smartness' operating as an individual's capacity to learn, it has been 'culturally produced'; a lived experience that causes non-dominant students to adopt and accept, often unknowingly, an identity of inferiority (Hatt, 2012). Educators must remain aware of the social positioning that often naturally occurs in the classroom and take intentional steps to become culturally responsive 
educators (Hatt, 2012).

Despite the many challenges that exist, there are numerous examples of high-achieving schools in ethnically and economically diverse communities, which provide evidence that the opportunity gap can and should be closed by changing school-based practices. The limitations exist only as a result of deficit-thinking and not because of the effects of poverty on learning (Comer, 2004; Baquedano-Lopez et al., 2013; Parrett \& Budge, 2012). For example, an audit completed by Kannapel, Clements, Taylor, and Hibpshman (2005) comparing high-performing vs. low-performing high-poverty schools identified the common traits of high performing schools including:

1. School-wide ethic of high expectations for faculty, staff and students

2. Caring, respectful relationships

3. Strong academic, instructional focus

4. Systems for assessing individual students on a regular basis

5. Collaborative decision-making led by non-authoritarian principals

6. Strong work ethic and high faculty morale

7. Recruitment, hiring, and assignment strategy for teachers. (p. 14)

Notably, the researchers expected to find a correlation between the role of district leadership and the success of these high achieving schools (Kannapel et al., 2005). Surprisingly, they identified that the "district influence was somewhat less direct than we anticipated" (Kannapel et al., 2005, p. 24).

Additionally, Parrett and Budge (2012), in their text Turning High-Poverty Schools Into High Performing Schools, dispel the myth that high-poverty schools cannot perform well. Parrett and Budge (2012) suggest that we all possess 'mental maps' about our world that 
influence our thinking including stereotypes about those who live in poverty. However, the authors provide numerous examples of individual schools meeting or exceeding expectations on standardized state assessments and found that effective leadership was central to the positive results of high-poverty, high-performing schools (Parrett \& Budge, 2012). Effective leadership believes that social justice is achieved through equity, high expectations, and a safe, healthy environment for learning (Parrett \& Budge, 2012). In each of the examples, effective principals were at the heart of the transformation. However, while numerous studies have been completed on the impact of school-level leadership, very little has been written about the practices of superintendents in these districts.

\section{Purpose of Study}

While compelling research such as Parrett and Budge (2012), Kannapel, Clements, Taylor, and Hibpshman (2005), and others exists and provides evidence of best practices of schools and principals in successful, high-poverty districts, little has been written about the practices of superintendents in those districts. Those leaders who have the ability to navigate this new terrain in economically and ethnically diverse school districts may provide valuable information to other active superintendents and to those who aspire to serve as a superintendent in a similar school leadership capacity. This study examined the leadership approaches of three exceptional superintendents serving in economically and ethnically diverse school districts with the intent to extract meaningful insights, thus contributing to an understanding of the role of the superintendent. This study was intended to provide insight that may be used to emulate the successes of the identified superintendents by both improving school districts' ability to match the needs of the district with an appropriate candidate and by providing knowledge to existing and aspiring superintendents as they continue to grow in their own understanding of this ever- 
evolving role. In examining the larger picture, this study may have significant implications for school districts including the potential to positively impact student growth. The purpose of this study, therefore, was to look directly to those exceptional superintendents to see what they do differently to provide new knowledge to our understanding of exceptional leadership and ensure a narrowing of the opportunity gap in low income, ethnically diverse school districts. A

theoretical frame of "culturally responsive leadership" was used to frame the analysis and guide the study.

In summary, there is a lack of research on the practices of exceptional superintendents in ethnically and economically diverse school districts. Moreover, there is a conspicuous absence of literature linking a culturally responsive pedagogy to district-level leadership. Despite the abundance of data on recent 'successful' school reform efforts, the students represented by this study continue to suffer from an opportunity gap that appears to be worsening in the state of Illinois. This research illuminated the inequities and provided insight to inform the practice of superintendents serving in ethnically and economically diverse school districts. In the following section, I explain how this study informed my own practice as active superintendent in Illinois.

\section{Research Questions}

This study examined the leadership of exceptional superintendents serving in ethnically and economically diverse school districts by answering the following research questions:

1. What is the nature of superintendent leadership in ethnically and economically diverse school districts that indicate a closing of the opportunity gap?

2. What leadership traits do each of the identified superintendents possess?

3. What are the identifiable best practices of exceptional superintendents serving in ethnically and economically diverse school districts? 


\section{Relationship of Study to Personal Experiences and Knowledge}

In selecting a topic to research, I wanted to study something that was both meaningful and immediately practical as I continue my own journey. As an Illinois superintendent, nothing is more motivating for me than refining my leadership to improve outcomes for all students. For this reason, I selected a topic that would contribute to my existing knowledge as a school leader and inform my understanding of what it means to be an effective superintendent. For as often as I have been inspired and educated by the practices of exceptional, high-quality superintendents, I have also been disenchanted by the leadership of ineffective superintendents. I believe that this opportunity to study superintendents who understand how their own role impacts student learning will elevate my own leadership and contribute to our field. Looking ahead, I have always found that I learn best by teaching others and I selected a topic that I find personally relevant, meaningful and highly interesting. As I study these change agents, I expect to experience profound growth and inspiration. More importantly, I want to understand how a superintendent can support achievement for all learners, regardless of ethnicity or economic status, and feel this is best achieved by looking at those effective leaders who have come before.

\section{Type of Study}

A comparative case study approach using interviews as the primary source of data collection combined with observations to examine the practices of exceptional superintendents was employed in this study. A comparative case study is employed to help determine an answer to research questions and can be defined as a detailed examination of an event or process involving one or more individuals within a set period and in a specific setting or location (Creswell, 2009). In the context of this qualitative study, three superintendents were examined for their leadership ability through a series of interviews and observations with identified 
participants, including interviews with two members of the superintendent's administrative team. Central office administrators were also interviewed. These individuals were selected by the superintendents. Additionally, the superintendents were observed in their own context to collect pertinent information related to their day-to-day practices and interactions with staff. The interviews focused on the superintendent's background, experience, reform efforts, beliefs, values, and priorities. Through the case studies, commonalities and leadership paths were identified. These commonalities illuminated insights that will contribute to existing knowledge on the topic of exceptional educational leadership. A comparative case study was employed in this research because it is designed to achieve insight into people's actions, beliefs and values (Creswell, 2009).

\section{Summary}

Despite research leading to numerous programs, systems, and initiatives aimed at closing the opportunity gap, students in ethnically and economically diverse school districts continue to lag behind their white peers. The district superintendent has an opportunity to promote attitudes, beliefs and practices that have the potential to impact an entire school district. This study examined the beliefs and practices of three exceptional superintendents who have made a difference in his or her community by closing the opportunity gap for low income students and students of color.

The research statement, purpose of study, relationship of study to personal experience and knowledge, and the kind of study are discussed in this chapter. The goal of Chapter II was to review and analyze the literature by examining successful leadership within two subsections. The first subsection will examine the literature on broadly defined best district leadership practices while the second section will provide an overview of culturally responsive pedagogy, 
the theoretical framework employed for this research. Chapter III will depict the research methodology, which includes the research questions, research methods, research paradigm, participants, data collection techniques, contributions of pilot study to current thoughts and proposed approaches, data analysis procedures, consideration of possible ethical issues, trustworthiness, implications, policy, practice, and benefit to participants. 


\section{CHAPTER II}

\section{REVIEW OF THE LITERATURE}

At the heart of this study was a search for an understanding of the complexity of exceptional district leadership in ethnically and economically diverse public schools. In an effort to discover 'new' knowledge, it is imperative to assess existing research to ensure this study is able to add to the field of knowledge. In accomplishing this, I felt it was important to organize my literature review in a way that addresses the core question of this study: How can a superintendent lead to effectively meet the needs of an ethnically and economically diverse school district?

To thoroughly answer this question, it is a prerequisite to first understand what it means to be a leader serving in the context of a public school district. While the word 'leadership' is familiar to most people, it is extremely difficult to define as evidenced in the multiple leadership definitions offered through the decades (Rost, 1991). Moreover, defining strong leadership in a dynamic, ever-changing context such as the $21^{\text {st }}$ century school districts which now exist is much more complex (Bjork \& Kowalski, 2005). There is evidence to support a new reality as a strong correlation has been discovered between leadership and student achievement (Waters \& Marzano, 2005). The year 2001 saw a heightening of demands for all students with the passage of No Child Left Behind Act. As a result, superintendents, arguably more than any other position in education, are under incredible pressure to meet the many demands of the local, state and federal government (Bjork \& Kowalski, 2005). This increased call for accountability has changed the role of the superintendent from district manager of resources to active instructional leader (Eller \& Carlson, 2009). With that being said, superintendents equipped with the proper tools can make a significant difference in diverse school districts struggling to close the 
opportunity gap (Glass, 2000). The superintendents identified and interviewed for this study have found a way to achieve success, as defined by this study, despite the challenges associated with serving in ethnically and economically diverse school districts.

This review of literature is composed of four distinct sections. The first section identifies what we know about exceptional district leadership, specifically as it relates to the demands of superintendents serving in ethnically and economically diverse districts. This will be achieved by examining the written work of several key experts on district leadership. I then explain why each of these authors falls short of addressing the most significant needs of ethnically diverse and economically disadvantaged students. In part two of this literature review, I provide the basic definition of Culturally Responsive Pedagogy (CRP), which will serve as the framework for this study. Additionally, the prevalence of CRP in the literature on district leadership is vetted, and I provide a rationale for using this framework as the lens for this topic. In the third section, I explore culturally responsive pedagogy as it relates specifically to superintendent leadership. It is significant to note a conspicuous lack of research linking CRP to the beliefs and practices of exceptional superintendents. Therefore, I expand upon the definition of culturally responsive pedagogy, examines the tenets of CRP, and provides the rationale for selecting it as the theoretical framework for studying exceptional superintendents. I achieve this by exploring four notable pieces including a review of two seminal texts, an analysis of a practical manual on implementation of the pedagogy, and a meta-analysis of CRP. In part four, I summarize the findings, which include an examination of CRP's role in existing research on district leadership. I conclude by explaining the rationale for why further research is needed to explore CRP as it relates to the quality of superintendent leadership and evaluate the viability of applying culturally responsive pedagogy to district-level leadership. 


\section{What Do We Know About Exceptional School District Leadership?}

In this first section, the complex position of the superintendent and what we know about exceptional district leadership is explored, specifically as it relates to the demands of superintendents serving in ethnically and economically diverse districts.

The position of superintendent has appeared to have gone full circle since its inception in the nineteenth century, evolving from that of schoolmaster in its earliest days, to manager, and now, once again, schoolmaster (Glass, Bjork, Cryss, \& Brunner, 2000). Certainly, increased accountability with respect to student achievement and overall district performance has changed the role of administrator since the release of a landmark report in 1983 entitled A Nation at Risk, in which America's public education system was first determined to have been failing our children (Glass et al., 2000). According to Marzano and Waters (2005), there is an indisputable correlation between student achievement and district leadership, and administrators must take responsibility for improving student outcomes. Moreover, local, state, and federal governments are putting increased pressure on school districts to both increase achievement for all students and narrow the opportunity gap between students of color and white students, effectively bringing the superintendent closer to the classroom (Cowan, 2003; Marzano \& Waters, 2009). As a superintendent in the state of Illinois, I can personally attest to these realities firsthand as public schools continue to face fiscal uncertainty and depleted budgets. Where the superintendent was once the financial and political face of the district, the position has changed to include numerous other responsibilities and the position continues to grow and evolve over time (Bjork \& Kowalski, 2005).

Paramount among these great challenges, school leaders are facing increased poverty and greater ethnic diversity among students requiring new approaches to meet differentiated student 
needs (Beachum, 2011). At the same time, the teaching force and leadership have become less ethnically diverse, which has created a gap between the lived experiences of students versus teachers and administrators (Cowan, 2010). Despite requests for additional funding or new revenue sources to adequately and equitably support all students, school leaders are often not supported by federal, state and local government and are left to develop new ideas on how to meet these increasing demands (Bjork \& Kowalski, 2005). According to Bjork and Kowalksi (2005), “expectations for educational excellence have risen, [but] public support, particularly in the form of increased financing has not been similarly increased, forcing superintendents and other central office administrators to do more with less." Therefore, school leaders are forced to assume they must find solutions to address these challenges that will have the greatest impact on student achievement without the benefit of additional funding (Bjork \& Kowalski, 2005).

Regardless, school district leaders, arguably the most visible individuals in a school system, must show perseverance and resilience (Sergiovanni, 1992). Fortunately, research exists that provides knowledge as it relates to effective district leadership, even in this new, changing context. Therefore, we must first examine existing research on leadership in economically disadvantaged and ethnically diverse school districts.

\section{What Do We Know About Exceptional Leadership in}

\section{Ethnically and Economically Diverse School Districts?}

There are still many traditional responsibilities belonging to the $21^{\text {st }}$ century superintendent including that of fiscal manager, political figurehead, human resources director, curriculum expert, facilities director, etc. (Kowalski, 2013). However, above all else, any leadership position demands a moral obligation to educate every child at the highest level possible, regardless of socio-economic status or cultural heritage (Gay, 2010; Lyman \& Villani, 
2004). We have seen a shift in the priority of the superintendent to include increased responsibility for closing the opportunity gap for economically disadvantaged and ethnically diverse students (Wright \& Harris, 2010). Bjork and Kowalski (2010) recognize the dramatically changing role of the superintendent: "Within the past decade particularly with the passage of NCLB, superintendents have been called to introduce district-wide, systemic reform efforts and educate all children to proficiency, regardless of ethnicity, income, or family background" (p. 187). Wagner (2010) suggests that, to close this opportunity gap, superintendents must have a strong understanding of data literacy and show evidence of implementing research-based strategies to support the needs of all learners. Valencia (1997) suggests that individuals must also challenge our biases and begin to view race and class as assets and not obstacles to student achievement.

While understanding the data is significant, successful superintendents are also intentional about caring, which includes time devoted to forming meaningful relationships with students and parents (Kowalski, 2013). Exceptional leaders understand the importance of relationships with students, families and community members and how these relationships can transform a school (Comer, 2004; Lyman \& Villani, 2004). To meet the needs of a diverse group of learners, leadership has a responsibility to eradicating deficit-thinking, hiring and developing culturally sensitive leaders, and intentionally root itself in relationships and truly care for others (Comer, 2004; Lyman \& Villani, 2004). Lyman (2000), in her book, How Do You Know They Care?: The Principal's Challenge, suggests that caring educators have the potential to 'enhance' a child's ability to learn new information. It is the leader's duty and responsibility to ensure that the faculty, staff and community are surrounding students in a positive, caring environment (Lyman, 2000). Lyman's (2000) research indicates that students who attend a caring early 
learning school with a positive culture are more likely to survive and thrive later in their academic journey. Caring requires instructional leaders who understand that children need the support of the community every day; then they take responsibility for leading in the caring (Lyman, 2000). Exceptional leaders do not act as the figurehead of the organization; rather they serve as a partner, colleague, and advocate to ensure all students succeed (Lyman, 2000).

Bjork and Kowalski (2005) believe school leaders must be willing and able to move from 'equal opportunity to equal outcomes' focusing on reform that ensures all children achieve at the highest possible level regardless of ethnicity or socioeconomic status. Arguably, the most effective way to narrow this opportunity gap is through cultural proficiency (Wright \& Harris, 2010). Hatt (2007) suggests that students are often marginalized by the perceptions of what they believe it takes to be successful in school, which does not include their own culture, beliefs and values. To truly encourage 'equal outcomes' educators must understand the culture of the students and establish meaningful relationships with students, parents and the community (Lyman \& Villani, 2004; Wright \& Harris, 2010). The superintendent must provide strategies for building these relationships including attending political functions, speaking at various churches and community centers, and helping students at school to feel connected (Wright \& Harris, 2010). Professional development and evaluation in planning are also significant when superintendents discussed the multicultural strategies employed in their district. There is a need for superintendents to create a 'community of learners' and this may be accomplished through cultural responsiveness (Comer 2004; Lindsey, Lindsey, Nuri-Robins, \& Terrell, 2011). In order to begin to make a significant impact, leadership must understand the needs and makeup of the community (Comer, 2004; Wright \& Harris, 2010). District leaders must build learning communities both inside and outside the school walls, while also acting as 'applied social 
scientists' as they determine scientifically-proven strategies that work as well as those that do not (Bjork \& Kowalski, 2005).

It has become clear that cultural responsiveness is paramount in school districts as demographic and societal changes have changed school reform efforts, effectively rewriting the job description of superintendents as social activists and community leaders (Bjork \& Kowalski, 2005). School leaders can develop an empathetic attitude towards students by taking the time to get to know the families, cultures, and community agencies intimately (Lyman \& Villani, 2004). Maslow's Hierarchy of Needs (1943) informs us that physiological and safety needs must be met as a matter of survival; then love and belonging needs must be fulfilled before the esteem and self-actualization can take root. Effective educators understand that respect and love for students and families are essential to the learning process and that students who feel valued and accepted are more likely to retain what they learn (Lyman, 2000). Superintendents are expected to not only understand the reform phenomenon, but also use their position to impact learning by changing school-community relations through modifying school structures and practices (Bjork \& Kowalski, 2005; Comer, 2004). Bjork and Kowalski (2005) suggest that this begins with relationships:

To effectively address diversity issues, educational leaders need to be skilled in relating to people who have different needs and different values. Questions arise about the degree to which administrator-preparation programs develop proficiencies that support the development of shared and enacted visions build coalitions of community leaders, or support the growth of political expertise. (p. 198)

We must do more than simply acknowledge others' beliefs, values and worldviews; we must work to understand them (Ladson-Billings, 2009). This is significant with respect to ethnicity, particularly in Illinois schools where the Illinois State Board of Education reports that $83 \%$ of our teachers are white, while $51 \%$ of our students are non-white (Illinois School Report 
Card, 2014).

Therefore, in light of the age of school reform efforts, a superintendent must make eliminating the opportunity gap between white students and students of color one of the highest priorities and must be able and willing to re-write the position to meet the needs of all children as an 'applied social scientist' and social activist (Bjork \& Kowalski, 2005). It is the charge and responsibility of school leaders to serve all students regardless of race or economic background (Kowalski, 2013). Lyman and Villani (2004) offer a convicting truth: "if believing all children can learn is critical to achievement, than beliefs or attitudes to the contrary hold back the academic achievement of children living in poverty" (p. 117).

Making this change begins by employing educators who reflect the diversity of the community (Gay, 2010). As the number of students of color continues to increase it will have a significant impact on the nature of schooling and that this must include how schools are designed included the makeup of those who lead them (Glass et al., 2000). Moreover, one-third of the nation will be nonwhite by the year 2020 , and the projected population of minority students will increase by 38\% (Glass et al., 2000). Meeting the needs of these students may be a challenge for school leaders as many do not share the same cultural or racial makeup as their students (Glass et al., 2000). For example,

The vast majority, $94.9 \%$ of American superintendents are white, and $86.6 \%$ are male. However, the number of female and minority superintendents has increased since 1992. The number of female superintendents increased from 6.6\% in 1992 to $13.2 \%$ in 2000. Superintendent positions held by minorities moved from $3.9 \%$ to $5.1 \%$ during the same period. (Glass et al., 2000, p. 15)

While this is significant data that may inform recruitment efforts of school districts and university programs, it will be imperative for practicing school leaders in many communities to recognize the fact that they may have a significant lack of cultural understanding of their own 
students (Gay, 2010; Ladson-Billings, 2009).

This research indicates that the role of superintendent requires leaders who desire to extend their reach beyond the school walls and understand the cultural norms and expectations of the greater community. The data provides evidence that significant cultural differences continue to exist between educators and students, yet administrator preparation programs and district mentoring efforts offer little support for understanding students' lives through their own eyes with full recognition of the hierarchy of needs and the traditional definition of school district leadership prevails. Simply stated, while this research has identified several shortcomings of leadership in economically disadvantaged and ethnically diverse school districts, it has not provided a solution. However, there is evidence of districts finding success through caring relationships, the hiring of culturally responsive educators, and taking steps to personalize instruction around the student's needs. Although we know what has been effective and meaningful, these steps have not been taken. We have identified the shortcomings of these leaders; now we will examine what the authorities on district-level leadership say about leading through differentiation to meet the specific cultural and academic needs of all students.

\section{What Do Experts Say are the Most Effective Ways}

\section{for District Leaders to Improve Learning for all}

\section{Students, Particularly Students in Ethnically}

\section{and Economically Diverse School Districts?}

Numerous authors have written on the subject of closing the opportunity gap in economically disadvantaged and ethnically diverse communities. However, several experts on district-level leadership, specifically superintendent leadership, have emerged to provide unique theoretical frameworks for serving all students effectively and closing the opportunity 
gap. These specific authors were identified and selected for their prominence in the field and their contributions to improving district-level leadership, specifically regarding how superintendents can meet the needs of all students regardless of ethnicity or socioeconomic condition. These experts have unique, but overlapping models for district leadership and they all use compelling evidence to support their respective frameworks and address (some more than others) how to close the opportunity gap for economically disadvantaged and ethnically diverse students.

Kowalski. The first of these experts, Theodore J. Kowalski, provides theory, case studies and practical knowledge for aspiring and practicing district leaders. Kowalski’s The School Superintendent (2013) clearly outlines principles and practices that he asserts will lead to improving the instructional program for district students. Chief among those practices is collaboratively setting a clear and strong vision for the school district and articulating that vision to all stakeholders (Kowalski, 2013). This practice is not limited to superficial and ineffective meetings that are political in nature; rather, these are meaningful, regular, community-driven conversations based on the collective knowledge of all constituents (Kowalski, 2013).

Furthermore, Kowalski asserts that strong statements must be articulated including a plan for district and school improvements, the mission of the school district and a philosophy of teaching and learning (Kowalski, 2013). Kowalski believes that effective school leaders must be transformational in their approach to leadership including an effort to be intimately involved in the instructional program. Kowalski (2013) suggests that superintendents are transformational instructional leaders; more than just the district figurehead; they are accountable for other key responsibilities and are expected to work collaboratively and model key behaviors: "Transformational leadership emphasizes morally purposeful and elevating behavior that is 
accomplished by working with and through others" (p. 210). Kowalski (2013) asserts that a transformational leader has the ability to enable and empower team members and constituents for the purpose of improving the organization in a profound and meaningful way. An innovative and transformational leader will guide school personnel and community members to take ownership over the goals developed collaboratively and assume responsibility for meeting said goals (Kowalski, 2013).

A transformational leader can achieve this through the following actions:

1. Building a shared vision of the school

2. Creating and aligning school district goals

3. Creating an intellectually stimulating environment

4. Nurturing a positive, learning-oriented culture

5. Providing individual support and development opportunities

6. Modeling best practices and learning oriented organizational values

7. Creating authentic organizational structures that support shared decision-making venues

8. Establishing high expectations for student and adult learning (Kowalski, 2013, p. 210)

To ensure a transformational environment, Kowalski (2013) believes it is imperative to hire exceptional principals and other key personnel. Hiring these principals and teacher leaders who have the capacity to learn and implement research-based strategies in the classroom is paramount to ensuring quality and equity of instruction. Superintendents who understand schoollevel instructional needs and how to meet those needs can indirectly improve the learning environment through the hiring of highly-qualified and proven leaders (Kowalski, 2013). Kowalski refers to capacity building and expresses a need to focus on the district leader's 
responsibility to develop this capacity in parents, teachers, and administrators to improve learning for all students. Kowalski (2013) states that, "a central function of the superintendent is a transformational leader who is facilitating organizational change, including altering decisions and governance structures" (p. 208). Superintendents are often the most visible public representative of their school districts and must be conscious of actions in all contexts, whether in an official capacity or otherwise (Kowalski, 2013).

Moreover, Kowalski asserts that effective leaders encourage and promote democracy through civic engagement with the community (2013). Kowalski states that these community conversations and the relationships they foster are key to impacting students on a meaningful level (2013). This often takes the form of strategic planning, which Kowalski believes is superior to long-range, operational planning. Administrators who serve others and work collaboratively create a climate of trust and high expectations through modeling the desired behavior (Kowalski, 2013). Not only does involving the community improve decision-making, it also has a direct impact on student learning. Effective leaders involve local stakeholders because it is not only morally and ethically necessary, but because it has a profound impact on student learning (Kowalski, 2013).

Moreover, superintendents must recognize two profound truths in working with the board to create a strong relationship with the community (Kowalski, 2013). First, public schools are democratic institutions; second, local school boards have the responsibility and the power to make a significant impact on the quality of the communities involvement in decision-making (Kowalski, 2013). The superintendent must encourage and foster this approach to leadership taking community involvement beyond 'keeping stakeholders informed' and instead intend on 'keeping stakeholders involved' (Kowalski, 2013). Partnerships with these stakeholders must 
involve local corporations, other school districts, cooperatives, and community organizations like Rotary or the local Chamber of Commerce (Kowalski, 2013). The opportunity gap that exists in schools provides a compelling rationale for the increasing number of school and community partnerships (Kowalski, 2013). As the number of students living in poverty increases, community organizations may be capable of providing services and or financial resources to support these students and their families, which may have an impact on narrowing the opportunity gap (Kowalski, 2013). Kowalski's work should be commended for recognizing that exceptional leaders need to actively engage district constituents in every aspect of planning and decision-making. He makes numerous references to collaboratively setting a clear and strong vision and ensuring that community members be given ownership over their own local schools. However, there are several limitations to his work.

Summary and critique. First, while Kowalski recognizes a need for community-driven conversations to inform decision-making, his approach to this relationship lacks specific details about how often these relationships develop and where these meetings should occur. The focus, therefore, is on communication and involvement and not on understanding the culture of the community. Kowalski also spends significant time discussing transformational instructional leaders and their responsibilities rather than their relationships. He states that superintendents are not just the district figurehead but the key leader and model for others (Kowalski, 2013). His approach to 'innovative and transformational leadership' is to guide school personnel and community to employ collaborative goals, and hire effective leadership. His focus is on what is happening within the school and not as much on the impact of the community on the school. $\mathrm{He}$ does not address the importance of customs, traditions, and the norms of the students and community. Similar to Kowalski, whose focus appears to be clear two-way communication and 
collaborative goal alignment with the involvement of stakeholders within the existing school context, Robert Marzano contends that district-wide achievement is highly dependent upon the clarity and consistency of the communication structure supported by district-level leaders.

Marzano. Robert Marzano has drafted several texts delineating what he believes are the practices executed by exceptional district-level leaders. In District Leadership that Works, Marzano and Waters (2009) focus on specific actions that can be taken by superintendents and district leaders to directly improve student outcomes. Marzano and Waters (2009) set out to determine the level of impact, if any, district-level leadership has on student achievement. The authors determine in an extensive meta-analysis that there is indeed a direct correlation between student achievement and district leadership (2009). Marzano and Waters further assert that this correlation indicates the need for specific research-based practices and that they must occur in each and every district school. If district leadership intends to positively impact student outcomes, these actions must be implemented with intention and monitored (Marzano \& Waters, 2009). Marzano and Waters identified five necessary actions district leadership could take that will increase the likelihood of success:

1. Ensuring collaborative goal setting

2. Establishing non-negotiable goals for achievement and instruction

3. Creating board alignment with and support of district goals

4. Monitoring achievement and instruction goals

5. Allocating resources to support the goals for achievement and instruction (pp. 21-22) District-wide student achievement gains are positively impacted by those leaders who work well with teachers to set meaningful goals (Marzano \& DuFour, 2011; Marzano \& Waters, 2009). Teacher leadership and the process of bottom-up versus top-down leadership is a key 
ingredient to ensure success (Marzano \& Waters, 2009). However, in these districts, superintendents must also work with existing leadership including the board of education and district administrators to communicate and clearly articulate needs and identify studentachievement goals within specific schools and specific subgroups (Marzano \& DuFour, 2011). Marzano and DuFour (2011) believe that effective district-level leadership will meet goals only after introducing data-driven methods intended to establish a 'common framework'. Marzano and Waters (2009) identify specific actions that district leadership can encourage district-wide to support student learning including: district-designed formative assessment, resources and support for progress monitoring for individual students, a redesign of the report card to make it goals-based, introduction of high-quality teachers, a focus on pedagogy, teacher mentorship, and a common model for instruction and common communication to make learning clear.

Exceptional superintendents are intentional in limiting initiatives and managing mandates, while ensuring the vision is articulated early and often (Marzano \& DuFour, 2011). For the vision to be effective and meaningful, specific, widely-understood language, actionable steps, and a shared knowledge of expectations will help to meet district goals and expectations (Marzano \& DuFour, 2011). Marzano and Dufour also address the key role superintendents have with district principals. Each principal is accountable to share evidence of learning and 'specific conditions' identified and expected in each and every school.

Furthermore, principals are expected to monitor the work of the teams and report on the results to the superintendent and board of education (Marzano \& DuFour, 2011). Board alignment and community support are prerequisites to achieving meaningful change (Marzano \& DuFour, 2011). 
Summary and critique. In summarizing Marzano's approach to effective district-level leadership, several notable omissions exist including little to no mention of community involvement in decision-making. While the focus on the need for consistency among researchbased practices, personnel, and programs may have had a positive impact on student achievement, one must question how much more effective the district would be with the involvement of the local community. Marzano also discusses the need for non-negotiable goals, board alignment, progress monitoring, and the allocation of resources, but he does not make specific suggestions as to how the stakeholders participate in these processes. Marzano supports the idea of a common framework for all district schools, but given the diverse nature of school districts, he does not discuss the inherent differences that may exist from community to community, school to school and student to student. How might those differences impact student achievement? What prerequisite knowledge might be needed to first connect with communities to build a relationship before true learning can occur? Marzano suggests that a formula including specific actions (e.g. district-designed formative assessment, progress monitoring, a standardsbased report card redesign, high-quality teachers, teacher mentorship, strong pedagogy, and a clear, consistent program) in district schools will have an impact on student achievement. Perhaps, but are their other responsibilities on the hierarchy that must be achieved to apply this type of consistent framework? Next, I will discuss The Superintendent's Fieldbook by James Harvey, Nelda Cambron-McCabe, Luvern L. Cunningham, and Robert H. Koff (2013), which promotes a relationship-driven approach to leadership.

The Superintendent's Fieldbook. James Harvey et al. (2013) drafted The Superintendent's Fieldbook to help $21^{\text {st }}$-century superintendents to lead effectively through a moral framework. While the desired outcome for student achievement through outstanding 
leadership is similar to those desired by Kowalski and Marzano, the approach taken puts a greater emphasis on social justice through equality and a community-driven approach to education. Simply put, the authors repeatedly advocate that superintendents must 'think assets, not deficits.' Very early in the text, the authors bring attention to the years of prejudice and oppression faced because of differences in race and class (Harvey et al., 2013). Harvey et al. (2013) posits that the single most challenging task the superintendent will face is discussing and addressing the opportunity gap. Seven key factors must be in place to close the opportunity gap, including:

1. The community must be involved

2. Resources must be equal

3. Adequacy from board

4. High expectations for all students

5. District will not ignore race or class

6. Hold families and community responsible

7. Identify outstanding schools, teachers and principals and celebrate accomplishments (Harvey et al., 2013)

As evidenced, conversations about race and class can be some of the most challenging a superintendent will have with constituents (Harvey et al., 2013). If these discussions are downplayed or ignored, it could keep a superintendent from finding success in the school district (Harvey et al., 2013). Based on available data, it would appear that few schools are taking on this key issue and segregation in our schools is not much different from the days of Jim Crow (Harvey et al., 2013). This requires courageous leadership that is willing to address the subtle and obvious issues (Harvey et al., 2013). 
Among those issues is the fact that most teachers do not resemble the students in their classrooms (Harvey et al., 2013). Harvey et al. (2013) explain that “...four out of five teachers in the United States are white; about 86 percent, two-thirds of them are 40 years of age or older; and nearly 3/4 are women." It is important to look closely at what is occurring both in the community and in the classroom to begin conversations on class and race (Harvey et al., 2013). Harvey et al. (2013) spend considerable time-sharing strategies that will enable district leadership to experience an understanding of diverse experiences. To effectively facilitate these conversations, it is important to have a diverse group of facilitators who have training on this topic and fully comprehend the issue from the students' perspective (Harvey et al., 2013).

Furthermore, the authors concluded that district leaders are often frustrated by the lack of power over changing these issues as the conversations are centered around adults, not students, and are not given adequate time (Harvey et al., 2013). Disaggregating data is identified as a catalyst for entering these sometimes challenging conversations. Harvey et al. (2013) further asserts that superintendents will have to be courageous and intentional in these conversations and communicate that it is not just about the opportunity gap, but also about moving people forward and away from stereotypes. Harvey et al. (2013) believe that relationships and resources are necessary to close the opportunity gap and this begins and ends with the community.

Schools cannot achieve this without necessary support as students spend most of their time outside of school (Harvey et al., 2013). The best predictor of a child's success comes from the child's home life and the family must be healthy, strong, and supportive (Harvey et al., 2013). Harvey et al. argue that the district office must take responsibility for supporting these families by taking the initiative to bridging the gap between the school and the community. While the concept of community expands well beyond the support of parents, it is necessary to 
focus much of the energy on parents as they are the most significant individuals in a child's' life (Harvey et al., 2013). Harvey et al. (2013) suggest that parents are assets and that they should drive decision-making. To engage parents, they must be viewed as partners and given ample opportunities to serve and participate in the school (Harvey et al., 2013). To collaborate with families, district-level administrators must begin by identifying core community values:

1. Identify Stakeholders

2. Determine Process

3. Establish Timeline

4. Locate Responsibility

5. Agree on Process

6. Communications Plan

7. Encourage Use

8. Provide Assistance

9. Identify Barriers

10. Celebrate Success (Harvey et al., 2013, pp. 258-259)

In moving towards a community-engaged environment, listening to the stakeholders is central to student achievement (Harvey et al., 2013).

The Superintendent's Fieldbook emphasizes a moral framework focused on social justice. The authors of this text describe communities as assets and encourage school leaders to engage in the kinds relationships with the community that will liberate and accelerate learning. Like Marzano $(2009,2011)$ and Kowalski $(2005,2013)$, the focus is on closing the opportunity gap, but the method to achieving the result is quite different. 
Summary and critique. Community is not part of the equation; rather, it is the focus of the model. This unique framework appears to have many positives, but one major limitation is that it may not go far enough to engage the community. The authors continue to focus on parent involvement and effective communication. As identified earlier, Harvey et al. (2013) identified eight factors that must be employed to close the opportunity gap. While some of these factors overlap with the other authorities on effective district leadership, there is a greater emphasis on recognizing race and class, equalizing resources, and holding the community responsible for student outcomes. Harvey encourages courageous discussions on race and class and even goes as far as to suggest these conversations are the foundation for success; a prerequisite for closing the opportunity gap.

The authors understand that the majority of students do not share an ethnicity with their teachers so it is necessary for these educators to receive training and support before they can impact learning. A strength of The Superintendent's Fieldbook is that it balances the need to understand and apply the data, which often opens the door to conversations about race and class. The text charges the superintendent with the responsibility to move the team toward these challenging conversations. Moreover, superintendents must recognize that students spend the majority of their lives at home away from school and that parents are an asset that cannot go ignored if we are to close the opportunity gap. Harvey's focus is similar to Comer (2004) in that parents must be provided ample opportunities to serve and participate in the school. To collaborate with families, district-level administrators must begin by identifying core community values and work within the limitations of the community members, despite convenience to school district personnel. Of the three approaches to leadership that we will compare, Harvey moves us closest to the community in an effort to eliminate the opportunity gap. In the next 
section, the previous approaches will be compared and discussed.

Comparison of approaches to district leadership. In analyzing these authorities on district-level leadership, it is clear that each suggests a unique approach to effective leadership for superintendents and district-level leaders in their quest to improve achievement in economically and ethnically diverse school districts. Where Marzano suggests that school districts should develop and apply a clear, consistent framework and articulate this framework in every district school, Harvey takes an approach that is much more community focused.

Kowalski's approach seems to balance the other two as he calls for consistent goal setting and a communication plan that includes the involvement of stakeholders. All three examples articulate the need for a vision and state that clear goals are essential for growth; however, Marzano speaks less about who in the community is involved in establishing these goals and more about the way these goals must be communicated and implemented. Kowalski states that goal setting must come in cooperation with stakeholders and must emerge organically through meaningful community conversations, but does not go as far as Harvey who believes the communities must be intimately involved in the education process. Kowalski specifically references the practice of 'transformational' leadership. Moreover, he believes that one of the most important roles of the superintendent is to build an effective administrative team and hire outstanding principals and then form a community around these leaders to encourage civic engagement. This is similar to Marzano, who discusses the hiring of a highly qualified, proven team who understand the district goals and can articulate these effectively. Harvey, on the other hand, focuses more on student achievement through the superintendent and school district's intentional engagement with the community. Harvey suggests that communities must be an active and living part of the school and viewed by the faculty and board of education as an asset. Harvey also believes that it is the 
school district's responsibility to ensure families are connecting with the school and engaged in authentic decision-making. Moreover, Harvey supports a social justice approach including helping specific families understand their responsibility to their child's learning. Similarly, Kowalski repeatedly discusses the importance of community but focuses more on the involvement of local corporations, community groups, cooperatives, residents, and other school districts. Each acknowledges the need for setting and monitoring goals, but Marzano asserts that these practices are the key to increasing achievement in the district if they are research-based and monitored regularly. Additionally, Marzano advises superintendents and central office staff to intentionally limit local initiatives and to act as a buffer to mandates.

These experts provide evidence that their research-based methods for improving outcomes are effective and I believe that all three of these experts on district leadership have identified concrete, meaningful ways to impact the community. Practices such as 'hiring effective principals and teachers,' 'working with the community,' or 'meaningful goal setting' appear to have a positive impact on a school district. These authors also unanimously communicate that closing the opportunity gap requires some form of relationship-building with students and a commitment to working closely with community members through the long-range planning process, strategic planning, and other traditional efforts. In this way, Harvey appears to go the furthest in recognizing the need for superintendents and central office administrators to truly engage with the community and recognize issues of equity, adequacy and high expectations from the community. Even so, this has not been enough to close the opportunity gap. At a district-level these relationships appear to focus on policy, communication, representation and student development rather than understanding culture. These three experts offer their research to elevate student outcomes through the direct impact of the district-level leader. Despite the 
value of the research including its ability to support practitioners as they work to improve student achievement, significant gaps continue to exist.

It is clear to see that these efforts have not been enough. The one-size-fits-all models have been unsuccessful in raising student achievement for many students from ethnically and economically diverse backgrounds. A new paradigm is needed to ensure that all students have equal prospects for success and that the opportunity gap closes. These authors neglect to delve into the complexities of understanding student culture and the importance that this plays in authentic learning. Therefore, we will examine Culturally Responsive Pedagogy, an existing, proven framework for effective leadership, which may have significant implications for all students, particularly those in ethnically or economically diverse school districts.

\section{What is Culturally Responsive Pedagogy and}

\section{Why Should School Leaders Care?}

In the second part of this review of the literature, I will provide an overview of Culturally Responsive Pedagogy (CRP) and how it may help district leadership to close the opportunity gap. This overview will include the definition of CRP and the tenets of the pedagogy. Additionally, I will summarize the prevalence of CRP in the literature on school district leadership, and provide my rationale for using this framework for my research as there is a conspicuous lack of knowledge specifically linking culturally responsive pedagogy to the beliefs and practices of exceptional superintendents.

Over the past 10 years schools in the United States have seen rapid growth in the number of students from diverse cultural backgrounds, though it is widely accepted that many schools have failed to adequately prepare all students for the ever-changing workforce they will soon be entering (Bazron, Osher, \& Fleischman, 2005). For example, Latham (1997) explains that in 
"1990, 70\% of all American students were Caucasian. Remarkably, current projections indicate by the year 2026 this percentage will be reversed and 70\% will be nonwhite or Latino." Schools must prepare a diverse body of students to master the competencies (social, intellectual, emotional and technical) to prepare them for life in a career and/or college (Barzon et al., 2005). Unfortunately, culture, family and community are often overlooked in educators' wellintentioned attempt to make schools more equitable (Auerbach, 2009). Hatt (2007), in her study exploring how 'smartness' is defined in schools, explains the importance of a democratic classroom that recognizes culture and each child's personal experience as significant to meaningful instruction:

It centers upon building relationships between teachers and students, students and students, and families and schools. It invites students' lives and experiences into the classroom. It requires a critically, reflective teacher willing to challenge her/his own assumptions and biases. It involves a curriculum that de-centers whiteness and is more co-constructed rather than pre-packaged and standardized. (p. 164)

Remaining culturally responsive allows educators to meet the diverse needs of a multicultural classroom to bridge the gap that exists between home and school (Barzon et al., 2005; Hatt, 2007; Ladson-Billings, 2009). Moreover, rather than address the lack of attention given to the cultural needs of students, many educators instead blame poverty for the opportunity gap that exists between white and minority students (Lyman \& Villani, 2004). One proposed solution to supporting the needs of students of all ethnicities or socio-economic position is Culturally Responsive Pedagogy (CRP).

Culturally Responsive Pedagogy (CRP) is the belief that the cultural knowledge of the student should inform classroom teaching practices, thus liberating and empowering students to achieve to their greatest potential (Ladson-Billings, 1992; Gay, 2000). Culturally responsive pedagogy is often used synonymously with the following terms: culturally relevant, culturally 
responsible, culturally congruent, and multicultural (Irving \& Armento, 2000). These terms describe several similar teaching techniques that imply the teacher actively embeds the students' culture into the classroom (Irving \& Armento, 2000). Although these terms have continued to thrive in research and practice, it is also significant to recognize modifications to the pedagogy. One notable shift in terminology was to 'culturally sustaining pedagogy, which was introduced by Django Paris in 2012. Paris (2012) contends that the terms 'relevant' and 'responsive' describes the research and not the maintenance of rich multiethnic and multicultural identities. This approach offers a strategy to resist attempts to convert our society into a monocultural and monolingual society.

The general concept of recognizing and celebrating culture to inform instruction was introduced by Gloria Ladson-Billings in 1992 as Culturally Responsive Teaching:

Culturally responsive teaching is a pedagogy that empowers students intellectually, socially, emotionally, and politically by using cultural referents to impart knowledge, skills, and attitudes. These cultural referents are not merely vehicles for bridging or explaining the dominant culture; they are aspects of the curriculum in their own right. (pp. 17-18)

The goal of CRP is to make the classroom much more congruent with the norms, beliefs and values of the students, therefore replacing rhetoric on achievement with meaningful action (Auerbach, 2009; Barzon et al., 2005). Irvine, Armento, Causey, Jones, Frasher and Weinburgh, (2000), in their practical teaching guide to CRP entitled Culturally Responsive Teaching, state that there are "four critical elements that support a culturally responsive pedagogy:"

1. Culture is a powerful variable that influences teaching and learning processes.

2. Effective teaching research is compatible with and supportive of the principles of culturally responsive pedagogy.

3. Teacher knowledge and reflection are important considerations when designing implementing a culturally responsive lesson.

4. High standards and expectations are important components of culturally responsive pedagogy. (Irvine et al., 2000, p. 4) 
Recognizing the strengths of a diverse learning community will require that school leaders and individual teachers make a significant shift and begin to recognize the importance of culture in effective teaching (Barzon et al., 2005). The home base must be pursued and celebrated before trust and relationships can impact learning (Auerbach, 2000; Hatt, 2007). Neglecting the home and community as an integral part of instruction may lead a child to an inferior self-image and, ultimately, disengagement from school (Hatt, 2007). A responsive educator is one who does not simply subscribe to a single teaching method; rather a responsive educator understands that differentiation is required to teach well and this requires recognizing that each student has a background, interests and abilities (Gay, 2010; Ladson-Billings, 2009; Irvine et al., 2000).

\section{What Do We Know About Culturally Responsive Pedagogy from Existing Research?}

In this section of the literature review, I will provide an exploration of four notable texts including a review of two seminal texts that helped to define CRP, an early practitioner's guide, and a meta-analysis of CRP. I will expand upon the definition of culturally responsive pedagogy, examine the tenets of CRP, and provide the rationale for selecting it as the lens by which to complete this research.

Ladson-Billings. A wealth of literature exists on the concept of culturally responsive teaching and the body of knowledge has continued to grow since its groundbreaking introduction by Gloria Ladson-Billings in 1992. Although she did not coin the term 'culturally responsive teaching' until 1992, her research started when she received funding in 1988 from a postdoctoral grant. Ladson-Billings (1995) contends that culturally responsive pedagogy has three main criteria: 
1. Students must experience academic success.

2. Students must develop and/or maintain cultural competence.

3. Students must develop a critical consciousness. (p. 160)

Ladson-Billing's seminal text, The Dreamkeepers: Successful Teachers of African American Children (2009), outlines the inequity that exists between students of color and their white counterparts. The author defines culturally relevant teaching and provides specific examples of successful teachers of students of color. This text is significant as it both establishes the pedagogy and outlines specific steps to improving teaching and has been cited by numerous authors researching race and equity in education. Ladson-Billings (2009) contends that CRP is significant as African-American students and other students of color have fallen significantly behind their white counterparts and are nearly three times as likely to drop out of school. Additionally, students in the inner city are about twice as likely to be suspended as white students (Ladson-Billings, 2009). The text promotes effective teaching for students of any race or background, but specifically addresses the needs of African-American students and makes a case for teaching that both increases academic ability and helps students to develop and maintain pride in their cultural identity (Ladson-Billings, 2009). Furthermore, Ladson-Billings expands cultural relevance to moving beyond language to tying cultural identity to all other aspects of school (2009). She explains that, in achieving this, the culturally responsive teacher will counteract the negative impact of school culture as it exists. Ladson-Billings (2009) explains that CRP "is a pedagogy that empowers students intellectually, socially, emotionally, and politically by using a cultural reference to impart knowledge, skills, and attitudes" (p. 382). LadsonBillings (2009) explains that one of the primary goals of culturally responsive teaching is to allow students to choose to celebrate and engage in their culture while also experiencing 
academic excellence. Ladson-Billings also contends that students must be able to achieve while fully identifying with their own unique culture. To provide guidance to culturally responsive teachers, Ladson-Billings (2009) provides specific traits of those educators who effectively practice CRP and suggests they may be identified by the way they view themselves and others:

They see their teaching as an art rather than a technical skill. They believe that all of their students can succeed rather than that failure is inevitable for some. They see themselves as a part of the community, and they see teaching as giving back to the community. They help students make connections between their local, national, racial, cultural, and global identities. (p. 28)

It is significant to note that, unlike other less impactful methods of connecting with and educating students, culturally responsive teaching cannot be achieved by following a specific template or model (Ladson-Billings, 2009). The success of the culturally responsive teacher originates from an understanding of the community, the students, and of self. Supporting this point of view, Irvine et al. (2000) define culture as that which one thinks is important, true, or valuable, including the norms of life, how and why things are done a certain way.

Unlike traditional studies, Ladson-Billings' (2009) research did not consider strong performance on standardized tests as an indicator of quality teaching; rather, her focus was on the 'educational consumers' - the parents. She also spent considerable time working with administrators to identify teachers who had a particular effectiveness in connecting with students of color. She found that culturally responsive teachers have great respect for others and view themselves as 'artists' who are charged with the responsibility to become a living, breathing part of the community and to ensure students are able to make similar connections with the greater community (Ladson-Billings, 2009).

Additionally, Ladson-Billings (2009) believes that knowledge is constantly re-created; it is recycled and reused to be shared by teachers and pupils. Culturally responsive teachers take 
student diversity and individual differences into account in everything they do and LadsonBillings (2009) argues that students will show 'competence' when they are treated as 'competent', and this can be achieved through instructional scaffolding. Ladson-Billings (2009) takes great care in articulating the needs and involvement of the parents in their child's education. She explains that the home culture must be honored and that students must understand the world as it exists from their unique perspective in order to change it for the better. Although Ladson-Billings (2009) believes that the traits of quality teaching are primarily intended for the classroom and school context, the tenets of CRP can be applied to district leadership.

According to Ladson-Billings (2009), the individual is credited with the idea that learning must be connected with an appreciation for culture and community, continues to contribute to the conversation. Upon reflection of the history of CRP and influenced by an experience with the First Wave program, an 'innovative spoken word and hip-hop arts program, Ladson-Billings (2014) acknowledged that her theory might need updating or a 're-mix,' which she believes is vital in any discipline or theory. Feeling as though there exists a 'static conception' of cultural relevancy, she decided that a change to the theory was necessitated to ensure the theory remains true and meaningful (Ladson-Billings, 2014). The evolution of her theory has led her to support Culturally Sustaining Pedagogy, which was introduced by Django Paris in 2012. As previously mentioned, Paris (2012) suggests that the terms 'relevant' and 'responsive' are in need of replacement because they fail to describe the effort that must be made to ensure sustaining of so many rich multiethnic and multicultural identities. This approach suggests that we make efforts to preserve global identities through the active, often artistic exploration of language and culture (Ladson-Billings, 2014). She also acknowledges Culturally Revitalizing Pedagogy, first 
proposed by McCarty and Lee (2014), which focuses on supporting indigenous youth to preserve and revitalize disappearing languages and cultures.

In addition, Ladson-Billings (2000) has been a tireless advocate for improving teacherpreparation programs to better meet the needs of African-American students. She offers numerous strategies to replace Eurocentric teacher-education programs with programs that will support a diverse classroom including: reassessing admissions procedures, reexamining course work, restructuring field experiences, and recruiting and retaining African American Scholars (Ladson-Billings, 2000).

Moreover, in 2006, Ladson-Billings wrote a metaphorical piece comparing the national debt to the cumulative "education debt" that has grown over time and comprises "historical, economic, sociopolitical, and moral components" (p. 3). Her contention is that we not focus on the opportunity gap, which she compares to our national deficit, but rather the 'education debt' which has grown and is way past due (Ladson-Billings, 2006). More importantly, however, she makes suggestions for addressing this debt including "(a)...addressing the impact the debt has on education progress, (b)...understanding this debt in relation to past education research findings and, (c) the potential for forging a better educational future" (Ladson-Billings, 2006). These more recent studies speak directly to Ladson-Billings' continued passion for a culturally relevant pedagogy and her desire to see her field of work continued to grow and evolve.

Summary and critique. Ladson-Billings clearly believes that all students must experience success in the classroom before we are able to dissolve the 'educational debt' and she offers significant research that enables teachers and school leaders to improve student outcomes. While she spends time describing the inequity that exists between students, she also provides specific strategies for overcoming this dilemma through the outlining of specific steps 
to improving teaching. Unlike some of the traditional approaches we explored earlier, LadsonBillings emphasizes the belief that the key to achievement is linking cultural identity to all other aspects of school by 'counteracting' the inherently negative impact of the school culture on students. Ladson-Billings also describes effective teaching and the attributes effective teachers possess while also acknowledging that this success is not easily emulated. It originates from a desire to truly understand a community including beliefs, values and norms that may be unlike your own. This includes the involvement of parents in child's education, a concept that is not accepted by all educators. A key tenet of CRP is that the home culture is to be revered as it has had the largest impact on that child's personal worldview. Making connections to understand a child's personal story, which is expanded upon by Geneva Gay, is a concept that lends itself to effective teaching, which will be discussed next.

Gay. Similar to Ladson-Billings (2009), Geneva Gay's (2010) seminal text, Culturally Responsive Teaching, suggests that a cultural understanding can validate students' own personal story and heritage completely changing daily classroom instruction:

Culturally responsive teaching can be defined as using the cultural knowledge, prior experiences, frames of reference, and performance styles of ethnically diverse students to make learning encounters more responsive and effective for them. It teaches to and through the strengths of these students. It is validating and affirming. (p. 31)

However, she also states that culturally responsive teaching (CRT), derived from CRP, will not do enough on its own to close the opportunity gap or solve the devastating issue of marginalization of students of color. Gay (2010) contends that "[o]ther aspects of the educational enterprise such as funding, administration, and policy making must also be reformed, and major changes must be made to eliminate the social, political, and economic inequities rampant in society at large" (p. 1). 
Nevertheless, Gay (2010) contends that CRT will go a long way to improving the educational experience for students, but that teachers will need to take the time to truly understand that the communicative norms, etiquette, and expectations of each culture will be unique and remain sensitive to this truth. Without this understanding, CRT is not possible (Gay, 2010). Unfortunately, as our system exists, there is a belief that education is one-size-fits-all and that the intellectual, vocational can be taught and learned in the same way for all (Gay, 2010). In contrast with traditional practice, Gay (2010) believes that every individual has a 'personal story' that must be told and reflected in the classroom. Teachers must differentiate and begin to sincerely attempt to understand the abilities of students and develop strategies to capitalize on these strengths in developing teaching strategies; if this is accomplished with fidelity, only then school achievement will improve (Gay, 2010).

Gay boldly states that "intention without action is insufficient" and that "test scores and grades are symptoms, not causes, of achievement problems" (2010, p. 8). Gay (2010) presents four aspects of culturally responsive teaching that act as a cure for the cause of these symptoms: 'caring, communication, curriculum, and instruction.' She delivers a compelling case as to how these four aspects of teaching have a profound impact on student learning and can lead to academic success through a multiethnic classroom experience (Gay, 2010).

Summary and critique. Although her approach is clearly defined, Gay (2010) argues that several obstacles exist that make it difficult for teachers to differentiate including the entrenched Eurocentric framework, fear of racial discrimination for treating students differently, and the belief that education has more to do with academic and vocational skills than cultural heritage. Although critics may argue that good teachers do not need to identify issues of race, ethnicity and heritage, Gay (2010) believes that good teachers truly get to know their students by 
understanding who they are at an organic level. The next text provides the critical next step, a practical tool to support the work of Ladson-Billings and Gay.

Irvine, Armento, Causey, Jones, Frasher and Weinburgh. Unlike the texts from Ladson-Billings and Gay, Culturally Responsive Teaching: Lesson Planning for Elementary and Middle Grades (Irvine et al., 2000) is among the first practical manuals intended to support classroom teachers and pre-service educators as they begin to understand what it is to teach in a culturally diverse classroom. Although the book is laden with usable lessons, it contains a thorough summary of CRP and offers a simple, yet compelling argument for its application in the classroom. Among the greatest messages in this text is the importance of caring (Irvine et al., 2000). Irvine et al. (2000) explain a core principle of effective educators: "Teaching is a social interaction that develops relationships..." (p. 4). Irvine et al. (2000) posit that the welldocumented failure of culturally diverse students is ample evidence of the inequality in our classrooms due to the inexperience, lack of training, and lack of culturally appropriate resources for classroom teachers.

Teachers often feel unprepared to deliver effective instruction for the multicultural student populations that they instruct (Irvine et al., 2000). Inexperienced educators need access to culturally responsive texts and leaders who will help them to meet the diverse needs in their classrooms (Irvine et al., 2000). The pages of our textbooks and general curriculum should better reflect the democratic nature and brilliant history of our great, diverse nation (Irvine et al., 2000). Teachers must first be willing to critique their own classrooms to identify the priorities they have introduced into the existing environment (Irvine et al., 2000). Culturally responsive pedagogy relies heavily upon cultural understanding, experiences, and ways of knowing the world followed by direct action (Irvine \& Armenta, 2000). 
Irvine et al. (2000) suggest that cultural sensitivity simply means teaching appropriately given the context of the participants including a sensitivity to the abilities, interests and cultural background of the students. Irvine et al. (2000) explain that "Cultural variables are often overlooked factors that help to explain the school failure of diverse, non-mainstream children" (p. 6). Moreover, culturally responsive teachers differentiate at a high level by increasing their own knowledge through study and training, and by paying close attention to student needs and the cultural makeup of the classroom (Irvine et al., 2000). The culturally sensitive classroom teacher, Irvine et al. (2000) claim, is spending an immense amount of time and energy getting to know students in order to teach and love them well. Classroom teachers must allow students to share personal stories about family and culture; this honors the child, encourages teacher knowledge, and develops a warm and culturally comfortable setting for learning (Irvine et al., 2000). Unlike many educators' attempts to infuse culture into the classroom by recognizing specific events or holidays, culturally responsive teachers build relationships and differentiate each and every day (Irvine et al., 2000).

It is significant to note that a culturally responsive pedagogy prepares students to affect change in society and not merely fit into it (Irvine et al., 2000; Ladson-Billings, 1992). Teachers can encourage students' ability to change our world by ensuring culture is the hero of the classroom (Irvine et al., 2000). These teachers have the ability to use cultural knowledge and skills to promote students intellectual, emotional and political understanding of the world (Irvine, et al. 2000). Moreover, it is important to note that white, middle-class students have beliefs, norms, learning styles, and values that they bring to school each day (Irvine et al., 2000). Culturally responsive pedagogy does not mean that the classroom teacher must become an expert on each of cultures represented (Irvine et al., 2000). The increased knowledge of students is a 
byproduct of the culturally responsive pedagogy and leads to a stronger worldview and less stereotyping from students and educators (Irvine et al., 2000).

In agreement with Ladson-Billings (2009) and Gay (2006), Irvine et al. (2000) state that the tenets of CRP are not new and that the pedagogy is consistent with strong teaching practices: "It is a myth that culturally responsive pedagogy is a new and special type of pedagogy that is responsive only to low income, urban students of color" (p. 13). Furthermore, the authors argue that teachers working in classrooms right now, regardless of race, culture, or personal beliefs different from the students in the classroom, are able to begin practice of CRP (2000). CRP is not dependent upon the cultural makeup of the school or the instructor since culture is a part of every human life (Irvine et al., 2000).

Summary and critique. Irvine et al. (2000) point out that culturally responsive teachers use the best of what they know and continue to learn about the students in their own classrooms in an effort to improve their own ability to teach: "Effective teachers are identified by their character traits, what they know, what they teach, how they teach, what they expect from their students, how their students react to them, and how they manage the classroom" (p. 10). Other elements of strong teaching present in culturally responsive pedagogy include teacher reflection, or 'thought and action based on experience,' high expectations for students based on challenging standards, and strong communication with parents and community members (Irvine et al., 2000). In short, Irvine et al. (2000) exclaim that "culturally responsive pedagogy is not a bag of tricks that minimizes the difficulty of teaching some students of color" (p. 10).

Hanley and Noblit. Hanley and Noblit's (2009) meta-analysis of CRP, Cultural Responsiveness, Racial Identity and Academic Success: A Review of Literature, is the most upto-date and comprehensive literature review of CRP available and provides incredible insight 
into the power of CRP. Hanley and Noblit (2009) cited 146 studies in the review with a goal to compile a true assessment of CRP to determine its validity and effectiveness in improving student outcomes. This study by Hanley and Noblit (2009) fully examines teaching as it relates to culture, ethnicity and academic success and comes to the conclusion that CRP has merit: "We have concluded that there is sufficient literature to indicate that culturally responsive pedagogy and racial identity are related to achievement and resilience. This is part of developing a critical consciousness within a project of racial uplift" (p. 81). The study makes it clear that when personal identity is suppressed students are effectively 'disempowered' and will find it difficult to use their culture to connect with the world and ultimately succeed (Hanley \& Noblit, 2009). Therefore, an educator serving in a culturally responsive classroom must maximize students' cultural attributes and embed this into student learning objectives, classroom expectations, behavior plans, etc. in an effort to truly engage students and encourage achievement (Hanley \& Noblit, 2009). Hanley and Noblit (2009) identified specific themes as a part of CRP:

1. Involve the community

2. Use culture to promote racial identity

3. Use culture and race as an asset

4. Educate about racism and racial uplift

5. Develop caring relationships

6. Assume success

7. Promote active learning, problem-based instruction and student involvement

8. Employ the arts

9. Acknowledge the challenges (pp. 7-8)

Through the authors' themes, the central message of CRP is delivered: student growth (academic, social and emotional) requires access to the students' cultural knowledge in an attempt to fully engage individuals in learning. Students should be empowered by their cultural knowledge, rather than penalized (Hanley \& Noblit, 2009). Empowerment will lead to success, as Hanley and Noblit (2009) go on to explain. 
Defining success in a culturally responsive classroom. This meta-analysis demonstrates that students will achieve success at significantly higher levels when the school, the community, and their own parents come together as allies (Hanley \& Noblit, 2009). Success is defined as more than just academic achievement and includes other significant accomplishments such as discovering academic identity, understanding behavioral expectations, and acquiring the ability to solve difficult problems (Hanley \& Noblit, 2009). However, because of the subjective nature of the word 'success', Hanley and Noblit (2009) stop short of defining how any specific culture or group defines the word success. Hanley and Noblit (2009) posit, "Students bring a complex web of meaning to the classroom. By the time they enter kindergarten, they have learned to walk, talk, and think as individuals and to understand their group cultural norms" (p. 27). Teaching without first identifying and recognizing the stories of the each individual limits learning because culture is self-identity; new concepts and ideas cannot occur without an understanding of self, including personal worldview and how each person fits into the bigger picture (Hanley \& Noblit, 2009). Effective educators will understand that prior knowledge is non-negotiable to supporting students (Hanley \& Noblit, 2009). To support this effort, educators can easily acquire a baseline of cultural knowledge about students by looking to students' first and most dedicated teachers, their parents and family members (Comer, 2004). Hanley and Noblit (2009) found that each family has an identity and understanding that identity can impact student achievement. A child who understands that his or her own beliefs, values and norms are celebrated will have confidence in who he is, effectively enabling him to discover the world freely leading to increased potential for success in school and in life (Hanley \& Noblit, 2009). However, when students' personal identity is suppressed, disengagement is likely to take place, which is often mistaken for apathy or inability to achieve at high levels (Hanley \& Noblit, 2009; Hatt, 2007). 
Validating community and culture. Hanley and Noblit (2009) examine several significant studies that demonstrate the necessary coexistence of academics and personal identity and how the home culture is the root of learning and self-identity for the earliest and most formative years of one's life (Hanley \& Noblit, 2009). The study also found that many schools continue to leave families with contrasting feelings about the institution, both recognizing the benefit of an education while also witnessing the suppression of their home culture (Hanley \& Noblit, 2009). Therefore, a culturally sensitive instructor will put in the time and effort to research, understand, and apply knowledge about students' home culture and identify perceptions about school and how they construct meaning as a prerequisite to effective teaching (Hanley \& Noblit, 2009). Educators who implement CRP with fidelity must ensure that students' understanding of life experiences are valued as significant as this will recognize and validate students as learners (Hanley \& Noblit, 2009). Hanley and Noblit (2009) take particular care to emphasize the importance of systematic culturally responsive programming addressing the issues of 'deficit-thinking' and 'racial uplift' to promote a positive self-identity and resilience in the greater school environment. This might be accomplished by a curriculum that engages because it speaks to the child's experiences and involves the student in the decision-making process (Hanley \& Noblit, 2009). A child-centered pedagogy may consist of models of contextual teaching methods including inquiry-based, problem-based, service learning and project-based, which speaks to students' interests, knowledge and beliefs (Hanley and Noblit, 2009). A truly culturally responsive curriculum must engage and understand the beliefs of the active community because the community is the cornerstone of the curriculum (Hanley \& Noblit, 2009).

Hanley and Noblit (2009) suggest that it is a" challenge for some professionals...to design programming and/or pedagogy for a culture that is not theirs" (p. 8). A curriculum that does not 
recognize the culture of each child in the classroom has the potential to send an unintended message to students (Hanley \& Noblit, 2009). Hanley and Noblit (2009) suggest that culture is determined by the relationships between the dominant systems in a society; therefore, it is a commonly held belief that achievement for racial minorities is dependent upon assimilation into the existing predominant culture in American schools. "Another way of looking at this is that those with the most power determine the meanings, values, and practices that frame the society, and those who are subordinates develop cultures within that context" (Hanley \& Noblit, 2009, p. 24). To address the problem of equity in schools, educators must engage all children by understanding and appreciating the diversity of all children (Hanley \& Noblit, 2009). Hanley and Noblit's research provides strong evidence that a culturally responsive curriculum strengthened students' personal identity and, in turn, improved academic achievement.

Summary and critique. Hanley and Noblit (2009) went to great lengths to assess CRP of its ability to close the opportunity gap. This piece supports culturally responsive pedagogy and racial identity to achievement and resilience. The study provides evidence that suppressing culture will also suppress learning, which indicates that it is a critical function of the classroom teacher, building principal, superintendent, etc. to make cultural proficiency a priority (Hanley \& Noblit, 2009). The study suggests that educators go beyond 'involvement' to full engagement through discussions about racial identity, participation in cultural activities, and relationship building outside of the context of the school day, which will enable students to see their cultural identity as an asset and empower them to identify the strengths they inherently possess (Hanley \& Noblit, 2009). The study also provided evidence that resiliency increased as a result of improved self-esteem. The study does not define success as that is dependent largely upon the individual culture of that child. Educators must first look to parents and family members to 
establish a cultural baseline. Hanley and Noblit (2009) include several notable pieces that link the celebration of home culture to positive academic outcomes. The authors argue that it is the responsibility of the educators to research and engage in the culture of the child to build empathy and to promote a positive self-identity. This enables an educator to design lessons that recognize and validate cultural experiences, engage students' interests, and validate students' personal knowledge and beliefs. In summary, Hanley and Noblit suggest that rather than forcing students to acclimate to the culturally dominant group, that each child's own cultural identity be validated and celebrated.

\section{Culturally Responsive Leadership}

The research on culturally responsive administrative leadership is limited but significant and it offers support for this study. It is clear that just as culturally responsive teaching reaffirms, equitable leadership puts the needs of others first and is willing to share power with others (Brown, 2004). The tenets of culturally responsive pedagogy discussed in this literature review are consistently applied to the practices of effective school leaders, namely principals, in ethnically diverse, economically disadvantaged settings (Beachum \& McCray, 2011). Like culturally responsive teachers, successful principals will, above all else, believe in the abilities of all students, regardless of cultural heritage, and understand and care about where students come from (Lyman \& Villani, 2004). Furthermore, culturally responsive leaders support the larger framework and encourage teaching methods unique to the needs and culture of the students while generating opportunities for the local community to engage (Beachum \& McCray, 2011). It is the moral obligation of these school leaders to promote meaningful programs and practices that recognize the beliefs, values and identity of the prevailing culture (Riehl, 2000). However, for this to occur with fidelity, leaders need to, "explore self-understandings that are systemically 
embedded in mindsets, worldviews, values, and experiences" (Brown, 2004, p. 87).

Summary of findings. Ethical responsibilities to promote cultural relevancy exists in each school and in each position within the school; however, the roles and duties of the district superintendent are unique to the job and quite dissimilar to the roles and responsibilities of a culturally responsive principal or teacher. Whether the educator is in the classroom, the school office, or the district headquarters, the goal of each individual should be to encourage student success through a personal and organizational commitment to equity and a deep-rooted knowledge of the prevailing needs of the local community (Brown, 2004). While the goal is common, the unique role and subsequent action steps of each position is not. Therefore, the tenets of a classroom teacher and school principal must be applied to that of a culturally responsive superintendent as an outcome of this research.

The review of the literature provides a strong rationale for this study. The review both defines the incredible demands of the superintendency and explores what we know about effective district leadership, specifically those challenges faced by superintendents in ethnically and economically diverse districts. Additionally, the literature review examined Culturally Responsive Pedagogy (CRP) and provides evidence for its development as the appropriate theoretical framework for this research by providing the definition of CRP as well as its tenets.

The literature review provides a conspicuous absence of research linking a culturally responsive pedagogy to the beliefs and practices of effective superintendents. Although strong evidence exists to support the power of a culturally responsive pedagogy in the classroom and school-wide levels, there is little research on the employment of a culturally responsive pedagogy at the district-level. The implications for developing a framework for Culturally Responsive District-Level Leadership are profound and could have a substantial impact on 
student achievement and educational equity. This study and its findings may inform superintendent leadership and, consequently, have a significant impact on our nation's schools.

District leaders have a unique opportunity in roles that might allow for the full alignment of CRP in numerous school buildings. Some of the superintendent responsibilities that might be re-examined by this lens include how funds are directed, how principals and building leaders are evaluated, what curricular materials are selected, district vision and goals, perception by media, attitude of local government, and the importance of recognizing culture and equity district-wide. The culturally responsive leader may dramatically change the definition of schooling and education for a multitude of students.

This literature review supports the need to build/expand upon CRP to create a model for cultural responsiveness at the school district-level based on the existing model. It is possible that exceptional superintendents serving in ethnically and economically diverse school districts may already be practicing the tenets of cultural responsiveness, though there is a lack of research connecting the theory to documented practice. Therefore, I examine the beliefs and practices of effective superintendents in ethnically and economically diverse school districts.

\section{What Would a Culturally Responsive Superintendent Do Differently?}

After a thorough examination of the existing research, the question must be asked: How might culturally responsive pedagogy be applied to district leadership? The research reveals that effective educators must acquire the cultural knowledge of the student and use that knowledge to inform classroom teaching practices (Gay, 2010). This differentiation has been employed at the classroom and school level, but has not been previously vetted at the district-level. Similar to a teacher's understanding of culture and differentiating for students in the classroom or building, I suggest that the superintendent has a responsibility to apply the CRP framework to his or her 
school district to empower the greater community and realize the assets that exist. I begin to develop this framework in the table below. The job responsibilities listed in Table 1 were identified using the Superintendent Job Transition Worksheet developed by the Illinois Association of School Administrators (IASA). The table identifies the common responsibilities tended to by a district superintendent and other stakeholders. The first table represents common practice and personal experience. This is labeled 'traditional approach to responsibilities and meetings'. Table 2 is labeled 'culturally responsive approach to responsibilities and meetings' and represents the approach a culturally responsive superintendent might take in handling similar tasks required of the job. This table does not go into depth when examining these responsibilities. Rather, it is limited to asking: Who is involved in the meetings? When would the meetings occur? Where would the meetings take place? 
Table 1

Traditional Superintendent Approach to Responsibilities and Meetings

\begin{tabular}{|c|c|c|c|}
\hline \multirow{2}{*}{$\begin{array}{l}\text { SUPERINTENDENT } \\
\text { RESPONSIBILITIES }\end{array}$} & \multicolumn{3}{|l|}{ TRADITIONAL APPROACH } \\
\hline & Who & When & Where \\
\hline $\begin{array}{l}\text { Community } \\
\text { Relationships/Planning }\end{array}$ & $\begin{array}{l}\text { Rotary, PTO, Boosters, } \\
\text { Corporate Partners, etc. }\end{array}$ & Monthly meetings & $\begin{array}{l}\text { School District or } \\
\text { predetermined } \\
\text { location }\end{array}$ \\
\hline Board Policy & $\begin{array}{l}\text { Board Policy Committee of } \\
\text { Teachers/Board of Ed. }\end{array}$ & $\begin{array}{l}\text { As needed, Press } \\
\text { Updates }\end{array}$ & $\begin{array}{l}\text { District Office, } \\
\text { Board Room }\end{array}$ \\
\hline Budget/Financial Planning & $\begin{array}{l}\text { Superintendent and/or } \\
\text { Business Manager }\end{array}$ & Throughout Year & District Office \\
\hline Strategic Planning & $\begin{array}{l}\text { District committee made up } \\
\text { of mostly board and admin- } \\
\text { istration, but also include } \\
\text { several teachers, parents, } \\
\text { and community members }\end{array}$ & $\begin{array}{l}2-3 \text { meetings for half } \\
\text { or full day }\end{array}$ & $\begin{array}{l}\text { District Office, } \\
\text { Board Room }\end{array}$ \\
\hline $\begin{array}{l}\text { Curriculum and Assessment } \\
\text { Plan }\end{array}$ & District Administrators & $\begin{array}{l}6 \text { months - } 18 \\
\text { months before } \\
\text { implementation }\end{array}$ & District Office \\
\hline $\begin{array}{l}\text { Communication } \\
\text { Planning/Work with Press }\end{array}$ & $\begin{array}{l}\text { District Administrators and } \\
\text { Board }\end{array}$ & $\begin{array}{l}\text { Ongoing, no regular } \\
\text { meetings }\end{array}$ & District Office \\
\hline PERA Committee & $\begin{array}{l}\text { Committee of } \\
\text { administrators and teachers } \\
\text { (mandated) }\end{array}$ & $\begin{array}{l}\text { Regular meetings } \\
\text { from October - } \\
\text { April, annually }\end{array}$ & District Office \\
\hline Labor/Union and CBA & $\begin{array}{l}\text { Meeting of two committees } \\
\text { including teachers, superin- } \\
\text { tendent and board members }\end{array}$ & $\begin{array}{l}\text { As needed, based on } \\
\text { CBA }\end{array}$ & $\begin{array}{l}\text { District Office, } \\
\text { Board Room }\end{array}$ \\
\hline Technology & $\begin{array}{l}\text { Teachers, Principals, and } \\
\text { (superintendents) }\end{array}$ & Quarterly Meetings & District Office \\
\hline Transportation & $\begin{array}{l}\text { Superintendent, Business } \\
\text { Manager }\end{array}$ & As needed & District Office \\
\hline Emergency Planning & $\begin{array}{l}\text { Superintendent, Fire } \\
\text { Personnel, Police Personnel, } \\
\text { Business Manager, } \\
\text { Principals, Park District } \\
\text { Personnel }\end{array}$ & $\begin{array}{l}\text { Annual Meeting (as } \\
\text { mandated) }\end{array}$ & $\begin{array}{l}\text { District Office, Fire } \\
\text { Department, Police } \\
\text { Department }\end{array}$ \\
\hline
\end{tabular}


Table continued

\begin{tabular}{|c|c|c|c|}
\hline \multirow{2}{*}{$\begin{array}{l}\text { SUPERINTENDENT } \\
\text { RESPONSIBILITIES }\end{array}$} & \multicolumn{3}{|l|}{ TRADITIONAL APPROACH } \\
\hline & Who & When & Where \\
\hline $\begin{array}{l}\text { Professional Development } \\
\text { Program }\end{array}$ & Administrative Team & $\begin{array}{l}\text { Annual for the } \\
\text { following year }\end{array}$ & District Office \\
\hline $\begin{array}{l}\text { District Vision, Mission, and } \\
\text { Goal Statements }\end{array}$ & Board and Administration & As needed & District Office \\
\hline Hiring/Recruitment & Administrators & As needed & $\begin{array}{l}\text { District Office or } \\
\text { School Buildings }\end{array}$ \\
\hline Facility Planning & $\begin{array}{l}\text { Superintendent, Principals, } \\
\text { Business Manager, and } \\
\text { Maintenance Director }\end{array}$ & $\begin{array}{l}\text { Annual, throughout } \\
\text { the year }\end{array}$ & $\begin{array}{l}\text { District Office, } \\
\text { Various Buildings } \\
\text { (based on need) }\end{array}$ \\
\hline Food Service & $\begin{array}{l}\text { Cafeteria Director, } \\
\text { Superintendent }\end{array}$ & As needed & $\begin{array}{l}\text { District Office, } \\
\text { Cafeterias }\end{array}$ \\
\hline $\begin{array}{l}\text { Cooperative Agreements } \\
\text { (Special Education) }\end{array}$ & $\begin{array}{l}\text { Superintendent, Special Ed. } \\
\text { Director, Special Ed. } \\
\text { Coordinator, Principals }\end{array}$ & $\begin{array}{l}\text { Monthly } \\
\text { Cooperative } \\
\text { Meetings, District } \\
\text { meetings as needed }\end{array}$ & $\begin{array}{l}\text { District Office, } \\
\text { Special Education } \\
\text { Coordinators Office }\end{array}$ \\
\hline District Handbook & $\begin{array}{l}\text { Superintendent, Teachers, } \\
\text { and Parents }\end{array}$ & $\begin{array}{l}\text { Annual meeting to } \\
\text { update handbook }\end{array}$ & District Office \\
\hline $\begin{array}{l}\text { Evaluation of Principals, } \\
\text { District-level Staff }\end{array}$ & Superintendent & Annually & District Office \\
\hline
\end{tabular}

To grow in an understanding of the cultural capital of the community, the following responsibilities are viewed through the framework of Culturally Responsive Pedagogy. The table redefines the focus moving from a traditional district-centered philosophy to one that emphasizes the assets in the community. I suggest that, if employed correctly, this approach has the potential to inform the policy and practice of the superintendent and various committees to make decisions that both reflect the values, norms and beliefs of the greater community, and ultimately improve student outcomes. 
Table 2

Culturally Responsive Superintendent Approach to Responsibilities and Meetings

\begin{tabular}{|c|c|c|c|}
\hline \multirow[t]{2}{*}{$\begin{array}{l}\text { SUPERINTENDENT } \\
\text { RESPONSIBILITIES }\end{array}$} & \multicolumn{3}{|c|}{$\begin{array}{l}\text { CULTURALLY RESPONSIVE APPROACH } \\
\text { (changes in bold) }\end{array}$} \\
\hline & Who & When & Where \\
\hline $\begin{array}{l}\text { Community } \\
\text { Relationships/Planning }\end{array}$ & $\begin{array}{l}\text { Rotary, PTO, Boosters, } \\
\text { Rotary, Corporate Partners, } \\
\text { etc. (Participation of } \\
\text { Parent Advisory } \\
\text { Members) }\end{array}$ & Monthly meetings & $\begin{array}{l}\text { School District or } \\
\text { predetermined } \\
\text { location }\end{array}$ \\
\hline Board Policy & $\begin{array}{l}\text { Board Members, } \\
\text { Administrators, Teachers, } \\
\text { (Parent and Community } \\
\text { Representatives) }\end{array}$ & $\begin{array}{l}\text { As needed, Press } \\
\text { Updates }\end{array}$ & $\begin{array}{l}\text { District Office, } \\
\text { (Offsite location } \\
\text { including: local } \\
\text { business, places of } \\
\text { worship, library, } \\
\text { home) }\end{array}$ \\
\hline Budget/Financial Planning & $\begin{array}{l}\text { Superintendent, Business } \\
\text { Manager (Pre-planning } \\
\text { with community repre- } \\
\text { sentatives made up of } \\
\text { parents and local } \\
\text { leadership) }\end{array}$ & Throughout Year & $\begin{array}{l}\text { District Office, } \\
\text { (Pre-planning in } \\
\text { predetermined off- } \\
\text { site location) }\end{array}$ \\
\hline Strategic Planning & $\begin{array}{l}\text { District committee made up } \\
\text { of mostly board and admin- } \\
\text { istration, but also include } \\
\text { several teachers, parents, } \\
\text { and community members } \\
\text { (create a balance of } \\
\text { community members and } \\
\text { school personnel/elected } \\
\text { board members) }\end{array}$ & $\begin{array}{l}2-3 \text { meetings for } \\
\text { half or full day } \\
\text { (continuous } \\
\text { throughout the } \\
\text { year - perpetual } \\
\text { meetings) }\end{array}$ & $\begin{array}{l}\text { District Office } \\
\text { (Off-Site location } \\
\text { including: local } \\
\text { business, places of } \\
\text { worship, library, } \\
\text { home) }\end{array}$ \\
\hline $\begin{array}{l}\text { Curriculum and Assessment } \\
\text { Plan }\end{array}$ & $\begin{array}{l}\text { District Administrators } \\
\text { (pre-planning with } \\
\text { families, community } \\
\text { members) }\end{array}$ & $\begin{array}{l}6 \text { months }-18 \\
\text { months before } \\
\text { implementation }\end{array}$ & $\begin{array}{l}\text { District Office (Off- } \\
\text { site location } \\
\text { including: local } \\
\text { business, places of } \\
\text { worship, library, } \\
\text { home) }\end{array}$ \\
\hline
\end{tabular}


Table continued

\begin{tabular}{|c|c|c|c|}
\hline \multirow[t]{2}{*}{$\begin{array}{l}\text { SUPERINTENDENT } \\
\text { RESPONSIBILITIES }\end{array}$} & \multicolumn{3}{|c|}{$\begin{array}{l}\text { CULTURALLY RESPONSIVE APPROACH } \\
\text { (changes in bold) }\end{array}$} \\
\hline & Who & When & Where \\
\hline $\begin{array}{l}\text { Evaluate Staff/PERA } \\
\text { Committee }\end{array}$ & $\begin{array}{l}\text { Committee of } \\
\text { administrators and teachers } \\
\text { - mandated (pre-meeting to } \\
\text { discuss school } \\
\text { culture/climate/5 essentials } \\
\text { survey) }\end{array}$ & $\begin{array}{l}\text { Regular meetings } \\
\text { from October - } \\
\text { April, annually }\end{array}$ & $\begin{array}{l}\text { District Office (Pre- } \\
\text { meeting in an } \\
\text { offsite location } \\
\text { including: local } \\
\text { business, places of } \\
\text { worship, library, } \\
\text { home) }\end{array}$ \\
\hline Labor/Union and CBA & $\begin{array}{l}\text { Meeting of two committees } \\
\text { including teachers, } \\
\text { superintendent and board } \\
\text { members } \\
\text { (pre-meeting to discuss } \\
\text { school culture/climate/5 } \\
\text { essentials survey) }\end{array}$ & $\begin{array}{l}\text { As needed, based on } \\
\text { CBA }\end{array}$ & $\begin{array}{l}\text { District Office (Pre- } \\
\text { meeting in an } \\
\text { offsite location } \\
\text { including: local } \\
\text { business, places of } \\
\text { worship, library, } \\
\text { home) }\end{array}$ \\
\hline Technology & $\begin{array}{l}\text { Teachers, Principals, and } \\
\text { Superintendent (parents, } \\
\text { local business members } \\
\text { who may offer support/wi- } \\
\text { fi, community leaders) }\end{array}$ & $\begin{array}{l}\text { Quarterly Meetings } \\
\text { (monthly meetings) }\end{array}$ & $\begin{array}{l}\text { District Office } \\
\text { (occasionally meet } \\
\text { at offsite locations } \\
\text { to discuss access to } \\
\text { technology and } \\
\text { support in } \\
\text { community) }\end{array}$ \\
\hline Transportation & $\begin{array}{l}\text { Superintendent, Business } \\
\text { Manager (parents) }\end{array}$ & $\begin{array}{l}\text { As needed } \\
\text { (at least annually } \\
\text { at beginning of } \\
\text { year) }\end{array}$ & $\begin{array}{l}\text { District Office } \\
\text { (parents and } \\
\text { administrators ride } \\
\text { on bus routes) }\end{array}$ \\
\hline Emergency Planning & $\begin{array}{l}\text { Superintendent, Fire } \\
\text { Personnel, Police Personnel, } \\
\text { Business Manager, } \\
\text { Principals, Park District } \\
\text { Personnel (parents, } \\
\text { community leadership) }\end{array}$ & $\begin{array}{l}\text { Annual Meeting - as } \\
\text { mandated } \\
\text { (quarterly } \\
\text { meetings) }\end{array}$ & $\begin{array}{l}\text { District Office } \\
\text { (offsite location } \\
\text { including: local } \\
\text { business, places of } \\
\text { worship, library, } \\
\text { home) }\end{array}$ \\
\hline $\begin{array}{l}\text { Professional Development } \\
\text { Program }\end{array}$ & $\begin{array}{l}\text { Administrative Team } \\
\text { (community } \\
\text { representatives made up } \\
\text { of parents and local } \\
\text { leadership) }\end{array}$ & $\begin{array}{l}\text { Annual for the } \\
\text { following year }\end{array}$ & $\begin{array}{l}\text { District Office } \\
\text { (offsite location } \\
\text { including: local } \\
\text { business, places of } \\
\text { worship, library, } \\
\text { home) }\end{array}$ \\
\hline
\end{tabular}


Table continued

\begin{tabular}{|c|c|c|c|}
\hline \multirow[t]{2}{*}{$\begin{array}{l}\text { SUPERINTENDENT } \\
\text { RESPONSIBILITIES }\end{array}$} & \multicolumn{3}{|c|}{$\begin{array}{l}\text { CULTURALLY RESPONSIVE APPROACH } \\
\text { (changes in bold) }\end{array}$} \\
\hline & Who & When & Where \\
\hline Hiring/Recruitment & $\begin{array}{l}\text { Administrators (pre- } \\
\text { meeting to discuss culture, } \\
\text { climate and norms, beliefs } \\
\text { and values of the } \\
\text { community - members } \\
\text { also sit on interview team) }\end{array}$ & As needed & $\begin{array}{l}\text { District Office or } \\
\text { School Buildings } \\
\text { (off site location } \\
\text { including: local } \\
\text { business, places of } \\
\text { worship, library, } \\
\text { home) }\end{array}$ \\
\hline Facility Planning & $\begin{array}{l}\text { Superintendent, Principals, } \\
\text { Business Manager, and } \\
\text { Maintenance Director } \\
\text { (parents, community } \\
\text { members, local leadership) }\end{array}$ & $\begin{array}{l}\text { Annual, throughout } \\
\text { the year }\end{array}$ & $\begin{array}{l}\text { District Office, } \\
\text { Various Buildings } \\
\text { (based on need) }\end{array}$ \\
\hline Food Service & $\begin{array}{l}\text { Cafeteria Director, } \\
\text { Superintendent (parents, } \\
\text { community members, } \\
\text { local leadership) }\end{array}$ & As needed & $\begin{array}{l}\text { District Office, } \\
\text { Cafeterias }\end{array}$ \\
\hline $\begin{array}{l}\text { Cooperative Agreements } \\
\text { (Special Education) }\end{array}$ & $\begin{array}{l}\text { Superintendent, Special Ed. } \\
\text { Director, Special Ed. } \\
\text { Coordinator, Principals } \\
\text { (parents - particularly } \\
\text { parents who have students } \\
\text { participating in the } \\
\text { program, community } \\
\text { members, local leadership) }\end{array}$ & $\begin{array}{l}\text { Monthly } \\
\text { Cooperative } \\
\text { Meetings, District } \\
\text { meetings as needed }\end{array}$ & $\begin{array}{l}\text { District Office, } \\
\text { Special Education } \\
\text { Coordinators Office }\end{array}$ \\
\hline Handbook & $\begin{array}{l}\text { Superintendent, Teachers, } \\
\text { and Parents (parents, } \\
\text { community members, } \\
\text { local leadership) }\end{array}$ & $\begin{array}{l}\text { Annual meeting to } \\
\text { update handbook } \\
\text { (quarterly) }\end{array}$ & $\begin{array}{l}\text { District Office } \\
\text { (offsite location } \\
\text { including: local } \\
\text { business, places of } \\
\text { worship, library, } \\
\text { home) }\end{array}$ \\
\hline $\begin{array}{l}\text { Evaluation of Principals, } \\
\text { District-level Staff }\end{array}$ & Superintendent & Annually & $\begin{array}{l}\text { District Office (on } \\
\text { school site - focus } \\
\text { on CRP leadership/ } \\
\text { classrooms) }\end{array}$ \\
\hline
\end{tabular}


These tables illustrate my understanding of a culturally responsive superintendent before the data collection occurred. Therefore, these tables are limiting because they do not reflect the characteristics of effective superintendents as identified in Chapter V of this study. Therefore, I created an updated table in Chapter V that represents the beliefs and actions of culturally responsive superintendents. The updated table illustrates the how exceptional superintendents demonstrate cultural responsiveness within the key characteristics of exceptional superintendents. Creating this new model for district-level leadership using CRP will allow district-level leaders to directly impact the opportunity gap by focusing on the assets of a multicultural school district thus improving the potential to transform the community and the school district. This basic framework could provide a new lens to view leadership through empowerment and resiliency. Much evidence exists that supports the employment of CRP at the classroom and building level.

I believe the foundation for any effective team comes from an ability to work with those with a dissimilar worldview to bring these unique and sometimes opposing belief systems together to scaffold knowledge and build something new. Additionally, I suggest that as trust and comfort level is established, support for the school district also increases. The research suggests that district leadership must discover the treasure that is hiding in plain sight.

\section{Summary}

Despite the wealth of research that exists on school leadership, the question of how to begin to close the opportunity gap continues to exist. Therefore, the goal of this literature review was to answer the following question: How can superintendents lead to effectively meet the needs of an ethnically and economically diverse school district? To achieve this, I organized the review into four distinct sections. The first section identified what we know about exceptional 
district leadership by examining the written work of several experts on district leadership. I continued by sharing the main limitation to each of these texts in closing the opportunity gap for students in ethnically and economically diverse school districts. I then examined the basic definition of Culturally Responsive Pedagogy and explored CRP in the literature to determine its impact on student outcomes. In the third section, CRP was examined in the context of districtlevel leadership. It is significant to note that I identified a conspicuous lack of research linking CRP to the beliefs and practices of exceptional superintendents. Finally, findings were summarized and made a case for why additional research is required to further explore CRP and develop a new model for superintendent leadership. In the next chapter, the research methodology for the proposed study is discussed. 


\section{CHAPTER III}

\section{RESEARCH METHODOLOGY}

\section{Introduction}

A review of research literature revealed a need for an expanded and updated understanding of exceptional superintendent leadership in economically and ethnically diverse school districts. Specifically, the rapidly changing economic and political climate in Illinois supports a need for an understanding of what characteristics will be necessary to survive and thrive as a superintendent. Existing research provides a wealth of knowledge on the effectiveness of culturally responsive teachers; therefore, I compare what we know about the beliefs and practices of culturally responsive teachers to the beliefs and practices of culturally responsive superintendents. While I did not expect all of the specific responsibilities of the job to align, I anticipated common characteristics of CRP teachers and superintendents to emerge. Examples include, but are not limited to, the beliefs of the culturally responsive teachers identified in my review of the literature:

- They believe in a personalized learning experience

- They believe an understanding of the community is central to achievement

- They believe learning requires relationships

- They believe in high expectations for students, staff and community members

- They believe family engagement and involvement is paramount

- They believe in strong collaboration among faculty and staff

- They believe in intentional engagement in culturally responsive practices

The data was examined to see how the practices enacted by the superintendents matched up with the research literature. The data was analyzed with the new information provided on the best 
practices of superintendents serving in economically and culturally diverse school districts.

Additionally, I maintain a personal interest in better understanding what it takes to be a successful superintendent, which has contributed to the development of my questions.

\section{Research Questions}

This study examined the leadership of exceptional superintendents serving in ethnically and economically diverse school districts by answering the following research questions:

1. What is the nature of superintendent leadership in ethnically and economically diverse school districts that indicate a closing of the opportunity gap?

2. What leadership traits do each of the identified superintendents possess?

3. What are the identifiable best practices of exceptional superintendents serving in ethnically and economically diverse school districts?

As previously stated, the wisdom of these exceptional superintendents provided practical insights. These questions served as a guide in understanding the unique success enjoyed by the exceptional superintendents. These questions also allowed me to analyze data to identify the leadership practices and characteristics that are deemed significant. I interviewed, observed, and analyzed to enhance an understanding of exceptional leadership in economically and ethnically diverse school districts. I took a similar, informal approach to growth when I was a new

principal. I went straight to the experts, those proven leaders who have experienced growth, to increase my own likelihood of achieving success. This enabled me to emulate many of the successful beliefs, practices and policies to become a more effective leader. I employ a similar approach when examining the beliefs, practices and policies of the identified exceptional superintendents. 


\section{Research Methods}

A qualitative comparative case study design was utilized for this study. Interviews were the primary source of data collection. A case study was appropriate for this research because it allowed me to collect data through interviews, observation and artifact analysis. I examined the data to identify the participants' predominant characteristics as well as the commonalities and differences between the superintendents (Glesne, 2011). Additionally, this method supported my intent to collect multiple sources of data by observing the participants in a natural setting, while also collecting data through the interview questions and artifact analysis (Glesne, 2011).

\section{Research Paradigm}

The research paradigm applied to this study was critical theory. Critical theorists examine the organization of power in society, often in public institutions, to understand the marginalization of individuals or specific groups (Glesne, 1999). Critical theorists often question how reality has been formed through the political, social, cultural, economic and ethnic factors (Guba \& Lincoln, 1994). As understanding and knowledge is gained and refined over time, we get closer to reality (Guba \& Lincoln, 1994). Researchers who operate with this worldview often examine social science issues to apply research that will contribute to the betterment of society as a whole (Glesne, 1999).

Critical theory informed my work in that the purpose of my research was to create change and to encourage the kind of superintendents that low-income and/or students of color deserve. Additionally, this research was intended to help generate change in myself by making me a better superintendent. For these reasons, this research was not written and conducted like traditional research as the purposes were grounded in change and were personal. The writing style reflected this approach in that first person was commonly used throughout the dissertation and my 
personal experiences and reflections as the author were included.

\section{Participants}

A purposeful sampling strategy was employed to select case study participants (Hatch, 2002). Three superintendents participated in this study. I was able to identify four individuals who originally met the criteria; however, only three of the participants provided consent, while one of the four identified superintendents did not respond to my phone and email requests. The district eligibility criteria for this study included: (a) low-income enrollment or K-12 districts in which $40 \%$ or more of the students were eligible for free and reduced lunch, and (b) minority enrollment or districts in which more than $40 \%$ of student enrollment was students of color. Additionally, each district depicted a smaller than average opportunity gap between white students and students of color as well as low-income students and their peers. Districts were also required to achieve approximately the same PARCC scores as the state average according to 2015 Illinois Report Card data. The participants selected for this research also met the following criteria: (a) at least 5 years of superintendent experience, (b) revered by the community at large, and (c) longevity in current position (minimum of 3 years). These exemplary superintendents serving in ethnically and economically diverse school districts were identified by providing the criteria to the Regional Superintendents. Participants were contacted only after all eligible superintendents were identified. Pseudonyms were used in place of names for all 10 participants.

\section{Data Collection Techniques}

Data presented included semi-structured interviews, observations, and artifact analysis. I conducted interviews with a total of 10 administrators, including three superintendents and seven administrative team members. The superintendent participants were asked to identify administrative team members who worked closely with the superintendent and could speak to the 
district's successes and achievements during the superintendent's tenure. Two administrative team members were interviewed for Superintendent 1, two administrative team members were interviewed for Superintendent 2, and three administrative team members were interviewed for Superintendent 3, at the request of the Superintendent. Interviews were conducted over a period of 6 weeks and all but one of the interviews were conducted in person in a location selected by the participant; however, two interviews required follow-up by phone. One administrative team member interview was conducted exclusively by phone as the selected administrative team member was not present on the date of my visit to the district. Each superintendent participant was interviewed at least once, with follow-up interviews occurring by phone. Table 3 is a data $\log$ of all interviews, observations and artifact analysis.

Table 3

Data Accounting Log

\begin{tabular}{|c|c|c|c|c|c|c|c|c|c|c|}
\hline & Supt 1 & $\mathrm{Cab} 1$ & $\mathrm{Cab} 2$ & Supt 2 & Cab 1 & $\mathrm{Cab} 2$ & Supt 3 & $\mathrm{Cab} 1$ & $\mathrm{Cab} 2$ & Cab 3 \\
\hline Interview & $\begin{array}{l}\text { Early } \\
\text { Nov. } \\
2017\end{array}$ & $\begin{array}{l}\text { Early } \\
\text { Nov. } \\
2017\end{array}$ & $\begin{array}{l}\text { Early } \\
\text { Nov. } \\
2017\end{array}$ & $\begin{array}{l}\text { Mid } \\
\text { Nov. } \\
2017\end{array}$ & $\begin{array}{l}\text { Mid } \\
\text { Nov. } \\
2017\end{array}$ & $\begin{array}{l}\text { Mid } \\
\text { Nov. } \\
2017\end{array}$ & $\begin{array}{l}\text { Late } \\
\text { Nov. } \\
2017\end{array}$ & $\begin{array}{l}\text { Late } \\
\text { Nov. } \\
2017\end{array}$ & $\begin{array}{l}\text { Late } \\
\text { Nov. } \\
2017\end{array}$ & $\begin{array}{l}\text { Late } \\
\text { Nov. } \\
2017\end{array}$ \\
\hline Location & $\begin{array}{c}\text { District } \\
\text { Office }\end{array}$ & $\begin{array}{l}\text { District } \\
\text { Office }\end{array}$ & $\begin{array}{c}\text { District } \\
\text { Office }\end{array}$ & $\begin{array}{l}\text { District } \\
\text { Office }\end{array}$ & $\begin{array}{c}\text { District } \\
\text { Office }\end{array}$ & $\begin{array}{l}\text { District } \\
\text { Office }\end{array}$ & $\begin{array}{l}\text { District } \\
\text { Office }\end{array}$ & $\begin{array}{l}\text { District } \\
\text { Office }\end{array}$ & $\begin{array}{c}\text { District } \\
\text { Office }\end{array}$ & Phone \\
\hline Observation & $\begin{array}{l}\text { Early } \\
\text { Nov. } \\
2017\end{array}$ & N/A & N/A & $\begin{array}{l}\text { Mid } \\
\text { Nov. } \\
2017\end{array}$ & N/A & N/A & $\begin{array}{l}\text { Late } \\
\text { Nov. } \\
2017\end{array}$ & N/A & N/A & N/A \\
\hline $\begin{array}{l}\text { Document } \\
\text { District } \\
\text { Website } \\
\text { ("X" or } \\
\text { N/A) }\end{array}$ & $\mathrm{X}$ & N/A & N/A & $\mathrm{X}$ & N/A & N/A & $\mathrm{X}$ & N/A & N/A & N/A \\
\hline $\begin{array}{l}\text { Document } \\
\text { Assessment } \\
\text { Data - } \\
\text { Illinois } \\
\text { Report Card }\end{array}$ & $\mathrm{X}$ & N/A & N/A & $\mathrm{X}$ & N/A & N/A & $\mathrm{X}$ & N/A & N/A & N/A \\
\hline
\end{tabular}


The superintendent and team-level administrators received a consent form prior to the interviews. Superintendent and team-level administrators were informed that interview and observation data was confidential and only to be used for the purposes of this study. These assurances reduced the potential for risk. Ten questions were used for the superintendent interviews. The first four questions for the administrative team participants were designed to establish a level of comfort and were not used for data collection purposes. If, in the context of these opening questions the superintendent was mentioned, I included and analyzed relevant data during the coding process. The interviews were conducted in a private location selected by the participants. Additionally, interviews were recorded digitally and later transcribed using transcription software. I engaged the participants in a series of interview questions in the selected location(s) to better understand the participants' own perceptions and experiences in a natural setting. This allowed participants to feel comfortable and allowed me to grow in an understanding of their personal experience (Glesne, 2011). Observations took place in the participants' natural workplace context, including the district office, selected district schools, and other associated locations. The goal was to capture a 'day in the life' of each of the exceptional superintendents.

Additionally, I took notes at meetings, classroom visits and school events. I paid particular attention to conversations, acts, and gestures and examined specific actions within those events (Glesne, 2011). The initial goal was to collect artifacts when a participant, either a superintendent or an administrative team member, provided personal documents, notes, or other written information and that content was deemed significant to the participant's identity as an effective leader and pertinent to the research. This occurred in District 1, but not in District 2 
or 3. Therefore, artifact analysis was primarily limited to data collected from the Illinois Report Card and the school websites.

\section{Contributions of Pilot Study to Current Thoughts and Proposed Approaches}

In preparing for this study, I conducted an interview with an active superintendent who met many of the identifiers of an exceptional district-level leader as defined by this study. While the parameters for selecting participants were not applied to this particular participant, the selected superintendent met several of the requirements set forth in this proposal. Therefore, an interview protocol was created and I conducted the pilot interview to allow for further development of the questions included in the appendix. While the questions were answered fully, I did not feel comfortable with the flow, as the questions did not lead into one another as expected. Therefore, I felt a natural inclination to reorganize the interview questions in a natural sequence. This improved the interview process and, as a result of these changes, the interview guide was presented to the participants in the updated format.

\section{Data Analysis Procedures}

The data was analyzed using typological analysis, in which I divided and categorized the data set into specific typological groups (Hatch, 2002). This method of analysis allowed me to identify patterns and create categories based on the research literature on culturally responsive practices in schools. I then identified patterns and categories within the common themes. I then utilized negative case analysis, which recognizes the fact that research is unpredictable and that my findings may not match my initial hypothesis, to provide real data (Creswell, 2013). This refining process supported my efforts to identify a complete story and assisted in articulating the leadership style of each superintendent (Hatch, 2002). Moreover, I employed Gee's (2010) "Making Strange Tool” to conduct discourse analysis, which provided guidance in reconstructing 
meaning from notes, interviews, recordings and observations. This 'tool' assisted me in providing an objective perspective on the topic of education administration, which is extremely familiar. This permitted me to view the study as an outsider looking in. I then examined biases and preconceived notions in an attempt to improve the ability to recognize that which was unusual or different. This tool assisted me in articulating the research in a way that was understandable to those who were not educational administrators.

The case studies were organized by district and were presented in the chronological order of the initial interviews. Brief descriptions of each district were provided for context. The data collected during fieldwork, including observations, interviews, and document analysis, was analyzed using codes: "A code in qualitative inquiry is most often a word or short phrase that symbolically assigns a summative, salient, essence-capturing, and/or evocative attribute for a portion of language-based or visual data" (Saldaña, 2016). The cumulative findings were presented according to the identified themes.

\section{Consideration of Possible Ethical Issues}

This study may have significant implications for leaders both within the state and nationally. The information collected has the potential to profoundly shape the way new and growing leaders inform their practice and conduct personal research. Additionally, the information collected may be used for instructional purposes in educational leadership preparation programs. Therefore, it was necessary that ethical issues were fully acknowledged and addressed from the onset of this research. Regarding reciprocity, it was important that the individuals sharing their expertise were honored and granted access to the research at any stage in the research process. This was achieved by practicing complete transparency and accessibility to the research. I maintained participants' confidentiality and explained that their participation 
was voluntary. Furthermore, participants received copies of the analysis and the results (i.e., member checking). This provided some insight as to what they do that is unique to their success and what practices are common among the superintendents selected for this study. This research may inform their own decision-making or simply affirm existing practices. IRB approval was obtained before initiating the research process.

\section{Trustworthiness/Reflexivity}

To ensure valid research, trustworthiness and reflexivity must be considered before during and after the research takes place (Glesne, 2011). Researchers must remain conscious of their personal motives for selecting and carrying out a study as it may directly impact the 'trustworthiness' of the research (Maxwell, 2005). My personal experience and reactivity were considered threats to the research (Bickman \& Rog, 2008). Therefore, I reflected throughout the research process. Creswell (2013) refers to these as 'validation strategies.' I employed the following specific measures to validate this research:

- Triangulation of Data: I used several sources of data including document review, interviews, and observations, I organized data from several sources to validate my findings (Creswell, 2013).

- Member Checking: After collecting and organizing the draft data, I presented the findings to the participants and asked them to verify the accuracy of the research (Creswell, 2013).

- Negative Case Analysis: Understanding that research is unpredictable and that my findings may not match my initial hypothesis, I employed negative case analysis to provide real data (Creswell, 2013). 
- Clarifying Researcher Bias: Those with past experiences related to the research should acknowledge this at the onset to display transparency and illuminate any bias (Creswell, 2013). As a practicing superintendent who has experience in an ethnically and economically diverse school district, I had personal views and opinions about what it means to be an exceptional superintendent in a similar context. I acknowledged the existence of personal beliefs, values, and opinions and took care to pay special attention to emotions to enhance awareness of subjectivity and how it may have influenced the research process.

- Peer Debriefing: I shared my research with a 'disinterested peer' with the objective of identifying, extracting and resolving that which made sense in one's own mind (Lincoln \& Guba, 1985).

\section{Implications, Significance, and Contributions}

The knowledge gained from this dissertation may contribute significant new information to what we know about what it takes to lead in a very specific, yet common, setting in districts across the country. Additionally, a new framework is proposed in the analysis of the identified superintendent characteristics. This research may contribute information with which to evaluate or select superintendents in ethnically and economically diverse public school settings. Finally, the information collected from this research may be used in graduate classes to inform instruction and preparation.

\section{Policy}

This research may contribute to policy by influencing preparation and/or requirements for leading in an economically and ethnically diverse school district. Superintendent and principal leadership programs may utilize the information provided in this study to enhance instruction. 
Furthermore, research could be used to provide an evaluation tool for school boards in evaluating superintendent practice and outcomes, which has the potential to support superintendents serving in similar contexts.

\section{Practice}

This research will be extremely practical for existing and aspiring school superintendents serving in ethnically and economically diverse school districts. The common characteristics of exceptional superintendents may be interpreted as 'best practices.' Additionally, this research may be used to help reform schools with similar demographics that struggle to close the opportunity gap.

\section{Benefit to Participants}

Participants may benefit from this research in several ways. First, research may benefit the participants in expanding their pedagogy and giving a name to their practice, thus impacting more students in a positive way. Additionally, participants will receive the intrinsic benefit of knowing they have contributed to the greater picture in supporting those who serve in similar settings. This study may also generate future opportunities or recognition of the superintendent's present role. Participants may elect to identify themselves as a selected 'exceptional superintendent,' which may lead to wide-scale recognition of their success. Finally, participants may enjoy an expanded network with colleagues in similar settings.

\section{Summary of Study}

The goal of this study was to identify and examine exceptional superintendents serving in ethnically and economically diverse school districts. The review of literature analyzed the existing research, which included the perspectives of numerous experts on district-level leadership. The research also included an analysis of culturally responsive pedagogy, including 
a review of four seminal texts and a meta-analysis of the research literature. The study identified the research methodology and attempted to answer the following research questions:

1. What is the nature of superintendent leadership in ethnically and economically diverse school districts that indicate a closing of the opportunity gap?

2. What leadership traits do each of the identified superintendents possess?

3. What are the identifiable best practices of exceptional superintendents serving in ethnically and economically diverse school districts?

I believe that the answers to these questions will have significant implications for school district leaders in ethnically and economically diverse school districts in fulfilling their responsibility of closing the opportunity gap. 


\section{CHAPTER IV}

\section{CASE STUDIES}

\section{Introduction}

This chapter is intended to tell a story. It begins by introducing exceptional superintendent leaders through brief, individual portraits. The 'stories' are knit together from the interviews, observations, and artifact analysis. The primary sources of these profiles are derived from the superintendent philosophy, identified district strengths, actions, leadership style, core beliefs, direct impact on students, and decision-making process. The case studies presented in the following chapter contain examples of exceptional leadership and, consequently, illustrate a picture of outstanding service to children who attend schools in ethnically and economically diverse communities. The chapter speaks for itself in that it shines a bright light on how these leaders have broken the mold and changed the narrative for children who have historically underperformed at school through authentic, culturally responsive leadership.

\section{Superintendent Portraits}

\section{Portrait 1: Dr. Paul James}

As Dr. Paul James leads me into a large, well-lit second grade dual language classroom, I see smiles form on the faces of the students and educators in the room. Dr. James is a white man in his 40s. Dr. James is well-dressed. He is not wearing a tie or a suit and his casual, professional style sends the message that he is here to get his hands dirty. He gregariously greets the students and tells them that he's excited to be in their classroom. During the visit to the classroom, the superintendent walks around the room speaking to the children, examining their work, and finally settling on a large, colorful rug to join the kids for a learning activity. The educator in the room smiles as she watches him. Like the majority of the students in the classroom, the teacher 
is Latino. Dr. James compliments a second-grade student on her 'efficient work', "I see you are fast; that is one of your strengths." Later, he squats down near a desk where a student is writing a letter. He quickly reads the letter and says to the boy, "I can see from your letter that you are a kind person." The boy explains the purpose of the letter assignment. Dr. James continues to walk around the room conversing with students and providing encouragement to the staff and the children. He steals a moment to speak with the principal, who is engaging students in another part of the classroom. "What are you seeing here?" The principal contemplates his question before responding. "I see students working together. They are doing a good job of collaborating." Later, the superintendent stops in a large, well-lit room to speak to another primary level teacher. She enthusiastically greets him and they chat for a moment. I hear them discuss the concept of 'structured autonomy' and Dr. James comments on the importance of "giving students choice". He smiles and takes a moment to compliment the teacher. He stops for a moment to tell me about the incredible talent in the district before he walks away to join students on a rug for a game. The students smile as he interacts with them.

The 14 schools that make up School District 1 educate approximately 7000 K-8 students, of which $60 \%$ are students of color. Specifically, Latino students constitute the largest ethnic group in the district at $43 \%$. White students make up $40 \%$ of the district, Asian students represent $11 \%$, and Black students 3\%. Additionally, 54\% of students are considered lowincome. Over 60 distinct languages are spoken in this diverse community, and 35\% of all students are English language learners. According to the 2015 Illinois Report Card data, the district mirrors the state almost identically when examining the PARCC assessment. Specifically, the district and state both saw $28 \%$ of students approaching standards, $28 \%$ of students meeting standards, and $4 \%$ exceeding standards. The district also boasts a slightly 
lower than average opportunity gap between students identified as low-income and their peers. While the opportunity gap between white students and students of color matches the state average, district achievement among students of color and low income exceed performance in other districts with similar demographics.

Dr. James is in his fourth year as superintendent of this diverse suburban school district. This is his $28^{\text {th }}$ year in education. He started his career as a middle school Biology teacher before accepting a position in an administrative program in a suburban district for 1 year. He then accepted an assistant principal position where he served for 2 years before being promoted to an elementary principal position. In that same district, he transferred to the middle school and served as principal for 8 years, also serving as assistant superintendent in charge of operations for the final 3 years. He then accepted a superintendency in a different Chicago suburb, where he served for 3 years. In 2013, he accepted the position in his current District. He is married and has five children.

Dr. James' collaborative interactions with the admin team indicate a comfort and a trust. His interactions appear to be less formal than that of the traditional superintendent. He jokes with the team often but remains focused on the work at hand. If I didn't know his role, I might have had a difficult time identifying him or any other individual as the superintendent. As conversations take place in an administrative meeting, I notice that he does not dominate conversations. He listens attentively and then asks questions to either collect more information, acquire an understanding, or challenge the individual to think deeper about their thoughts or ideas. When he speaks, he does so in a way that is thoughtful and intentional. As I observe Dr. James, I see that he smiles often. He appears to truly enjoy his role and seems to genuinely care for the people he works with. He is enthusiastic in his interactions with others and presents as a 
confident leader who believes in the work they are doing for the students in the school district.

Superintendent leadership philosophy. Each superintendent was asked about his or her personal leadership philosophy. Dr. James shared that he believes in situational leadership and developing educators who understand what quality instruction looks like. Situational leadership indicates that the superintendent is supporting his staff and leadership team with the support they need based on the context of the situation and the strengths of that particular individual. He indicates that he walks alongside teachers and administrators to help them determine a solution or a better way of doing things. He shares that he benefitted from similar leadership. "All great things happen on the shoulders of effective leaders. I like to empower our leaders to do their work." Dr. James goes on to speak about two mentors who were particularly encouraging in his journey to the superintendency and that coaching is something that he believes strongly in:

I have really high expectations for my leaders. I try to develop them to get better and I spend more time mentoring, looking at specific areas I can help them capitalize and grow their strengths. Those are some things I'm trying to get better at. Overall, I'd like to come in to look at a situation, assess it, and speak to the group about it and try to create a plan understanding that we are comfortable with that plan changing based on feedback we receive or things that we learn along the way.

This comment tells us that Dr. James believes in high expectations for all. He does not only expect his team to grow but also believes in personal growth. He helps others develop the ability to self-assess areas of strength and difficulty to foster continual improvement. He is a flexible leader who believes in his own growth as well as that of his peers. It is clear that he believes the same is true for the students in the district.

Identified strengths of district. When asked about the strengths of the district, each of the administrative team members recognized the cultural diversity of the community as an asset. Both administrative team members spoke at length about multi-culturalism as an area of strength in the community. Administrative team member, Ms. Andrews, summarized this point. 
"We are a very diverse community, we see that as an asset. We have 50-70 different languages in the district. We see this as a strength. To us this represents the real world." Similarly, the other administrative team member, Mr. Mark Ashner stated:

I do think what happens when you get to a majority ELL-you cannot go about it from a 'let's fix them'... we need to look at services as just part of Tier 1 instruction to access the general education curriculum. And we look at it as one curriculum. It is not like, here is the curriculum we use in these classes with these kids. We just embrace it as this is how they learn...we adopted a dual language philosophy and if we can help [students] develop two languages - talk about success for life! It became more of an enrichment opportunity than a remedial opportunity.

An example of this at work in the district is their approach to culture and language acquisition.

The district boasts a dual-language program that is available to all students. They recognize culture and language as a tool that will foster relationships and create opportunities for the students.

Dr. James and each of the administrative team members identified a priority on doing what is best for the students in the district. For students, this means that they have access to an academic program that is challenging, engaging, and meets the needs of the cultures represented in the community. Each participant identified this as a strength, both for the district and for the superintendent as leader. Ms. Andrews indicated that the superintendent expects the team to center instruction on the students' needs, culture, talents and passions. "We are developing things that work for the kids." He added, "it has really caused us to bring in the student agency piece. Focus on their passions and build on that." Dr. James expanded on this:

[The board] didn't want the status quo. They knew they wanted something different than that. They wanted to be recognized for doing great things for kids, for giving kids the best chance at having a great life. So I shared a vision of how that could happen and they embraced it.

Evidence of this statement and the Board's support of the superintendent's vision is clear all over the district. Multilingual programs, parent education opportunities, social-emotional initiatives, 
and a priority on innovative teaching and learning are examples of moving beyond the 'status quo.'

Mr. Ashner added that the focus on students expands well beyond academic success to other foundational areas: "Our focus on social-emotional learning and student self-awareness has even helped move [us] forward." This whole-child approach to not just teaching, but developing a human being was a pattern throughout the interviews with the superintendent and administrative team members, a fact the superintendent is very proud of. Dr. James stated, "[W]e have an amazingly talented leadership team I think some of the best in the business who are all about doing what's best for kids."

In this school district, doing what is best for kids includes robust multilingual opportunities, not just traditional ELL services. The district is also considering the impact of social emotional learning and the significant impact of SEL on students' ability to succeed in school. Moreover, the district is employing academic models to ensure students are challenged, engaged, and working on projects and activities that reflect their strengths, interests, and culture.

Finally, responses reveal that the district views their intense focus on quality instruction through skill-based outcomes as a significant strength. In this school district, skills-based learning is transitioning the classroom from a place where content is consumed through memorization and regurgitation to a place that encourages the skills needed for students to succeed in the evolving workplace. These skills include, but are not limited to: critical thinking, collaboration, understanding self, creativity, communication, and active learning. Dr. James stated that it was a "big shift to skill-based outcomes focused on the things we need to do to make sure kids are successful in life." Administrative team participant, Mr. Ashner stated:

Since Dr. James came into the district there has really been an instructional focus...we are focusing a lot of time energy and resources on the instructional piece. He's really 
driven that piece...I've only worked for three superintendents but [he] is the strongest instructionally. He has conversations on instruction not management.

The 'instructional focus' that Mr. Ashner identifies in Dr. James is a priority on ensuring students have access to the type of individualized learning that will help them to succeed in life. Where traditional superintendents are often not capable or intentional about providing direct leadership in curriculum, Dr. James is continually learning with the team to improve the instructional program. Dr. James is unique because he in personally involved in ensuring staff is prepared to provide instructional coaching, multilingual teaching, and an innovative, personalized program for all students.

Culturally responsive attitudes and actions. I was able to determine that Dr. James and all administrative team participants agreed that the achievement gains and shrinking opportunity gap could be attributed to the emphasis on being focused on students strengths and recognizing culture as a significant variable for learning. Although Dr. James did not refer to his own practice as 'culturally responsive,' the tenets of the pedagogy were clearly identifiable in his words and actions. This includes eliminating deficit-thinking, high expectations for all students, communicating intentionally with the community, and accessing culture and language as a key component of instruction. Dr. James shares his belief that we come into our roles as educators with preconceived notions and existing biases that serve as obstacles to truly educating a child. He recognizes intentional efforts by the district to understand the true impact of poverty and the missed opportunity that exists when we ignore culture. He suggests that a 'lack of understanding' prevents us from providing the instruction a child needs and can negatively impact student performance in school. Additionally, both administrative team level members made clear statements that validate the superintendent's belief that an understanding of culture is imperative to student success. In speaking about curriculum and home language, Mr. Ashner posited: 
Students need to identify in the curriculum. Students must be reflected in the curriculum - see themselves. We need to be careful to not unintentionally cast judgment even with language. You don't have to speak the language that they speak but you can send some pretty strong messages, either positive or not, in what you say about their home language. I think all of those things serve to help students of the school as a place where they have a role. Linguistically, for families and parents, they must know they have access. We have hired additional translators. Things like our magazine. Making sure the stories and the features and the messages in there reflect everybody. The message that everyone counts. We don't want to value achievement only in English. The time spent...is not spent in one culture but rather an appreciation and understanding of diversity in general.

In this exceptional school district, a focus on student equity and culturally responsiveness indicates that the whole child drives the instructional program. Dr. James is unique from other superintendents in that his words are reflected in actions and on display in the instructional program. Specifically, Dr. James and this exceptional school district:

- Reject deficit-thinking and acknowledges that bias will interfere with student achievement

- Maintain a belief that low achievement by students of color can be improved by changing practices rather than accepting the narrative of blaming students and families

- View second language as an asset

- Treat all people or all races and ethnicities with respect

- Communicate a welcoming presence to all families through print and electronic media.

- Designate significant financial resources to implement culturally responsive practices such as employing additional dual language teachers, translators, etc.

- Hire culturally responsive teachers and training teachers to tap into the strengths of students' culture and interests

Dr. James demonstrates that his leadership is based on seeing the potential in all of his students through asset-based thinking. 
Leadership style. Responses to the interview questions revealed that the superintendent and two administrative team members each identified several common traits of the superintendent's leadership; however, three themes were clearly identifiable in the responses of all three participants: an understanding of quality instruction, the practice of hiring and developing educators who understand culture and language, and a vision that denies deficitthinking.

When discussing Dr. James' leadership style, a focus on quality instruction emerged frequently. Dr. James identified this right away.

One commonality I have with all the people on the leadership team as they have to have a strong grasp of instructional leadership. There are few people in my administrative team that have not served in an instructional roll like a principalship.

Similarly, both administrative team members discussed the tendency for Dr. James to spend significant time in classrooms with principals, teachers and students, on the front lines of instruction. One administrative team member, Mr. Ashner, stated, "He is in the buildings a lot. His time is spent out there. He gets in the buildings all the time." The other administrative team member, Ms. Leah Andrews, reinforced this view of the superintendent with a strong statement of support:

His main strength from my perspective is just a strong level of understanding of instruction. He has very strong beliefs about what we can do for kids in classrooms. $\mathrm{He}$ is always on message with that. That piece flows through his day. He spends, I think, more time than any of us in schools and classrooms. He has done this the last two or three years. He is scheduling time in every building at least three classrooms to observe a full lesson. He is informing his understanding of where we are as an organization.

Dr. James is unique from other superintendents in the amount of time he spends in the classroom evaluating instruction. This out-of-the-box thinking has led the district to a successful instructional program that focuses on student agency. 
Dr. James hires and develops educators that understand culture and language are essential to learning. This is evidenced in the hiring of additional teachers and translators to support the instructional program as well as the addition of a parent liaison and Director of Social and Emotional Learning. I identified a strong correlation to the idea of Dr. James as coach, which surfaced when discussing the leadership style of the superintendent with the administrators. Dr. James repeatedly stated his belief in 'developing leaders' and others 'strengths' even referencing the approach taken by famed Chicago Bulls Coach, Phil Jackson. Ms. Andrews articulated, "He's a coach. He is totally a coach. He will walk up to you and give you feedback in the middle of a session...feedback and coaching are very common." Mr. Ashner also indicated that this is also how leadership meetings are run, "He guides that meeting, creates the agenda and takes us through and that is really his opportunity to build understanding for us and provide direction." He is hiring and coaching to develop a team of educators who will be able to support learning through an understanding of quality instruction with student strength and culture.

Finally, Dr. James has an out-of-the-box vision that denies deficit-thinking. Ms. Andrews shared that the superintendent can often be heard uttering a mantra that "flows through" all he does. The mantra is: "Be deliberate. We have to have a plan. Nothing happens by chance." Evidence of this is provided in the admin meeting as Dr. James discusses being 'intentional' about the work they do. Another administrative team member, Mr. Ashner, added,

[He is] visionary, with a meaningful, out of the box vision. [He] does not let obstacles really get in the way of planning for that. For example, we added a half hour to our school day. He doesn't cave to the traditional pressures and he is not afraid to take a leap. We are going to follow what we know is right. We won't let pressures take us off course.

Dr. James provides specific evidence of this as he speaks in-depth about hiring the right people - those who are 'visionary.' He described his belief in the 'Cascade Approach' and the practice of regularly monitoring progress when examining the district's growth: 
Leadership starts with a clear vision of what you want to accomplish. You develop that vision collaboratively with stakeholders and then you cascade that message, you know, throughout your organization. And I believe you measure your work and the things that you are doing against that vision and, as we discussed earlier, if we're not preparing kids to be successful in life with the work we're doing in the classroom or in the boardroom or at the leadership level and we aren't supporting that vision we need to ask ourselves 'is this a good use of time'?

It is evident from this statement that Dr. James hires the right people, but he does not simply hire people and walk away leaving initiatives to chance. He believes there is too much invested for him to not be involved in the development of those people who are so critical to the success of all students. He takes the time to ensure that the good work they are doing is properly implemented.

Core beliefs. The superintendent and two administrative team participants' responses to the interview questions were analyzed to identify patterns and themes in respect to the superintendent's core beliefs. One dominant theme emerged: the superintendent as a student strength-centered leader. Dr. James delivers a clear message about the "core of [his] core beliefs":

It's a moral obligation that we do everything we can to provide kids the best opportunities to be successful in life. I believe that strongly and that all of our thinking and planning should map back to: What does it mean to be a successful citizen? What does it mean to be a responsible citizen? What learning opportunities can we design for kids to make that happen? That is the core of my core beliefs.

Dr. James provides evidence of this as he interacts with students in the classroom, discusses student agency at the admin meeting, and in the way he talks about his work. He repeatedly refers to several district-wide initiatives including the dual language program. He believes above all else that it is the district's responsibility to prepare students for a successful life. This is a core piece of their mission statement, which is provided on the website. 
Dr. James rejects a deficit-thinking model. He takes time to share his opinion of response to intervention, commonly referred to as RtI, which he calls a deficit model. He posits that we would do better to "start creating interventions that speak to student strengths and interests." Both administrative team members discussed the need for a child's strengths to be at the center of the learning. Ms. Andrews added: "It's all about the relationships with kids and really connecting with kids. If we connect with kids, you know, the reality is things are going to be pretty positive. If we start with that the rest kind of flows from there." Similarly, Mr. Ashner stated, "We are for all students. Every student matters."

Direct impact on students. In this section, I address the ways Dr. James identified his own leadership practices. Dr. James shared how he has had a direct impact on students and how his practices relate back to culturally responsive practice. When asked about the impact Dr. James has on students, he responded:

I think understanding diversity and embracing it. There's a huge knowledge gap that we have as leaders, as support staff, as teachers in truly understanding diversity and more importantly the implications and impact that diversity and related experiences have on student learning and so often we confuse that with kids not being compliant-kids not being interested or kids not doing what's asked. The way they respond to teacher requests we sometimes look at it as disrespectful and truly understanding that and also the implications that diversity has on brain growth, brain development. I think those are significant pieces that negatively impact how we work with kids.

In this statement, Dr. James confronted biases and indicated his efforts to improve awareness to help staff become more culturally responsive. He believes that each child has differences that we must work to understand if we are to succeed in reaching them. He expressed concern that culture, brain development, and the role of parents in a child's education are paramount to achieving success. He stated that there is room for growth in this area and that it is our turn to go into their space to develop those relationships: 
We have a plan for training on cultural diversity and brain development so we've been working on that for the last 2 years and it's ongoing... We've learned quite a bit as an organization. A big gap we are trying to address though is the parent connection and the partnership with parents so we are throwing stuff at it. We have hired probably five [people] to get out into the community and make parents aware of resources that will support their families and resources that will help them support their own kids in their learning. The big challenge for us though is getting parents to get into our space. So our strategy now is how do we get into their space? We have limited space but we just the hired two additional full-time translators help with our communications. The outreach piece is something that we're struggling with but we're really trying to put plans in place to close the gap.

This statement is powerful because it supports the impact this particular district-level administrator has on student achievement by developing a culturally responsive environment. In this case, the superintendent has made a significant financial investment by hiring five educators to go out into the community and two more to help with translation. He values the community and understands that conventional approaches to community engagement have not been effective.

Ms. Andrews shares the superintendent's direct involvement with the community. "He goes out to meet with the PTO, he is with the Parent Advisory Group, not just parents but community members and he shares the direction we are on. It's all about building understanding within the community." Similarly, Mr. Ashner provides an example of what this looks like within the classrooms and with respect to the recent staffing changes led by the superintendent, specifically the hiring of the Social-Emotional Learning \& Community Outreach Specialist and how new staff have impacted the conversation.

Their first task was to identify those students who struggle the most and really connect with those parents, intentionally reaching out to those people, and there is typically a correlation with low income. We have added interventions. When you think about the number of staff that we have added to address the needs of low-income students that has been a huge reform. Other than instruction outside of SEL, we also have dual language K through 8 in Spanish and in Polish. 
The transition from a traditional ELL program to a multilingual approach in the form of a robust dual language program is a significant shift in that it rejects a deficit-thinking model and focuses on a strengths-based approach to culture and language. Students of all socioeconomic and ethnic backgrounds now have an opportunity to develop skills that would be otherwise unavailable.

Decision-making process. Dr. James is collaborative. The superintendent and both administrative team members all share examples of collaboration at work within the district. Dr. James discusses using other active and retired superintendent colleagues as a 'litmus test' but also speaks to the practice of making decisions collaboratively with the team:

We use a lot of staff feedback. We survey our staff. What's working, what's not working? Most of our surveys are connected to our priorities. We do a survey feedback at the end of every PT session. We get input from staff on what is working and what is not and what are the gaps and we do a little Ed. Camp as well to try and get some choices. Then we bring that information back to our leadership team and we cascade that through the Administrative Leadership Team. In regards to the Board, we have a governing cycle. Each Administrative team member is responsible for a different part of the plan. We have 6 checkpoints that are connected to our strategic plan growth, our data and results, and superintendent evaluation. They give formative feedback and a summative evaluation at the end of the year. So that is kind of what a change cycle looks like it really is a collaborative model based on things that the organization points out as necessary change work and if we have any quantitative data we will look at that.

Dr. James excels at collaboration. However, what makes him truly unique when compared with other superintendents is his desire to seek out feedback through relationship-building and conversation-making with staff, students, parents, and community members. He does not simply wait for feedback. He seeks it out and uses that information to improve the instructional program. Mrs. Andrews speaks to his desire to work with others in every position within the district:

[The superintendent] is someone who wants to hear about your ideas and sometimes he gets that from so many angles... if a teacher emailed him an idea he would be all over it and say, 'Hey, when can we talk?' I do think other people are able to do that. 
In examining the interview responses from all participants, several themes emerged, though none with the frequency of the superintendent as culturally responsive. It is evident that the district rejects deficit-thinking and acknowledges bias to intentionally incorporate specific practices directly into instruction. Moreover, the district hires and trains the team to ensure this belief is held district-wide. This promotes challenging instruction with high expectations for all students and an understanding that student achievement can be improved through culturally responsive teaching. The district also provides evidence that they believe a student's second language is an asset and a tool. Students take pride in having two languages and see the benefit to their academic and professional future. The districts programs, resources, and staff indicate that the district has put a significant financial and time commitment to ensuring a culturally responsive environment for students.

Most importantly, the district treats all people, regardless of ethnicity or income level with respect. The district has identified numerous ways to connect with families including the format of the communication and in how it is delivered as well as the recent hires who have joined the district. These educators are hired to support parents and students as they navigate the social and emotional piece, including developing self-worth and combating previous experience with a deficit-thinking. Dr. James asserts:

I think for us it's really understanding the negative implications from things like poverty and things like culture- those biases we have in terms of how we provide interventions for our students...just lack of an understanding and in some cases detrimental to student performance.

Dr. James is an exceptional superintendent. He acknowledges bias and he recognizes the challenges that those from an ethnically or economically diverse backgrounds may have faced. He is not taking excuses and leads his district with the knowledge that every child has something to offer. 


\section{Portrait 2: Dr. Mary Jacobs}

Dr. Mary Jacobs, a former recipient of the IASA 'Superintendent of Distinction' award, guides me to a seat in a large multi-purpose room with warm colors and comfortable stadiumlike seating. Dr. Jacobs is a white female in her 40s. She wears a suit and I notice that the many educators in the room are also dressed in a similar professional fashion. I wonder if this is the expectation or it is in honor of today's event. She explains that this program is one of several in the district that honors our military veterans. I notice that the room is filling quickly with welldressed children, parents, veterans, and other adults, presumably spouses of veterans and other community members. The energy in the room is palpable. As I meet these visitors, I learn that they are indeed people from the community here to view the students' performances and to honor what one gentleman in attendance calls 'our American Heroes.' Dr. Jacobs appears to know almost everyone by name. On more than one occasion, I witness Dr. Jacobs greet people with a hug. As the students recognize the veterans through song, comments, and handmade gifts, I can see that Dr. Jacobs and the staff in attendance are smiling as they watch the interaction between child and veteran. It is more difficult for me to see the parents' reactions from where I am sitting, but at the conclusion of this thirty-minute program I witness Dr. Jacobs greet the parents and other teachers warmly. Later, Dr. Jacobs states: "You know, the music teacher [who lead the program] was not feeling well today. But she is here anyway. She wouldn't miss this for the world. Those are the kinds of people we have in our district." I learn that the veterans are invited to stay for brunch where students, staff, and community members mingle in the large, open band room. Dr. Jacobs guides me into this modern-looking and well-lit space, where she mingles with adults and children alike. The children are immediately comfortable with her and engage in small talk. It becomes clear this is not her first time speaking with these students. The 
superintendent appears to treat her colleagues like friends and family and this is reciprocated. Her warm and welcoming personality draws people to her.

District 2 serves approximately 1,500 students in three schools. Approximately $64 \%$ of the students are considered low-income and 50\% of the population are students of color. Specifically, White students make up 50\% of the district, Latino students make up 38\% of the district and Asian students make up 7\% of the district. Despite serving a significant majority of low-income students, the 2015 Illinois Report Card data shows that the district maintains one of the smallest opportunity gaps in the state between students who are considered low-income and those who are not. Specifically, when examining the composite scores on the 2015 PARCC assessment, the district boasts an opportunity gap of only -5 compared to the state average of -29 . Moreover, the opportunity gap on the same assessment between Latino students and white students is at -11 compared to the state average of -20 . This is significant, as Latino students make up the second largest ethnic group the district. The district also performs approximately equal to the state average according to the 2015 PARCC assessment data. Dr. Jacobs was born and raised in the community, and her father before her. "We have pretty deep roots here," she says with a smile. She spent her entire teaching career in the district in an elementary setting, with her first position teaching kindergarten and then moving into a position teaching secondgrade. She indicated that one of her most powerful leadership experiences came as a reading teacher, in which she co-created a program for students in the district, born out of her passion for reading, combined with her daughter's own experience with a support program that helped her excel in reading. "It sparked an interest in me because I knew what was happening [in our district] wasn't enough." With her masters in reading she started to find a way to innovate on behalf of the children in her district. "I thought, boy, if we could figure out a way to start 
meeting kids at their instructional level in reading, this could be really powerful." The program saw increased reading scores in its first year. "It's still alive and kicking...it has just had a profound impact on our kids' achievement and, you know, it's just so much more effective." The experience inspired her to think more about a leadership role in the district and she would eventually move into the principalship at the primary level. The district superintendent encouraged her to obtain a doctoral degree, which she did, and when the superintendent retired, she interviewed for and accepted the position of superintendent in the district, where she has served for the past 6 years. She is married and has three children.

Dr. Jacobs makes a point to welcome parents and students outside of the school as they begin the day. She greets people warmly and her interactions indicate a familiarity and a strong partnership. There is a professional presence about Dr. Jacobs. She appears to be calm and confident and she smiles often. Several conversations with principals indicate that she is extremely collaborative. She follows up with questions rather than answers. She speaks with pride about the district and discusses the many initiatives in the district. She asks me about my school district and seems interested in learning more about my experiences as a superintendent. She is sincere and warm in her interactions with others.

Superintendent leadership philosophy. When asked about her leadership philosophy, Dr. Jacobs identified two strong traits, a focus on being student equity-centered and the need to be collaborative. Repeatedly, when responding to the question on leadership philosophy, the students were mentioned as the primary focus. Both Dr. Jacobs and an administrative team member, Ms. Sarah Abraham, made statements about students at the center of the district's practice. Dr. Jacobs stated: 
What I say in every situation is if we are making child-centered decisions every single time no one can fault us. If we consistently say 'what's best for kids?' and can bring it back to why we made that decision - this was the best decision for the kids. I think it takes the wind out of the sails of someone who wants to, you know, come in and be a naysayer and question the integrity of something you may or may not have done when you can bring it back to the kids. We all do-and there are times I will say to them was that an adult-centered decision or was that a child-centered decision? We want our teachers to like it here we want them to be happy here but we need to remind them of why we are here. And sometimes it is easier to make the teacher happy but at what cost?

A clear example of this that she describes in more detail is the requirement for teachers to receive an ELL endorsement before the district will support paying for other Masters-level courses. This decision helped develop the district teachers as they educate students from a different linguistic background. Similarly, administrative team member Ms. Sarah Abraham shared,

When it comes to being the leader of a school or a district, everybody puts the kids first. Leading with a vision and never straying from that no matter how difficult things get. Always bring it back to what is best for kids and that is what has been instilled in us by our superintendent.

Dr. Jacobs' leadership style includes centering what is best for students and following a vision, which will be discussed later in the section.

Dr. Jacobs also made strong statements about her priority of developing collaborative leaders. While she makes an intentional effort to collaborate as often as possible, she also recognized the need to be decisive when necessary:

We are very much a team. We lock elbows when we make decisions together. I really believe that if I involve my team and decisions that I have ownership. I know there have been times and there have been where the buck stops here and I have to draw the line and make the call. When I do that it is received differently because most of the other times were really working well together and building consensus getting in the room and pounding it out and leaving the room and feeling like everybody had a voice and it's something we can all live with. So when you do that most of the time there are just those few times where you have to say, you know, this is how this is going to look. I think the emotional bank account has enough deposits in it people can live with the decision, you know? 
Dr. Jacobs provided several examples of challenges that required collaboration to shift and a refocus on students including a standards-based grading initiative, the use of student data to inform instruction and teachers achieving an ELL endorsement.

Identified strengths of district. The prevailing strength of the district was a strong focus on student equity at the center of all they do. When asked about strengths, the superintendent identified a need to be responsive to student culture. Similar to Dr. James, Dr. Jacobs did not use the term 'culturally responsive' to describe her practice; however, she provided evidence that her leadership and the practices of district educators are indeed culturally responsive. Specifically, Dr. Jacobs discussed the importance of student culture and that the child's home culture is paramount in all we do from classroom instruction to hiring practices to our intentionality in communicating with home. She recognizes the biases that exist and that a deficit mindset must be replaced with an asset model. She states, "[The] diversity in our students. I really think that it is so rich and it makes us who we are and it forces us to think deeply about teaching and think deeply about our practice, think deeply about our communication." She speaks of parents as needing to be 'engaged' by the school district. Furthermore, she recognizes that teacher training must be adequate to serve the needs of the population. She discusses the districts approach to ELL and having every teacher in the district certified in ELL.

A couple of years ago we noticed our teachers really needed a toolbox for ELL. When we were looking at our ELL data and looking at our kids it was clear the teachers who had their ELL endorsement we're serving those kids better because they had a toolbox. So I went to the IRC and created cohorts of teachers to get endorsed. I'll tell you we are so close to having every single teacher with that endorsement 3 years later. Honestly, it has had a tremendous impact. This is our population so what are we doing to make sure that we can serve them the best that we can? It's been great and I appreciate the Board's support with that, I really do.

In this and other ways, Dr. Jacobs sets herself apart from other district leaders. Dr. Jacobs does not accept excuses for low achievement. She identified the impact of having the team certified 
in ELL and worked with the Board and Union to support this truly meaningful initiative. This is evidence of how she designates district resources to support the needs she identifies in an effort to close the opportunity gap. She goes on to add a strong statement about her feelings about keeping the child at the center of everything. "And then I'll say again, I've said this before, that team and our relationship with our Union, and our teachers, everybody is in it for the kids." This focus on students was paramount in the responses by all three participants. In response to the question, Ms. Abraham reinforces the superintendent's comments: “The vision never wavers. It is always about kids and we do whatever we have to do." Administrative team member Ms. Claudia Lucas adds, "Our kids. We learn so much from our kids." Dr. Jacobs provides evidence that a student equity-centered instructional program is designed around each child's talents, interests, culture and language. The claim to be student-centered is validated by the designation of resources and staff to meet student needs.

Culturally responsive attitudes and actions. The superintendent and two administrative team participants' responses to the interview questions clearly included two dominant themes: the superintendent is culturally responsive and the superintendent leads with an instructional focus. While neither term was used by the participants, all three participants included responses that indicated the importance of putting culture at the forefront of rigorous, intentional instruction. It was evident that this includes recognizing the students' home culture as an asset and that they believe parents have a say in the educational program. Statements made by all three administrators indicate that staff is expected to communicate intentionally with stakeholders to ensure excellence for every child. Administrative team member, Ms. Abraham, discussed the instructional program at length including the need for the students' home culture to be reflected in the people they see in the books they read and the resources they use. She also 
indicated that the district takes a comprehensive look at each and every child to ensure they are providing a program that meets their needs and reflects their culture. Similar to Dr. James, Dr. Jacobs put a priority on reflecting student culture in the curriculum. Ms. Abraham also spoke to the hierarchy of needs in providing items that make it possible for low-income students to learn. "If the kid needs a winter coat we go out we get a winter coat. That's the kind of environment these kids are learning in. That translates into everything we do." This single action indicates that the environment in the district is designed to wrap their arms around the student in every way including academic, emotional and physical support to ensure that students feel safe in an environment where they can excel. Meeting the needs of the whole child provides evidence that Superintendent Jacobs and her team are student-centered.

Additionally, administrator responses indicate the superintendent's belief in a rigorous, research-based approach to instruction that personalizes learning for students based on numerous factors including their personal ethnicity. The depth of Dr. Jacob's expertise in instruction leads to best practices in differentiated instruction for all students. All three participants identify the laser-like focus on quality instruction that emerges as specialized programming and differentiated learning. This is a significant strength and a practice that occurs daily in the district. Several comments were also made on the teams' regular data meetings in which they 'drill down' to the student level to better understand trends. Specifically, Ms. Lucas referred to Dr. Jacobs as the leader of the initiative.

She is an instructional leader. She was a teacher. She was a curriculum director. She was the principal. And now as superintendent, anytime we are going to consider curriculum changes or curricular work she is part of it. She is charging us as principals-'you need to be in the classroom you need to be an instructional leader.' Go do what you do best. Get in those classrooms with those teachers and those kids. When I think of her role it's just like coaching. Very hands-on and modeling. We're learning from her and she's helping coach us and she is modeling for us. 
Similar to Dr. James, Dr. Jacobs is personally involved in coaching the team. Participant responses indicate that she asks meaningful questions and helps the team to self-evaluate and identify areas of needed growth. Dr. Jacobs' outstanding grasp on quality instruction qualifies her to stand shoulder-to-shoulder with the principals and model the strategies and behaviors she would like to see in the classroom. As a result, the principals are better equipped to support the teachers. When asked about actions taken, the response from Dr. Jacobs revolved around the topic of quality instruction. In a direct reference to this strength, Dr. Jacobs stated:

I am constantly having conversations with them about student achievement and instruction so it helps me having been a teacher that I can do that and I think that that makes a big difference. I can walk into a classroom and have a conversation with the classroom teacher about practice and they know that. The teachers know I can. I put in my letter - my welcome back letter every year-expect to see me in the classroom and not for any other reason than I love to be there! But we are a very driven district constantly looking at how our kids are doing and making decisions. We really drill it down to the students. The principals sit down, one-on-one, and have these conversations with the teachers. These kids get one chance in second grade one chance in third grade and as teachers we have the responsibility to ensure they have the best possible experience!

It is significant to recognize Dr. Jacobs' confidence in understanding quality instruction. She has extremely high expectations for her principals and teachers because she knows these high expectations will be emulated with the students. She also creates a safe space for growth. She indicates that she loves to be in the classroom and that is why she is there, which is a nonthreatening way to engage teachers.

Dr. Jacobs and both administrative team members view culture as imperative to truly understanding the students whom they serve. This is evidenced through the following Culturally Responsive Attitudes and Actions:

- Maintaining a belief that high academic standards are for all students

- View second language as an asset 
- Adopt an asset model of education and acknowledges the existence of bias

- Respect and engage people of all races and ethnicities

- Believe that students must be reflected in the curriculum

- Provide a welcoming environment to all students and families

- Commit district dollars to culture and language such as the ELL endorsements

- Hire staff and speakers who reflect the ethnicity of the community

- Maintain a challenging curriculum with a high level of instructional integrity

Leadership style. The interview responses indicate that Dr. Jacobs effectively develops educators and is student strength-centered. Development through collaboration was identified as a strategy employed by Dr. Jacobs during each interview. This collaboration was described as everyone on the team having a voice and a trust for one another. Dr. Jacobs provides insight into her belief that nobody is more important than anyone else and that education is a team effort.

I try very hard not to - the whole hierarchy thing-you know, that I'm more important than anybody else. That just doesn't sit well with me so I really try to just keep it level. I don't want to be revered I don't want the position to be intimidating. I want to be perceived as one of you. I am one of you. For me, I had lunch with the bus drivers last week, you know, I just try to keep it real.

Both administrative team members concur with this statement. Ms. Lucas adds, "We talk all the time. There isn't a day that goes by that I don't talk to her. I hear from other principals that never talk to their superintendent." Ms. Abraham speaks to her wealth of experience in the classroom. "Her having that experience as a teacher has helped because she can relate. She can really carry on very high-level conversations and be that leader...she connects with everybody." She is actively communicating with the entire team as well as the Board, the community members, parents, and the students. She is collaborative and that provides ownership and voice to the constituents of the community. 
Related to her belief that the team must be collaborative to be successful, Dr. Jacobs is also a relationship builder and these relationships provide support and credibility. Once again, the superintendent and both administrative team members responded to the question on leadership style in a similar manner. Dr. Jacobs immediately identified this as a key trait of her leadership style. "The relationship piece is huge. I do a great job connecting." Ms. Lucas identified relationships with all constituents, including students, as paramount to her success. "She doesn't let herself become removed from the classroom. She'll go sit on the floor with the kindergarteners in the first week in the classroom." Ms. Abraham responded in a way that echoes the sentiment of Ms. Lucas:

She has a genuine care for every person in this district. Teachers, staff, students - she just leads very compassionately. I think it speaks volumes when you see kids that she has seen grow up here. They love her she gets on the floor with them and plays with them. She has this genuine caring about her that feels very parental.

Dr. Jacobs is unlike many other school leaders who do not clearly define the concept of putting student equity at the center of instruction. To actively engage with a child on the floor of their own classroom is symbolic. The comparison to the love of a parent for their own child indicates a sincere love for each child and a desire to know them at a deeper level. All three participants recognized her leadership to be focused on students' strengths and leadership that centers around the classroom and the community. Dr. Jacobs states, "I feel very strong in my beliefs and my philosophy what's good for kids. I know what good teaching looks like. I know what leadership looks like."

Both administrative team members also spoke to the superintendent's ability to make decisions focused on what children most need when sometimes those choices conflict with what staff may want. Ms. Abraham sais, "She is very strong. She does have to make unpopular decisions sometimes. She won't worry about it being an unpopular decision if it is good for 
kids." Similarly, Ms. Lucas stated, "We're not here for what is easy for us. We are not here to make decisions for the grown-ups. We are here to make good decisions for kids.” Both participants spoke generally about the superintendent's focus on instructional decisions that benefit students; however, a powerful example of this in action is the ELL certification program.

Core beliefs. From the responses of the superintendent and two administrative team members, it was evident that the superintendent has the district focused on one belief: that children are the center of the district and that the academic program must be differentiated and equitable to truly meet students personal needs, strengths, interests and culture. The children must be considered in every decision and in every action. This theme was clearly recognized as it was the only one identified by all three administrative team members in response to this interview question. Dr. Jacobs stated, "Making sure we are child-centered. It's not about anybody as an individual it is about the team. It is about the Learning Community as a whole. Really about bringing it right down to the classroom and the kids.” This statement supports the idea that the superintendent is collaborative, leading the team as the 'coach' and that the emphasis is on the community. Ms. Lucas added,

When we do things we get it done. If it's good for kids we're going to make it happen and find support and do it. I feel like everything here goes at a rapid pace if it's going to be good for kids.

Ms. Abraham immediately refers to the superintendent as "student-centered":

[She] never gives up on a child - recognizing that it does not matter how that child comes to you, you are going to meet them where they are and you are going to support them no matter what. Every child can learn and we will never give up on that child. Leading and providing with compassion. We are all here to do good and we are all here because we care about kids and that's what it comes down to.

Dr. James and Dr. Jacobs provide evidence that exceptional superintendents see the potential in every child as opposed to a deficit-thinking model. Dr. Jacobs understands that each child has 
the ability and that she must provide the opportunity and this involves supporting the principals, teachers, parents, community and Board members. Dr. Jacobs promotes the idea of unconditional love for each child and does not accept excuses for students not increasing achievement.

Direct impact on students. The superintendent has had a direct impact on students as a culturally responsive leader and as a coach to colleagues and board members. Dr. James provides detail with respect to actionable steps the district has taken to ensure home culture is reflected in district schools:

Bring in speakers for diversity training and understanding! I brought [a speaker] here for the first-day institute in August. That is how we kicked off the year. I made sure everybody was in that room: janitors, bus drivers, lunch support personnel, everybody. I wanted everybody to hear. You should have seen the line of people waiting to see her afterward. Employees came up to me, bilingual employees and said thank you, thank you! Because she represented something for them too, you know? She told her story how about where she grew up and look at her now, and so many of them can relate to that. People that work here, you know? People can relate to that. So we really do try.

The superintendent understands that culture must be a priority and provides evidence that resources must be directed to that end. Providing this professional support to the team helps educators to bridge the gap between traditional instruction and the students' home culture. The superintendent's strong statement on the importance of diversity and bridging the culture gap in the classroom was echoed by both administrative team members. Specifically, administrative team members spoke to the way technology has been utilized to support instruction in students' homes. Administrative team member Ms. Lucas discussed the opportunity to bridge learning between home and school through the 1:1 Apple iPad program. Ms. Abraham made similar statements and spoke to how using technology will increase accessibility while also helping to level the playing field. This is another example of how the school district is acting intentionally to close the opportunity gap. The district understands that providing resources at an early age will ensure equitable access to quality resources. 
The superintendent also directly impacts student learning by coaching others. Ms. Lucas

discussed how the superintendent has had a long-standing belief that internal coaching and professional development have been essential to the district's success:

I just think when it comes to professional development her philosophy is the train the trainer model. Ever since I can remember it's developing a core group of teachers that can be your leaders and who go out and learn and become the experts and bring it back and tailor the professional development to who we have in front of us, right? We have never really been big on bringing an expert in and supporting us along the way. Let's build the capacity and make our teachers be the ones who are teaching each other.

This priority on internal professional development is not limited to hired employees. Ms.

Abraham provided a strong example of the superintendent leading the Board of Education through the technology adoption process,

[She] brought the Board and from the very beginning of this conversation. They actually went to Apple headquarters in Chicago. Some of the Board members actually went and saw how the iPads could be used. I think without that foresight to bring everybody together it would have just been a check written for technology.

Dr. Jacobs said the following about her own desire to act as a coach and mentor in the classroom.

I see things with my own eyes instead of hearing it from someone and I can relate it to my own experience...I'm actually in the room participating and being able to make decisions and have good dialogue with my leaders, my curriculum people, and my leadership people.

Dr. Jacobs focuses on including all stakeholders. She is adept at building a team, providing professional opportunities to glow and learn, and then following up with the progress by actively participating in the rollout, evaluation and improvements.

Decision-making process. All three participants identified the superintendent as a collaborative decision-maker and an effective communicator. Ms. Lucas, an administrative team member, shared examples of how the superintendent is collaborative when significant decisions need to be made. "[Decision-making] is shared, right? We have an Apple teacher leader from every grade level in the district, [the superintendent], board members, community members. This 
is also true with the new facility project." Dr. Jacobs involved the Board and the staff in the decision to use Apple devices which created ownership over the program and provided a high level of engagement at the time of the rollout. Dr. Jacobs refers to herself as "Collaborative." She adds, "[I bring] everyone in the room and just hashing out that conversation... making sure you involve people in decisions, that ownership piece is important."

Additionally, effective communication is identified as essential to the superintendent's ability to make decisions. Dr. Jacobs stated:

I think for me when we have to make a difficult decision I really try to communicate the why before the decision gets made. That seems to help but what I've learned is if someone is going to have an issue with something I am doing they're going to have an issue. I just want to make sure that when we do that no one can ever say you didn't tell me-I think that communication is the single most important thing we do as superintendent.

She states that effective communication is not only necessary with staff but with the community. She understands that if she is making a decision that benefits students, it is possible that adults from the staff, parents, community, or Board may challenge the decision. This once again reinforces her claim to be focused on students' needs. In reference to an addition that is being constructed, Dr. Jacobs says that there was a "tremendous amount of communication we pushed out." Ms. Lucas adds that the building leadership teams value her input and that communication works both ways in the district. "Anytime there's an idea it is starting at the building level, sharing it out with the principal. I always think that she's kind of like our fourth. We never really want to have a discussion without having her part of it because we value her opinion, we respect her and want her to be part of the discussion.

Above all, the superintendent and both administrators spoke about their respect for students as people with strengths, interests, beliefs and cultures. Superintendent Jacobs summarized this belief: 
[The] diversity in our students. I really think that it is so rich and it makes us who we are and it forces us to think deeply about teaching and think deeply about our practice, think deeply about our communication. How are we engaging our parents? Because we are very diverse not just with ethnicity but when it comes to economics and economically disadvantaged kids. We do have kids whose families are doing just great, but the majority, they aren't.

Dr. Jacobs makes a strong and clear statement about who the educators are serving. There is a respect for students which is evidenced through 'thinking deeply' about teaching to provide an exceptional academic program. Her comment on the 'rich diversity' also provides evidence that she sees all of the students as assets with something to bring to the table and that ethnicity must be considered if we are to truly move forward. She remains sensitive to the challenges that families are facing and that we as educators must be sensitive enough to recognize both the struggles and the achievements.

\section{Portrait 3: Dr. Thomas Matthews}

Dr. Thomas Matthews and I enter the large, wide-halls of a historic high school. Dr. Matthews is a tall, white man in his late 50s. He wears a light gray suit and tie. As we walk through the building for a tour of the campus, he shares the history and the tradition of the school. I notice that the school colors run through the hallways and spill into the large classrooms. Even the students, in their school uniforms, don these same colors from head to toe. The superintendent picks up a conversation that was started earlier during interviews and shares his enthusiasm over a recent 'school commercial' in which students and the school mascot participate in parent-teacher conferences. There is an obvious sense of pride displayed by the superintendent as we walk the halls. He discusses this, his final year in the district before retirement, with a mixture of sentimentality and the pride of accomplishment. As we walk by students and staff, he greets each with a smile and playfully teases some of the teachers. After stopping to ask students a few questions about their day, he asks if I have heard of several award- 
winning teachers including an Illinois State Board of Education 'Teacher of the Year'. We discuss the districts' recent recognition for their Advanced Placement program, which was provided by the National College Board for having an increased number of students take AP classes while also seeing an increased number of successful test scores on the AP exams. As we continue to walk and talk, people appear to gravitate towards him. He speaks highly of the team but he makes it clear that the team has changed and evolved and that it "wasn't always this good." At one point during the day while in the presence of the Superintendent Secretary, he refers to her as "the best in the business." His interactions with colleagues are jovial and lighthearted.

District 3 is a large, suburban high-school district serving approximately 8,300 students. Students of color comprise $95 \%$ of the student body. Specifically, $89 \%$ of students are Latino, $5 \%$ of students are White, and $4 \%$ of students are Black. Additionally, $88 \%$ of students are considered low-income. The 2015 Illinois Report Card provides evidence that the district has managed an extraordinarily small opportunity gap between low-income students and their peers as well as white students and non-white students. The district boasts an opportunity gap of only -4 , compared to the state average of -29 between low-income students and their peers. Similarly, the gap between white students and Latino students stands at -8 compared to -20 for the state. This is particularly significant considering Latino students make up $89 \%$ of the district. Additionally, the district performed nearly as well as the state average on the 2015 PARCC assessment.

Dr. Matthews was the only superintendent to indicate that he once lived in poverty. He made significant sacrifices to become a teacher and shared a story of both he and his wife using all of the money they had to travel from Illinois to Florida to pursue interviews to become 
teachers. He indicates that this experience has informed his practice. The interviews were successful and he started his career in Florida as a PE teacher, but quickly moved into administration as an assistant principal in an elementary school district. After serving in Florida, he accepted a position in another suburban Illinois district where he served as a principal for 9 years in an elementary district. He then moved away from the Chicago suburbs to a district in north central Illinois where he served as an elementary school principal for 1 year before transitioning to the Executive Director for Research of Federal Programs and Grants. He then accepted a position in his current district as Assistant Superintendent for C\&I and grants. After several years in this role, he was hired as superintendent. He recently earned the Superintendent of Distinction Award from the IASA. He is serving his final year before retirement. He is married and has children.

Unlike the other two district superintendents, Dr. Matthews provided a third administrative team member, who was absent on the day of my visit to the district. The final administrative team member was interviewed by telephone.

Superintendent leadership philosophy. Each superintendent was asked about his or her personal leadership philosophy. Dr. Matthews provided evidence that he first looks to collaborate but will often make an executive decision. This is similar to Dr. Jacobs, who is collaborative, but indicated that she will not make a decision to do something that is not what is best for students. Dr. Matthews believes that it is critical to provide guidance to staff, but understands that risk-taking can also mean failure. This same approach is expected by Dr. Matthews when working with students. Dr. Matthews also shared that he is a believer in situational leadership and coaching:

Other people also have different styles of leadership that they have a need for. They have a need to be coached. There are some people that need to be led. Some people need to be 
directed. The ones that need to be directed aren't necessarily bad people, that's the style of leadership that they are either accustomed to or they haven't aspired to be collegial yet. But each situation determines what you need to do.

Dr. Matthews clearly supports the development of his team, but if a certain employee has not earned trust he will make the ultimate decision. Dr. Matthews referenced coaching often in our interview. He discussed his prior experiences as a former PE teacher, a successful coach, and a student-athlete in high school and college. He also referenced coaching in his responses to other interview questions. Throughout the interview, Dr. Matthews referred back to coaching as he spoke about his team and the students in the district. For him, this means walking alongside a teacher or an administrator and helping them to think through problems or those practices that will take them to the next level. He expects teachers to do the same for students.

Dr. Matthews then spoke of the 'heart' of the district and his ability to 'coach' his administrative team to organize a community event to a varsity soccer team playoff game, which speaks of as one of the hallmark events of his career. He steals a moment to talk about the pride he takes in the school and in the success of that team. The students and fans filled a parade of buses to the location of the championship game. In this way, he connected the Latino community to the school district and the partnership was solidified as they celebrated together in the victory of that championship game. Dr. Matthews said about this memory, "You know, little things like that grow into big things. Success breeds success."

Identified strengths of district. Dr. Matthews identified the students and the community served by the school district as assets. He made several references to student experiences as helping them to build resilience to the challenges they face. He also recognized the district's no excuses approach to academic achievement. The district does not blame kids or families for past performance. Instead, they change approaches to engage students with a challenging, robust 
academic program that encourages the development of students strengths and interest. Dr.

Matthews is not interested in passing responsibility on to others. He believes it is his job is to educate all students:

I think that our kids are humble, and like any kids they've been beat down a little bit by the system but they are pretty resilient. I do, I love our kids. I think they are very resilient, our kids, and they don't come from money and, a lot of our kids, about $20 \%$ of our kids are undocumented...if they come across our threshold we educate them. So we take that very seriously and we believe that, you know, zip code shouldn't determine the quality of education, so we try to do the right thing for kids.

Responses from the participants give credibility to his statement. Moreover, responses indicate that this was achieved by changing the narrative along. Dr. Matthews understands that every child, regardless of zip code or socioeconomic status, is capable of achieving and he started having conversations with the students to help them see their own potential. A significant turnaround occurred when students were mandated to take the AP test. Students who lacked the confidence or the encouragement started to believe in their own potential. This new approach to assessment, combined with standards-based grading and a social media campaign to generate school pride, all contributed to the district's success. Dr. Matthews credits the work of the staff in connecting with students and the community.

I have some very loyal people who put in a lot of hard work In spite of all the obstacles they are given and I believe we have won over the community. They know we care about their kids but the way to win over the community is to have the kids talk about it. Social media and everything we did with communication in our district was aimed at the families.

Dr. Matthews recognized that parents are partners and resources on the path to academic excellence. He started inviting parents in to participate in their YouTube video campaign, while speaking with families at music and theater performances as well as sporting events. Similarly, he encouraged his principals and members of the staff and student body to go into the community to have conversations and to serve as ambassadors of the school district. Dr. 
Matthews spent considerable time discussing the importance of service in the community and even discussed his personal involvement in an annual tradition he stared a few years back. He takes pride in the relationships they have started at the local senior center making regular visits and inviting the residents to school plays at no cost. It is just one example of his intentional efforts to connect the school with the community. "We go to the Senior Citizen Center and it makes a big difference. I can't do it all myself so I take all these people...it has become a tradition.”

Dr. Matthews also identifies the district as being focused on the students' strengths and interests. He shared several anecdotes including the popular 'pride commercials' that represent every student club and group in the school. These commercials always include a cameo by the school mascot. A quick YouTube search illustrates the popularity of the videos; some have been viewed over 4,000 times. He says the following about the students' pride in the district:

Once they see success they feel pride in that and it keeps on growing. This has been a great place. It has been hard but I'm very proud of it because this is my baby. We have taken it from nowhere to somewhere. Our AP [recognition], we have been talking before we even got the award they asked us to speak because when I came here only white students were in AP. We had only 200 kids in AP classes, we now have over $3000 . .$. those are the things we are impressed with.

By reflecting the students and the things they care about into the academic program, the district has been able to develop ownership. Students understand that they belong to something significant and, perhaps more importantly, something significant belongs to them. The school district has become a community that the students can take great pride in. Dr. Matthews shared that only white students were in AP classes in the past and that a clear racial divide existed. As a district they pushed the status quo aside and mandated that every student in the district take the test despite the criticism that would come from requiring additional testing. This would provide every student the opportunity to succeed and receive college credit for their work. Dr. Matthews 
stated about the history of AP: "The truth be told, our kids were getting honor roll points to be in AP classes. But there was nothing to demonstrate that that was any more rigorous than any other class." Unfortunately, Dr. Matthews battled criticism for this decision from naysayers who believed the district was setting students up for failure. He was also criticized for mandating additional testing in an era of over-testing. Dr. Matthews indicated that he suspected some of the naysayers to operate from a deficit mindset.

Dr. Matthews transitions from the AP award to the topic of instruction, which is also identified as a significant strength of the district. On several occasions during his response, he complimented the Board and the teachers for the leadership exhibited to improve student outcomes. Specific instructional initiatives discussed include honors coursework, high-interest electives, standards-based grading and the multilingual program. These instructional programs speak to the district's high expectations for student learning and attempt to engage with students through connecting student strengths interests and culture.

Culturally responsive attitudes and actions. Dr. Matthews immediately identifies his belief that the superintendent has a direct impact on student achievement through a focus on recognizing culture as an asset. He discusses the summer school program for struggling students and, in that context, recognizes the role culture plays in differentiating instruction.

It's all about the culture. You have to understand the culture and you have to embrace it. People said 'Why don't they learn English?' Well, how about this? They speak two languages now. What we did was we embraced it and we were one of the first places to bring the Seal of Bi-literacy and we put that up and we make a big deal about it! Those are the kids that are going to be more successful because they speak two languages. Their culture is an asset. They are not afraid of hard work...it is okay to fail as long as you are learning something.

This statement provides evidence that district leadership emphatically believes in the potential of all students. District educator's confidence in the ability of the students is helping these young 
men and women to see the potential in themselves. Moreover, the district supports high academic standards for all students. Administrative team members Mr. Michael Phillips and Ms. Lois Ruth provide further evidence that culture is considered when looking at student achievement in the district. Both administrative team members credit the superintendent with changing the history of underperformance in the district by connecting with the community in a meaningful way through relationships and consistent presence in the community. Ms. Ruth states, "I've never seen an individual balance the politics, the community - he is just known everywhere. It's truly amazing. And he's been here a while too and that helps."

Dr. Matthews and two administrative team members, Mr. Phillips and Ms. Ruth, also identify the superintendent's intense focus on instruction as a factor that has led to gains in student achievement and a shrinking of the opportunity gap. Mr. Phillips indicates that Dr. Matthews was involved in discussions that led to personnel changes and putting quality teachers in every classroom made a significant difference in the classroom. "You look at our demographics - our numbers speak for themselves. We get the best teachers in the classroom we possibly can." All participants reference the improvement of academic programs as a key reason for the success of the district. Dr. Matthews' focus on instruction was a driving force behind key instructional improvements including a summer program for struggling students, a support program for at-risk freshmen, and efforts to identify those teachers who were most effective and those who were not supporting student learning.

Finally, Dr. Matthews' remarks and comments made by the two administrative team members indicate a focus on student equity. The superintendent speaks of the summer programs and a focus on what the students need to be successful. An administrative team member, Ms. Ruth, says that the superintendent has had a "[h]uge impact on the District. He has definitely 
been our change agent. We had a good ole boy network that I don't feel was student-centered." Although Ms. Ruth did not expand on this comment, it seems as though she believes past efforts, as well-intentioned as they may have been, did not take the same approach to focusing on student equity, strengths, interests, and culture as central to the academic program. To truly focus on students in a diverse school district is to imply that each child is receiving an instructional program that reflects who they are as an individual. Mr. Philips supports the belief that the instructional program is all about the students. "[Students] want to achieve and they will if you give them that opportunity...treat them the way you want to be treated." This comment is significant and supports the existing evidence that the superintendent has significantly reduced deficit-thinking in the district. Recent initiatives including mandated AP testing, at-risk summer programs, a district-wide social-media campaign, and the Seal of Bi-Literacy are evidence of how the superintendent identifies students as assets. The new expectation in the district demands a shifting away from the negative rhetoric about students of color and students living at or below the poverty level to a belief that all students are expected to succeed.

Attitudes and actions identified as culturally responsive in Dr. Matthew's leadership include:

- An expectation that all students can achieve at a high level

- The belief that multilingualism is an advantage to students

- A rejection of deficit-thinking

- Intentional engagement of families and communities, including a commitment to service

- A belief in reflecting culture in the curriculum

- A shifting of district funds to culturally responsive practices 
- An intentional effort to hire staff to support culture and language development

- Encourages out-of-the-box thinking to promote excellence

Leadership style. The superintendent's leadership style focuses on effectively and intentionally engaging all stakeholders and developing educators who understand quality instruction, including the role of culture in learning. With respect to intentional engagement, Dr. Matthews shares that he spends considerable time in communication with the staff to ensure they are operating from a consistent framework. He also acts as a 'buffer' between the "outside political influences" and the administrative team to keep his staff from negative distractions. Mr. Phillips and Ms. Ruth speak to his affinity for meeting with parents and community members and his ability to engage an audience. Ms. Ruth states, "He is engaging. When he gets up in front of a group they listen. The way he speaks and connects with an audience whoever that audience is." This allows Dr. Matthews to go beyond effective communication to true engagement with the community.

Hiring the right people for the job and developing those individuals to help them obtain the necessary skills is also central to the Dr. Matthews' leadership. While the superintendent provided evidence of this throughout the interview, he did not explicitly identify hiring practices as a leadership style. Dr. Matthews' did, however, share that he expects his employees to help students achieve at least one year of growth each year. His ability to surround himself with talented leadership was also identified by all three administrative team participants. Mr. Phillips states:

He recognizes his assets. He is clearly a very intelligent man. He has surrounded himself with individuals who are well-versed in the area they work in and...utilizes the skills of the people who he surrounds himself with. And isn't afraid to roll up his sleeves and get involved with something but if there is someone sitting at the table who can do the job better because they're trained in a particular area he's smart enough to realize that and smart enough to know when to hold the ball and when to hand it off. 
Similar statements are made by Ms. Ruth in response to this question. "He leads so well he doesn't need to be here. This District runs like a heartbeat, it's crazy. He has definitely built a legacy here. His name will go down in infamy. He's a very good superintendent.” Ms. Ruth did not expand on this comment, but my interpretation of this statement leads me to believe that he is an effective communicator and manager who has clear expectations for the team.

Similar to the other superintendents in this study, Dr. Matthews has a leadership style compared to that of a coach. The superintendent and both administrative team members, Mr. Phillips and Ms. Ruth, identify the superintendent's ability to help others improve by modeling leadership. Dr. Matthews identifies this as a skill and a future interest, post retirement. "All things being equal I would like to be more of a coach to all people. That is more my style and something I look forward to doing in the future." Dr. Matthew's has exhibited that it is necessary to provide examples of culturally responsive leadership in practice. His effectiveness as a leader is a result of his personal beliefs and actions about students and an elimination of a deficit mindset. Mr. Phillips provides evidence of this modeling.

One of the things that's unique about [him] and the reason things work around here, is that he doesn't expect you to do anything he wouldn't do himself. There is a lot of leading by example that takes place... it gains the respect of those around him. He has his hands and a lot of things and devotes a lot of hours to this District. And he expects the same from his administrative team and his administrators. It's not a situation of 'do as I say, not as I do.' It's just the opposite.

I was fortunate to witness evidence of this as I interviewed Ms. Ruth. Dr. Matthews took the opportunity to meet with a gentleman who appeared to be the technology director in the district. They worked on a spreadsheet together and discussed the development of this form to monitor data. To provide additional support to the superintendent as a coach, it is appropriate to include that three of the four participants identified a common mantra used by the superintendent "Early is on time, on time is late, late is unacceptable." My interpretation of this comment is that he 
expects his team to provide the absolute best for the students. He believes that the actions of district leadership sets the tone. High expectations apply to students and staff.

Core beliefs. Two core beliefs emerged from the responses of the participants. Although the term culturally responsive was not used, the participants' answers with respect to the superintendent's core beliefs indicate a focus on culture as imperative to instruction. Moreover, all four participants indicate that the superintendent maintains a focus on student equity.

Dr. Matthews clearly explains that it is the educator's responsibility to change the prevailing beliefs that exist in society, including deficit-thinking. Dr. Matthews does not believe ethnicity or financial situation need be indicators of academic success. Similarly, administrator participants agree that all students have potential to achieve and the goal of the high school district must be to give every student an opportunity to succeed. Administrative team members Mr. Phillips and Mr. Peters provide additional evidence that the district puts an emphasis on viewing students' culture as an asset. Mr. Peters states, “All kids, regardless of their race, color, or financial situation in the home - they are going to get support because we know about them; because we know who they are." Although he did not expand upon this comment, I interpreted this to mean that the educators are expected to know about their students' cultural norms, and personal interests and strengths.

The superintendent and all three administrative team members made statements that indicate a core belief of the district is that student equity is at the center of instruction. Mr. Peters shared that Dr. Matthews is all about the students and that, at times, decisions must be made for students that are not well-received by the teachers. Dr. Matthews added a strong statement that expectations are high and kids are not to blame when they do not learn:

When we would hire staff we would ask 'Do you know why we have an opening?' and they would say 'Did the teacher leave?' And I would say 'We have 125 kids that don't 
know algebra. At the end of the year I don't want you to report back that you have a 125 kids that don't know algebra. We already know they don't know algebra that's why we hired you.' And there is a correlation between teaching and learning. If the kids didn't learn you didn't teach. You may have worked hard, I'm not saying you didn't work hard but if they didn't learn, you didn't teach... now you can't blame the kids.

As stated, Dr. Matthews does not blame students or families for achievement and holds teachers and administrators accountable for student learning. He does not make excuses because and he has proven that the toxic rhetoric surrounding poverty and diversity is a distraction from the mission.

Direct impact on students. Dr. Matthews has a laser-like focus on developing students' equity through development of strengths and interests. All four respondents reported that the superintendent puts student needs ahead of all else. Dr. Matthews believes that all students need to achieve success and says this belief comes from his experience as a parent.

Our goal is make them all [a success]...when your statement is 'success for all' then all means all!...Everyone thinks they need to differentiate and say 'you're an A student or a B student'. That's not our job, our job is to teach them all. And that's what my philosophy is, and it comes from being a parent.

This statement is further evidence that Dr. Matthews focuses on equity. While all students deserve equity, Dr. Matthews understands that this is achieved by meeting the specific needs of the learner in the classroom. Initiatives like standards-based grading ensure that the teacher understands the specific needs of the student to improve instruction. Administrative team members reference initiatives such as standards-based grading, uniforms, and updated facilities to provide evidence that students are the centerpiece of the district. Ms. Ruth, in discussing the process of Standards-Based Grading, shares how students were always at the center of the conversation.

For standards-based grading they actually brought families in, provided English and Spanish. They discussed the whole process of the change and how it affects the 
students...[they] went over and above to help the parents because they really struggled [with the change].

The important piece in both of these examples is the intentional effort to engage the voice of the community in the midst of difficult change. Where traditional superintendents may have made changes without community input to avoid difficult conversations, Dr. Matthews took the opposite approach and received support on two issues that are particularly challenging at the high school level.

Decision-making process. The superintendent and administrative team members were asked about the change process and decision-making in the district. Dr. Matthews collaborates with the team and district constituents. He listens to others opinions but returns to the belief that the superintendent has the final word. The superintendent speaks directly to this process:

Identify with the true problem is. Sometimes people jump the gun. Identify what the problem is. After that, identify some alternative possible solutions. We select the best solution and we implement it and then we evaluate it. Did it work? At the end of the day the decision is mine. I'm ultimately responsible. People like to be part of the process if you're upfront with them and honest.

All administrative team members identified a similar process when making decisions in the district. The appropriate stakeholders are invited and consulted, but the superintendent has the final word. Mr. Phillips echoed the superintendent's wish for people to bring solutions to the table.

Once you get to know him he doesn't really want to hear about your problems he wants to hear about how you are fixing those problems. It's kind of a big deal for him. He expects you to come with answers, otherwise why does he have you in that position.

Mr. Peters added, "He has strong personal relationships...collaborative, but the superintendent has the final word." My interpretation of these comments is that Dr. Matthews identifies a moral imperative and if a decision is not reflective of ethical practices he is going to make a contrary decision in favor of the students. An example of this is the resistance he faced when explaining 
the benefits of requiring uniforms in school. He encountered resistance from staff but felt that it was necessary for student safety and to help eliminate a class system. Therefore, it can also be inferred that he has high expectations for his team to do the right thing by students.

Dr. Matthews' responses, as well as those of his administrative team, indicate that a rigorous, relevant, research-based approach to student instruction is essential to student success. He speaks early and often about the need to focus on culture as an asset instead of operating from a deficit model and articulates the importance actively engaging the community. He hires and develops educators who believe in the potential of all students if provided equity. He believes that skilled educators are advocates for students who have the ability to change the rhetoric. Accomplishing this requires intentionality.

We're trying to take this 'disadvantaged' thing and turn it to our favor. We are saying we want to be the number one Latino High School in the state of Illinois. We want to show the kids that we are advocating for them...we need to be an advocate for the kids and we need to get the parents to understand that too.

Dr. Matthews believes that educators are advocates for students. They do not simply prepare lesson plans to be consumed. They empower students to realize their own potential and they provide opportunities to students that help them to achieve.

\section{Summary}

This chapter told a story of the incredible work of three exceptional superintendents in Illinois who are living proof that a deficit-thinking model around culture and poverty is dangerous and toxic. It also suggested that the traditional approaches to district-level leadership must be critiqued and re-defined. In this chapter, we analyzed the philosophies, strengths, culturally responsive attitudes and actions, leadership styles, core beliefs, decision-making process, and impact superintendents are having on student achievement and on the closing of the opportunity gap. The responses to the questions provide the substance to the case studies 
presented in this chapter. The case studies illuminate the strength of the culturally responsive superintendent. While all participants recognize culture as an asset that must be leveraged for learning in the district, the absence of research linking culturally responsive pedagogy to superintendent practice made this framework difficult for participants to define. However, when examining participants' responses to the interview questions, it becomes evident that these superintendents share culturally-responsive beliefs and actions and drive their success. Examples of these commonalities are summarized below and organized into themes in Chapter V.

Each of the superintendents is clearly student equity-centered. These leaders strongly oppose the common-held belief that income or ethnicity determine student ability and, ultimately, student outcomes. They keep culture at the center of instruction. They make no excuses for low achievement in their schools and do not tolerate deficit-thinking from faculty and staff. They focus instead on providing exactly what each child needs to be successful. Additionally, these exceptional superintendents possess a strong understanding of instructional design as a result of a personal conviction as well as experience in curriculum as teachers and building level administrators and use this knowledge to close the opportunity gap. Each was able to identify the characteristics of an exceptional instructional program and hold high expectations for students. They agree that learning must be personalized based on culture, interests and strengths in an effort to engage and challenge students.

These superintendents improve achievement and narrows the opportunity gap through a commitment to engaging all community stakeholders. These leaders understand family engagement is paramount as these leaders understand that culture is foundational to student success. The superintendent bridges the gap between home and school through a purposeful and intentional engagement opportunities. This is achieved through relationship-building at 
community events, district programs, community events and through electronic and print communications sent home in the students' native language.

Exceptional superintendents hire educators who understand the significance of culture in learning. They also act intentionally to hire educators that reflect the cultural makeup of the school environment. They develop deep, meaningful relationship with these educators and leverage relationships to provide rich professional development including active coaching through modeling the behaviors they expect to see. They are present and active in the classroom with principals, teachers, and students to clearly communicate expectations while building relationships and providing powerful professional development.

Exceptional superintendents narrow the achievement gap by working with the community to articulate a vision that rejects deficit-thinking. The actions and beliefs of the superintendent do not tolerate a watering down of expectations. Students, staff and community members observe the conviction and confidence in their ability to achieve and begin to believe. This vision becomes a part of each person's own identity leading to increased ownership. Examples of this are laden in the three districts in the form of meaningful goal setting, embedding culture into instruction, and cultivating school pride through social media campaigns.

Finally, these superintendents innovate with their teams to develop out-of-the-box solutions to problems. These leaders then allocate district resources to make innovations a reality. They expend district dollars in a strategic way to close the opportunity gap. Examples of this includes hiring educators to connect home culture and language, providing digital resources to level the playing field, providing professional development on culture and language, and providing multilingual communications in digital and print. These beliefs and actions are organized into themes in the next chapter. 


\section{CHAPTER V}

\section{RESEARCH FINDINGS}

An analysis of the data collected during the case studies revealed that the findings align with the review of the literature in that effective educators develop cultural competency to increase achievement and narrow the opportunity gap. Superintendents, like classroom teachers, greatly benefit students when they apply a culturally responsive framework to their role and responsibilities. As the literature review revealed, all educators must recognize bias, challenge deficit-thinking, and work to support the needs of a multicultural and multilingual classroom to bridge the gap that exists between home and school (Gay, 2010; Hatt, 2007; Ladson-Billings, 2009). These exceptional superintendents deconstruct the existing norms and reframe thinking in their respective organizations to systematically improve student achievement and close the achievement gap.

As a strategy to effectively organize data, broad themes were identified while coding the responses of the all three superintendents and their respective administrative team members. For the sake of this study, the traits were defined as the patterns that emerged with respect to the superintendents' practices and beliefs. These patterns emerged when a trait was identified at least twice during the coding process and by more than one participant in each school district throughout the interview process. Initially, a total of 10 broad themes were identified. However, an examination of the specific beliefs and actions and an overall refining of the data led to the identification of specific characteristics. These characteristics were organized based on frequency and consolidation to avoid redundancy. Ultimately, six traits were identified.

These common traits were examined through this study's theoretical framework. An examination of the data illuminated the common, central theme of cultural responsive leadership 
woven in and among all other traits. This one common denominator existed as a core component of the other six characteristics; therefore, these six traits are known as The Key Characteristics of Culturally Responsive Superintendents Serving in Ethnically and Economically Diverse School Districts. A review of the literature revealed that the beliefs and practices of these exceptional superintendents align closely with practices of culturally responsive teachers. Although the roles and responsibilities of each position are unique, the tenets of culturally responsive teachers mirror the identified characteristics of culturally responsive superintendents. These characteristics are examined in greater detail.

\section{The Key Characteristics of Culturally Responsive Superintendents} Serving in Ethnically and Economically Diverse School Districts

1. The Culturally Responsive Superintendent Recognizes Culture as Paramount to Effective Instruction

2. The Culturally Responsive Superintendent has a Deep Understanding of What Quality Instruction Looks Like

3. The Culturally Responsive Superintendent Effectively Engages The Community

4. The Culturally Responsive Superintendent Hires and Develops Educators Who Understand Culture and Language are Essential to Learning

5. The Culturally Responsive Superintendent Articulates a Vision that Denies DeficitThinking

6. The Culturally Responsive Superintendent Innovates to Ensure Equity and Excellence for Every Child 


\section{Characteristic 1: The Culturally Responsive Superintendent \\ Recognizes Culture as Paramount to Effective Instruction}

Viewing student culture as an asset essential to the instructional program was identified by all three superintendents and administrative team members. The literature review and the data collection both revealed that a reverence for and recognition of student culture is a key component of culturally responsive teachers and culturally responsive superintendents.

Specifically, we know that culturally responsive teachers use the knowledge about the cultural of students in their own classrooms in an effort to improve their own ability to teach (Irvine et al., 2000). Similarly, each superintendent recognized and prioritized the importance of activating connections to students' home culture and expects to see culture intentionally embedded in the instructional program providing evidence that they are student equity-centered leaders. They reject commonly held assumptions that ethnicity or student income are barriers to improvement. They do not permit excuses to exist and expect classrooms to recognize culture as paramount to instruction to create a personalized learning experience. Specifically, school districts are using instructional materials and strategies that both respect and represent the ethnicity of students to close the opportunity gap. For example, administrator Claudia Lucas stated:

The culture of the teachers may not be reflective of that of the students, so what are we teaching? What are we using for our literature? What are the stories we are using? Are they seeing kids that look like them? The kids need to see characters that look like them. When it comes to the approach... every kid is their own person whether they need language support or special education support it is looking at each of them and what they need.

This powerful statement on eliminating deficit-thinking and creating opportunities for personalized learning based on student interests, strengths, and home culture was echoed in the three districts participating in this case study. The outcome of these beliefs about students have led to improved achievement in these identified school districts. Exceptional superintendents 
have discovered that closing the opportunity gap expands beyond just implementing the use of instructional materials reflective of home culture. They also include large programmatic initiatives like the dual language initiative in District 1, which suggests that they understand culture and language is an asset and an advantage. District 2, similarly, supports the home language needs of all students by mandating that teachers receive an ELL endorsement before the district will pay for the cost of other masters programs. In an effort to narrow the opportunity gap, the superintendent created cohorts of teachers who are being trained to meet the cultural and linguistic needs of all students. District 3 has shifted the thinking on culture by setting the goal of being the number one Latino high school in Illinois. They have made systematic changes and now have more Latino students in AP classes than any other high school in the state. These realistic goals put the student and their cultural norms front and center. Moreover, these initiatives include families in the instructional program through shared decision-making and by developing a relationship with parents and community members. These are intentional efforts to improve instruction through cultural competency.

A key component of designing an instructional program that is culturally responsive is keeping the focus on the students. Responses of the three superintendents and all administrative team members indicated that the superintendent's actions are student equity-centered. Participants described superintendents as putting students first when decisions made about the instructional program were based on the culture, needs, interests, and strengths of the students. Superintendents identified that focusing on the child may be in conflict with the desires of the staff, community, school board, or other constituents. Dr. Jacobs indicated she must be persistent in working with her team to build a culturally-responsive instructional program that is centered around the needs of the child: 
And the other thing I say in every situation is if we are making child-centered decisions every single time no one can fault us. If we consistently say what's best for kids? And can bring it back to why we made that decision - this was the best decision for the kids. I think it takes the wind out of the sails of someone who wants to, you know, come in and be a naysayer and question the integrity of something you may or may not have done when you can bring it back to the kids. We all do-and there are times I will say to them 'Was that an adult-centered decision or was that a child-centered decision?' We want our teachers to like it here we want them to be happy here but we need to remind them of why we are here. And sometimes it is easier to make the teacher happy but at what cost?

Similarly, the other superintendents indicated that they expect teachers to take an instructional approach that focuses on the culture, strengths, and interests of students instead of centering instruction around the norms and interests of the educator. Mr. Peters says the following about Dr. Matthews, "We're here for the kids — we're here for the kids. He cares about teachers, but I'll tell you what, teachers are essential to students. So, it's students first. It really is. His actions permeate the organization to that end." Interviews and observations indicated that these superintendents don't just talk about centering instruction around the needs of the diverse student body, they all participate in making sure it is happening in the classrooms. All three exceptional superintendents were observed emphatically interacting with the students in the classrooms. Interviews with all participants illuminated the fact that the culturally responsive superintendents genuinely enjoy spending time with students in the classrooms and at extracurricular events; therefore, it is a part of the day for each of them.

Summary of characteristic 1. The superintendent rejects a deficit mindset resulting in a narrowing of the opportunity gap through intentional efforts that ensure instruction is student equity-centered. Student culture, strengths, and interests are paramount in planning and executing a high-quality instructional program. The child cannot be separated from his or her ethnicity, beliefs, strengths, or interests. The superintendent understands the need to personalize instruction and recognizes culture as an asset leading to a narrowing of the opportunity gap. 


\section{Characteristic 2: The Culturally Responsive Superintendent Has}

\section{a Deep Understanding of What Quality Instruction Looks Like}

Culturally responsive superintendents possess an understanding of challenging and equitable instructional design and expect educators to use data in a meaningful way to support and improve instruction. Similarly, the literature review reveals that culturally responsive teachers have great respect for the intellectual capabilities of all students and design an instructional program that is reflective of this belief (Ladson-Billings, 2009). Culturally responsive teachers and culturally responsive superintendents believe that 'rigor' is essential to effective instruction. The opportunity gap is closing in the identified districts as a result of high instructional standards. Exceptional superintendents respect the intellectual potential of students and do not believe the rhetoric surrounding achievement of students of color or socio-economic status. The high expectations embedded into instructional program in the identified districts reflect that belief and, consequently, lead to a narrowing of the opportunity gap in these exceptional school districts. For example, to ensure the integrity of the instructional program, all three superintendents regularly spend considerable time in schools on the front lines evaluating classroom instruction and supporting effective principal leadership through coaching and development of principal leadership.

The ability of the superintendent to keep the district focused on achieving high expectations through effective, culturally responsive instruction and regular formative and summative feedback is central to the district's success. Interview questions reveal that superintendents meet with administrative team level staff and school principals on a consistent, regular basis to examine and evaluate the impact of instructional initiatives by examining assessments. While all three districts do spend time evaluating the results of large, standardized 
assessments, they did not believe that the PARCC assessment provided the whole picture.

Exceptional superintendents examined multiple measures, paying specific attention to student growth on local assessments. At least one interview participant from each district made a statement about the negative impact of standardized testing in ethnically and economically diverse school districts and expressed a direct, strategic approach to formative and summative assessment in a meaningful way. Ms. Andrews stated:

With our previous superintendent, it was all about the [ISAT] scores. [Our current superintendent] doesn't want to say that scores are not important or that he doesn't care, he just wants to send a very consistent message that we can take the time to look at that but we are not teaching to the PARCC. We are not analyzing the PARCC to determine our curriculum and instruction. We are looking at it as a dipstick how are we doing on that measure? The use of those results are more for system-wide analysis. He was so consistent and thoughtful in those messages.

All three districts employed a culturally responsive approach to a rigorous

curriculum. Though at different places in this journey, each district is making intentional efforts to achieve this in the classroom and beyond. Examples from all three districts include: ensuring a challenging and robust curriculum that both respects the students ability and honors home culture, including parents in the instructional program, and building student context for learning through the district's participation in cultural celebrations, festivals or other events that reflect heritage.

Summary of characteristic 2. Exceptional superintendents respect the intellectual potential of students. The superintendent narrows the opportunity gap by maintaining high instructional expectations and ensures educators challenge all students. They do not make negative assumptions about the abilities of children based on family income or culture. Instruction is rigorous as anything less would not be ethical. 


\section{Characteristic 3: The Culturally Responsive Superintendent Effectively Engages The Entire Community}

The superintendent bridges the gap between home culture and classroom instruction through intentional and effective communication with family, community, staff, students, and the school board in a variety of contexts, often off school grounds. The superintendents' ability to connect with constituents in a deeper way was identified in the responses of all participants. Similarly, a deep connection with the community was illuminated in the research on culturally responsive teachers, who spend immense time learning about students and families with the intent of building relationships and developing an understanding of cultural norms, values, and beliefs that may differ from that of the educator (Ladson-Billings, 2014). Administrative team members acknowledged that this approach to relationship building has been effective at building trust while informing practice. As a result, a network of support has formed between the school and community leading to a narrowing of the opportunity gap. This begins with establishing a relationship, particularly when the cultural norms of the community may be different from those of the superintendent. For example, Superintendent Jacobs grew up in the community where she now serves. Although she does not share the same ethnicity of the majority of her students, she is able to make a personal connection through this commonality she shares with the families. Dr. James achieves similar connections by attending school and community events to seek out and speak with parents. He also reaches out to families and community members to invite them to district events, including board meetings. Similarly, Superintendent Matthews goes out into the community regularly. He does not miss an almost 50-year-old annual festival and parade honoring the heritage of the community because it provides an opportunity to build relationships in a place where parents and community members are comfortable. Moreover, Dr. Matthews 
arranged a fan bus to join the soccer team in their pursuit of a state title. In these ways, he honors his students, their families, and their traditions. All administrative team members spoke positively about the superintendent's relationships with students, staff, board members, and community members, and all three superintendents expressed the importance of getting to know the people you serve and spending time in the schools. These relationships are a result of clear and intentional communication.

The trust that develops between the superintendent and stakeholders, including community members, pays dividends before, during, and after decisions are made. Even so, not every decision will be popular among all stakeholders. The administrative team members and the superintendents agree that open, honest communication rooted in relationships is helpful when making a difficult decision that will impact families or students. Dr. Jacobs explained:

I think for me when we have to make a difficult decision I really try to communicate the why before the decision gets made. That seems to help but what I've learned is if someone is going to have an issue with something I am doing they're going to have an issue. I just want to make sure that when we do that no one can ever say you didn't tell me-I think that communication is the single most important thing we do as superintendents.

Culturally responsive superintendents understand the political nature of the position and the need to communicate effectively with a variety of audiences in a variety of formats. To ensure equity and close the opportunity gap between home and school, the parents and community members in all three school districts receive regular electronic and print communication from the district. This communication is sent with regularity to ensure that all families are involved, not just those who can attend district meetings or those who have access to digital print. These formats include email, bulletins, brochures, magazines and other publications. Moreover, each district provides correspondence English and Spanish. 
A narrowing of the opportunity gap can also be attributed to effective communication and meaningful partnerships with administrative team members and teachers. Interviews and observations lead to the conclusion that the superintendent is highly effective at building relationships with the team. Specifically, during the interviews, I observed each administrative team member speak about the superintendent with reverence and familiarity. Words like "friend" "colleague" and "visionary" indicate a respect for their superintendent. The superintendents reciprocated these feelings.

Administrative team members and superintendent participants revealed that the superintendent is also collaborative with families, community, and staff, which reflects the research of culturally responsive pedagogy. Harvey et al. (2013) recognize that parents and community members are assets to any school district and they are to be viewed as partners and a key component of the school program. This is further evidence that the superintendent values the voices in the community and understands the impact relationships and the importance of listening to the good ideas and opinions of those people who are closest to students, the parents. It manifests itself in the superintendents' ability to work well with others and share much of the decision-making with other administrators, staff members, community members, board members and students.

Even with the support from the community and the staff, superintendents turn to those mentors who have experience in this challenging role for support on difficult issues. Dr. James states, "I have a couple of superintendents that I use as a litmus test and that is really effective. I really believe in the power of mentoring..." Responses to the interview questions indicate that exceptional superintendents are excellent listeners who consider others points of view before making a decision, although there were some differences between the superintendents on how 
others input is used, which is addressed in the section on superintendent differences. It was evident that team members are expected to come to problem-solving meetings with proposed solutions. While all districts indicated that the superintendent relies heavily on the team, the majority of superintendent and administrative team level participants also added that the final decision often falls to the superintendent.

Summary of characteristic 3. The superintendent narrows the opportunity gap by intentionally going out into the community to develop relationships and harvest ideas. Culturally responsive superintendent do not rely on district-organized parent meetings; rather, they go to athletic competition, cultural events, service events, student performances and others. In this way, the superintendent exhibits a belief that schools are an extension of the community. The culturally responsive superintendent also communicates with families and community members in a variety of written formats, including electronic and print notifications. The district provides this written communication in the native languages of the community. In soliciting input from the community, the superintendent builds relationships and recognizes the authority of parents as an asset that can provide insight into better teaching and learning.

\section{Characteristic 4: The Culturally Responsive Superintendent}

\section{Hires and Develops Educators Who Understand Culture}

\section{and Language are Essential to Learning}

In examining responses to interview questions, it was evident that all superintendents improved achievement and closed the opportunity gap through intentional, culturally-responsive employment decisions and professional development. Exceptional superintendents do not tolerate excuses for underperformance because they understand the significance of embedding culture in learning and provide evidence that they expect only the best educators who understand 
that deficit-thinking has no place in the district. These exceptional superintendents hire effective educators, develop existing staff, and release employees who don't personalize instruction based on culture, strengths and interests.

Specifically, exceptional superintendents created positions needed to fill existing gaps in the instructional program to better meet the needs of the at-risk students. Dr. James recently hired a Director of Social-Emotional Learning and Community Engagement. This individual works directly with parents and educators to support dialogue with the community while also training staff on meaningful social-emotional and cultural instructional practices to better serve student needs. Similarly, two of the three district superintendents also added staff who serve as liaisons to parents and community and could help bridge the gap between home and school. All three superintendents spoke to the level of talent and commitment in their own teams and recognized the fact that everyone has unique strengths that they may not possess.

Moreover, these leaders made intentional efforts to ensure the staff they hire reflects the diversity of the students and in all three districts. Two of the three school districts, District 1 and District 3, had significantly higher numbers of educators who reflect the diversity of the students than the state average. District 1 has 9\% more Latino employees than the state average, and District 3 has $10 \%$ more Latino educators than the state average. While it may not be possible for the staff to share the cultural heritage of every child, exceptional superintendents believe every employee should be capable of differentiating based on strengths, interest, and culture to serve the district's children. Dr. Jacobs shared the power of an educator who can achieve this:

Like I said, you have to know where you are when you are serving so we try to hire in a way that reflects [culture], you know. We just hired a Spanish Bilingual Teacher. I wish you could have met her. The kids just adore her. We're having trouble with this little kindergartner but when she is with him he's a completely different kid. You know, she understands his culture, she understands his frustrations and she can speak to him the way his mom speaks to him, right? So it is just different. I think we are very aware of our 
diversity and we try and embrace it and we try to make sure the key players on our board to not just support the kids and also the employees at a high level.

This powerful statement on the importance of an educator who understands the needs of a child provides support to the shrinking opportunity gap in Dr. Jacob's district. Similar examples in other districts provide evidence that a higher proportion of educators who reflect the diversity of the students is a factor in the closing of the opportunity gap.

The literature review indicated that superintendents should not just hire culturally responsive educators, but also provide training in culturally responsive teaching to new and veteran educators. Specifically, we know that culturally responsive teachers require high-level professional development on the cultural makeup of the classroom if they are to differentiate to meet the academic needs of students (Irvine et al., 2000). These leaders believe in developing an understanding of culture and that differences in race and class must not be seen as an obstacle but an asset. It is significant to note that many of the people these superintendents hired have abilities and talents that are not the same as those abilities and talents possessed by the superintendent. All three superintendents gave credit to the effectiveness of their team. Dr. James stated:

I go back to my style is to hire leaders that are awesome leaders with great potential and try to be careful not to fall victim to the law of magnetism and just hiring people that are similar to my own leadership and look more broadly to hire a team of leaders that all have great strength but may be different [from me]. I've got some people that are visionary, but more so than others. I've got others that are great with details. I've got some people that just get the logistical part. And as we work together they all ask questions from that perspective; from those strengths that they have and it makes us all better.

To further support staff development, these leaders hire staff, consultants and special presenters to support team members and parents in understanding culture's impact on learning.

Research revealed that superintendents also participate in this development through direct coaching. This was a key practice in closing the achievement gap. In each district, and in at least 
one interview with administrative team members, the superintendent was referred to as a 'coach'. Participants provided evidence in interviews and observations that superintendents take an active role in the classroom developing principals while building relationships with teachers and students. In all three districts, the superintendent coached the administrative team members and classroom teachers on what it means to deliver effective instruction to close the opportunity gap.

The superintendents understand that they alone cannot coach the entire team. They recognize the need to hire and develop talent in district leadership. The superintendent identifies administrative leaders who are skilled in areas that they are not. They put these key administrative employees into strategic positions because they understand that leadership is essential to the district's success. Dr. James said:

I am comfortable not being the best leader in the room and I think I have a lot of people that work for me that are smarter than me, who have great vision and great potential. And I'm comfortable being that humble Phil Jackson, if you will.

Ms. Ruth said about the Dr. Matthews, "By bringing in a good administrative team he built this empire and we are just rocking right now." Findings reveal that culturally responsive superintendents do not accept mediocrity from staff. Instead, they work with all of the educators in the district to purposefully improve achievement and close the opportunity gap.

Summary of characteristic 4 . The superintendent narrows the opportunity gap by hiring, developing and retaining staff trained in culturally responsive pedagogy. Employees understand the expectation to reject deficit-thinking. Culturally responsive superintendents often hire educators who share the ethnicity of the community, although this is not an excuse for not teaching to student culture. The superintendent ensures that rich professional development is provided to staff to develop cultural competency. The superintendent is often directly involved in developing the staff as an instructional coach. 


\section{Characteristic 5: The Culturally Responsive Superintendent}

\section{Articulates a Vision that Denies Deficit-Thinking}

Exceptional superintendents close the opportunity gap by articulating a vision that rejects deficit-thinking and believes that all students can achieve success. Exceptional superintendents recognize bias and clearly and consistently communicate that culture is an asset that can improve instruction. In doing so, they help to raise a 'critical consciousness,' which is identified in the literature review as a characteristic of culturally responsive teachers. All superintendents acknowledge a vision where all students, regardless of culture or socio-economic status, have the ability, and therefore must be afforded the opportunity, to receive an outstanding education. This relates back to Valencia's (1997) examination of deficit-thinking that suggests educators may hold beliefs, sometimes unconsciously so, as a result of class and race bias. Moreover, the superintendent works with the community and family members to make sure the vision is shared and reflective of the beliefs of the community (Kowalski, 2013).

All superintendents agreed that this vision includes instruction that is personalized and meets the child's individual needs. A prevailing attitude is that of 'equal does not mean equality.' In other words, a one-size-fits-all model of education in which educators treat all kids the same is not equitable because it ignores culture, ability, interests, and other factors that make each child unique. Dr. Matthews supports the power of a clear, student strength-centered vision by dispelling systems that rely on a deficit model:

We were advocates for our kids and I think that's what makes the difference in closing the achievement gap. You know, believing our kids deserve to have this education and that they can achieve. We hold these belief systems about kids that are not necessarily true.

Each of these superintendents recognize these differences are strengths. The superintendents were described as leaders who know what they want and where they want the district to go. 
Specific examples of this turning vision into action include the social media campaign in District 3. Dr. Matthews uses social media to tell the story of the value and strength of their diverse student body helping educators, students, and parents take pride in the school district. Dr. Jacobs, superintendent in District 2, indicates that excuses for underperformance will not be tolerated. She has a vision that all educators in the district would serve the linguistic needs of ELL students, which has led to nearly every educator having an ELL endorsement. Similarly, Dr. James has a vision of a robust multilingual program to create a powerful dual language program available to all district students.

The superintendents took specific actions to ensure the vision is shared by the community to narrow the opportunity gap. They understand that conversations with families, community, and team members about culture, strengths and interests do much to acknowledge others' beliefs, values and worldviews (Ladson-Billings, 2009). These exceptional superintendents were actively and personally involved in keeping the team focused on the vision when there was a risk of going off course. The superintendents would use their strong instructional training to go into the schools and the classrooms to ensure the vision is implemented with fidelity. All three superintendents spoke about short-term and long-term goals for the district. This included involving stakeholders in the process, including students and parents. Mr. Phillips said the superintendent's leadership style is to "Plan ahead. Be forward thinking." Superintendents were always assessing and taking the temperature of the vision in case the district was not making the progress that was intended. Often, adjustments or changes were necessary to get the district back on track. Ms. Abraham said the superintendent is always "leading from a vision and never straying from that no matter how difficult things get." These leaders do not succumb to the pressures that may get the best of others. Mr. Ashner stated about Dr. Matthews, 
[He is] visionary, with a meaningful out-of-the-box vision. [He] does not let obstacles really get in the way of planning for that...He doesn't cave to the traditional pressures and he is not afraid to take a leap. We are going to follow....

All superintendents and administrative team members recognize the superintendent as having a clear vision that leads the districts. A main component of this vision is celebrating the diversity of their school districts as an asset and not a deficiency, which supports a shrinking of the opportunity gap. Superintendents feel that issues of race and class should be discussed—not because everyone should be treated equally, but because everyone is different, and it is those differences that make children special.

Summary of characteristic 5. The superintendent narrows the opportunity gap by collaborating with students, parents, community leaders, and stakeholders to develop a vision that is culturally responsive. The actions and beliefs of the district leader do not tolerate a watering down of the vision and the superintendent personally assesses the development of the vision as an active participant in schools. The vision guides students to develop a 'critical consciousness' to develop conviction and confidence.

\section{Characteristic 6: The Culturally Responsive Superintendent \\ Innovates to Ensure Equity and Excellence for Every Child}

Culturally responsive superintendents innovate with their teams to work with their communities to develop out-of-the-box solutions to challenges and then allocate district resources to make that vision a reality. These superintendents have invested significant dollars on programs, supplies, and employees that support culture. To name a few, districts provide dual language programs, additional staff (including parent liaisons and translators), professional development (in the form of ELL endorsements, consultants), additional AP testing, multilingual print, and personal devices equipped with internet access to level the playing field. They expend 
district dollars in a strategic way to close the opportunity gap. Administrative team members and superintendents spoke specifically with respect to the programs, classes and new instructional tools that they had either created or implemented to ensure that each child has a differentiated experience, regardless of socio-economic status. These exceptional superintendents work directly with the team to think outside of the box to identify solutions to an instructional challenges faced in ethnically and economically diverse schools. Dr. James spoke about these challenges and provided evidence of this practice:

The things that we are trying to do instructionally-I don't think there are too many schools that are doing this with integrity. I mean, there are a number that are saying that they are progressive. They are out buying a solution instead of trying to create something and own it. Sometimes it's hard to find someone who understands the instructional challenges we are going through and in those cases we usually have an instinct or a concept and I will take it to the team and say what do you think?

Research on culturally responsive teaching indicates that educators use what they know about students to create new solutions and elevate teaching (Irvine et al., 2000). Similarly, responses to the interview questions reveal that the superintendents close the opportunity gap by using what they know and what they have learned to make innovation a priority in a culturally responsive school district.

It is significant to note that innovation was particularly apparent in the way the districts utilized its technology, which was a primary equalizer. Superintendents spoke to how technology is used in the school district and the importance of low-income students having access to the same resources as their peers at home and at school. Every district commented on the ways technology was used to level the playing field. Additionally, tools that support and encourage creativity were identified as paramount by several administrative team members. Students are encouraged to use the technology to embed strengths, interests, and cultural identifiers into projects that demonstrate learning. Other culturally responsive innovations were also illuminated. 
Capital improvements and new construction were either recently erected or being erected in all three districts. In the two elementary districts, these projects were designed around two innovative designs that support early childhood and make sure rich educational experiences are available to all children at an early age. These include a parent training and resource center in one district and new literacy spaces in another district.

Culturally responsive superintendents are intentional about making sure no stone is left unturned when differentiating a curriculum based on student culture, strength, and interest. Ms. Abraham, an administrator in District 2, stated:

There's some unique programming that goes on here. Every student gets concentrated reading minutes. [These are] innovative programs and an innovative approach. We took time and resources to create curriculum maps around the Common Core over the summer we have teacher leaders coming in over the summer and they actually revamp their curriculum to work on aligning to the PARCC. Having technology and Innovation - we are very non-traditional here. I can't remember the last time you would walk in and see everybody open to the same book at the same time. It just doesn't happen because everybody is not at the same reading level.

Similarly, District 3 was innovative in their approach to all students participating in AP testing. They decided to help students overcome the fear of advance placement exams and classes by developing a system to ensure all students had an opportunity to take such classes. The district has experienced great success and has even been recognized as a College Board AP District of the Year. This innovative concept rejected deficit-thinking. It was culturally responsive in that it challenged the past practice of primarily white students taking AP classes and made those college credit classes available to all.

Exceptional superintendents are not afraid to develop out-of-the-box solutions to problems. Moreover, they commit significant funds to making sure initiatives are financially supported and implemented with fidelity. 
Summary of characteristic 6. The superintendent narrows the opportunity gap by developing and supporting innovations to help educators differentiate based on culture, knowledge, strengths and interests. Technology is provided to level the playing field and meet the needs of students who do not have home access. Financial resources are not spared to support innovative, culturally responsive solutions to chronic problems in ethnically and economically diverse school districts.

\section{Other Superintendent Commonalities}

The six characteristics were identified throughout the interviews and recognizable patterns emerged in the refining of the coded datum. However, I identified several other notable commonalities between the superintendents. The three superintendents had remarkably similar

backgrounds. All three are married and have children of their own. They started their career as a superintendent after receiving mentorship and encouragement from other educational leaders.

Dr. James stated that "All great things happen on the shoulders of effective leaders." All superintendents earned Doctorate Degrees and are active participants in professional organizations. Each superintendent started as a teacher in the classroom and served as a principal at some point in his or her career. All three superintendents have been recognized with professional awards. All three spoke with conviction about the role of public educations and each teacher's role in developing the next generation. Dr. Jacobs stated, “These kids get one chance in second grade, one chance in third grade, and as teachers we have the responsibility to ensure they have the best possible experience." Each spoke with enthusiasm about the community and positively about the students that they serve. This was also evidenced by the way superintendents prioritized their time as each of them visited students during my visit to the districts. Superintendent actions and administrative team member interview responses indicate 
that the superintendent makes it a priority to visit district schools and the classrooms on a consistent basis.

During interviews, all superintendents also expressed the importance of their relationship with the Board of Education. These exceptional superintendents saw their respective Boards as an asset to the community. All three superintendents expressed appreciation and credited the Board with supporting the district's vision and doing what was best for students. Each leader was also clear that they appreciated the Board's understanding of their role as elected community leaders who set policy and refrain from performing management functions that belonging to the superintendent and staff. All three superintendents appeared to have a true mutual respect and understanding built on relationships and trust. Dr. James stated:

Another strength is our Board of Education. Their willingness to hire me, and I was completely honest about, you know, my approach to schooling and they took a chance on that. They didn't want the status quo they knew they wanted something different from that. They wanted to be recognized for doing great things for kids for giving kids the best chance at having a great life so I shared a vision of how that could happen and they embraced it. They don't always agree with everything I say. As a board they're highly involved. They come to so much PD, so that's a strength.

All three superintendents referenced a phone call or meeting with a Board member on the day of my visit to the district. I was fortunate to meet one of the Board Members in Dr. James' district. This particular Board member was coming in to meet with him about an initiative he wanted to discuss as we were wrapping up our interview. While many superintendents struggle with their relationships with the elected Board of Education, this was not the case in any of the school districts identified for this study. I was able to determine that relationship building, through clear and consistent communication, developed the trust these exceptional leaders need to be effective as the eighth member of the district leadership team. 
Finally, superintendents exhibited or spoke about integrity and the moral obligation to do what is right and to stay true to promises. Dr. Jacobs stated,

Integrity and making sure my word means something. If I say I'm going to do it I'm going to do it. I don't want anyone to ever feel like I am dishonest or not trustworthy. That integrity is just so important.

All three superintendents spoke to doing what is right and not allowing anything to interfere with their principles and the work they do on behalf of students.

\section{Superintendent Differences}

Differences between the superintendents were identified when examining the commonalities. These differences were identified in relation to the superintendent's communication. Superintendents Dr. Jacobs and Dr. James had very similar approaches to communication, anchored In the $21^{\text {st }}$-century learning approaches such as the ' 4 C's': communication, creativity, collaboration, and critical thinking. Dr. Matthews similarly referenced the need for effective communication; however, several responses indicated that Dr. Matthews employed an approach to communication that was slightly more hierarchical than the other superintendents. While it is true that all superintendents agreed that the final decision would be made by the superintendent, the responses of Dr. Matthews and administrative team members indicate that this was not always the case in District 3. Dr. Matthews stated, "What people need to understand is there are times I'm going to be very collaborative and there are times I'm going to be dictatorial.” Administrative team member Mr. Peters reaffirmed this statement, "He is very direct and very opinionated. He has a way he wants things and he makes that known." Dr. Matthews spoke to this again in a way that showed his approach as a leader who listens and respects the team's contribution, but who also makes the final decision:

You want input but at the end of the day the decision is mine. I'm ultimately responsible. People like to be part of the process. If you're upfront with them and honest, you say 
listen, let me tell you how this is going to go. This is the process that we are doing at the end of the day, you know, I'm going to solicit your input and that is all it is. You are telling me what your belief system is. It's not a majority vote...

Dr. Matthews is also the only to serve in a high school setting. Additionally, it is the largest district of the three districts identified in this study.

\section{Summary}

These culturally responsive superintendents demonstrate the ability to close the opportunity gap and improve achievement. They acknowledge bias, deny deficit-thinking and take decisive action to support ethnically and economically diverse students in their respective school districts. Similarly, the research on culturally responsive teaching tells us that classroom educators make intentional efforts to bridge the gap that exists between home and school (Gay, 2010; Hanley \& Noblit, 2009; Ladson-Billings, 2014; Irvine et al., 2000). Moreover, culturally responsive superintendents do not resort to making excuses to justify under-performance on state and local assessments. This is also true in the research on culturally responsive teachers (Hatt, 2007; Lyman \& Villani, 2004). Rather, these exceptional educators support high instructional standards, a development of critical consciousness, and meaningful community engagement to close the opportunity gap and improve instruction (Ladson-Billings, 2014). These findings provide evidence that Culturally Responsive Pedagogy (CRP), or using the cultural knowledge of students, must inform instructional practices if we are to empower students to achieve (Gay, 2000; Hanley \& Noblit, 2009; Ladson-Billings, 1992).

Irvine et al. (2000) determined four critical elements that support a culturally responsive pedagogy:

1. Culture is a powerful variable that influences teaching and learning processes.

2. Effective teaching research is compatible with and supportive of the principles of culturally responsive pedagogy. 
3. Teacher knowledge and reflection are important considerations when designing implementing a culturally responsive lesson.

4. High standards and expectations are important components of culturally responsive pedagogy. (p. 4)

All of these four elements are present in each of The Key Characteristics of Culturally

Responsive Superintendents Serving in Ethnically and Economically Diverse School Districts.

Therefore, school leaders serving in similar communities must begin to significant shift their

thinking to recognize the importance of culture if they are to make meaningful change. Educators

would benefit from learning about students culture by establishing deep, meaningful

relationships with parents and community members. This will inform understanding and help

district leaders to support the team as they provide appropriate instruction (Auerbach,

2000). Superintendents have the ability and responsibility to support culturally responsive

instruction to close the opportunity gap and prevent an inferior self-image. 


\section{CHAPTER VI}

\section{CONCLUSIONS AND SUGGESTIONS FOR FUTURE RESEARCH}

The purpose of this study was to investigate the leadership traits of exceptional superintendents serving in ethnically and economically diverse school districts to better understand how individual characteristics might be emulated by other district leaders and put into practice. Additionally, the study aimed to identify best practices for superintendents who attempt to close the opportunity gap and raise student achievement in districts identified as economically and ethnically diverse. I explored existing literature on district-level leadership and culturally responsive pedagogy to identify strategies to improve achievement in economically and ethnically diverse school districts. This research revealed that culturally responsive pedagogy is at the heart of exceptional superintendent leadership. The research questions that guided this study were:

1. What is the nature of superintendent leadership in ethnically and economically diverse school districts that indicate a closing of the opportunity gap?

2. What leadership traits do each of the identified superintendents possess?

3. What are the identifiable best practices to raising student achievement and closing the opportunity gap in ethnically and economically diverse school districts?

To answer these research questions, I employed a qualitative comparative case study design collecting data through interviews and observations to identify the participants' predominant characteristics as well as the commonalities and differences between superintendents. Broad themes emerged during the coding of participants responses. These general themes were reorganized and refined based on frequency, redundancy, and the emergence of the central theme, Culturally Responsive Leadership. Once the broad themes were identified, I analyzed the 
data to compare what we know about the beliefs and practices of culturally responsive teachers to the beliefs and practices of culturally responsive superintendents. I refined the data to eliminate redundancy. After answering the research questions, I identified implications for policy and practice, as well as suggestions for aspiring superintendents, active superintendents, and superintendent preparatory programs.

\section{Research Question 1}

Research question one asked, "What is the nature of superintendent leadership in ethnically and economically diverse school districts that indicate a closing of the opportunity gap?”

The data suggests that superintendent leadership in ethnically and economically diverse school districts is effective when it is culturally responsive. Culturally responsive pedagogy was evident in the leadership of all three exceptional superintendents, who recognize culture as imperative to effective instruction. The data suggests that superintendents can have a direct impact on the narrowing of the opportunity gap when the leadership is applies a culturally responsive framework that rejects deficit-thinking. Specifically, each superintendent was identified as having a desire to recognize and celebrate home culture as an asset that must be represented in classroom instruction including an instructional program that reflects the diversity of the classroom. Exceptional superintendents serving in ethnically and economically diverse communities recognize bias, and believe that students' culture is an asset and must be central to instruction. They believe it is essential to allocate resources to areas of greatest need. Additionally, culturally responsive superintendents believe in bridging the gap between home culture and school. They achieve this through intentional community engagement inside and outside of school. These leaders believe that effective educators take advantage of the 
community assets available to the students such as parents and local churches. Ms. Andrews, administrative team member in District 1, summarized this point:

We partner with families and community organizations to support our kids. Lots of parent involvement in classrooms and other opportunities. We are looking at the research and hoping to grow. What does it mean for real parent involvement? Are there other ways to expand beyond what we do? The director of social-emotional learning is doing some work in that area. Just building an understanding of parent involvement.

Relationship building is an essential element of CRP. All superintendents discussed the importance of building relationships, not just with students but with families and the community. Administrative team member Ms. Lucas described this strength in Dr. Jacobs:

She's very connected to the community-born and raised here. She is always looking for partners on how to support our schools...She's very involved in being a part of the community and being a representative of the school district and supporting a focus on quality instruction.

While relationships and quality instruction emerged as themes, both were regularly discussed in the context of doing what was best for students.

Culturally responsive superintendents also hire effective team members, speakers and consultants who understand the connection between culture and learning. They do this intentionally because they understand the positive impact hiring decisions make on student learning. Exceptional superintendents make student-centered decisions. Interviews revealed that culturally responsive superintendents face challenges from staff, Board, and community members when student-centered decisions such as scheduling, selection of curriculum, allocation of resources, and others conflict with the desires of adults. These superintendents put the child at the focal point, rather than the educator, and require their teams to take a comprehensive look at each child to create an instructional program designed to meet the needs of each individual student. 
These superintendents believe that the narrative must be changed and that the diversity of the schools they serve affords them greater opportunities to learn about the world while also preparing for the realities of the $21^{\text {st }}$-century workplace. These exceptional leaders do not see socioeconomic status, family situation, or past academic struggles as an insurmountable obstacle. Rather, they treat that information as pertinent because it helps them to better understand the context of that child. Dr. Matthews spoke to the importance of understanding the student's culture if an educator is to have success. "It's all about the culture. You have to understand the culture and you have to embrace it." Dr. Matthews also shared the district's strong desire to see similar growth for its small population of African-American students. "African-American students need to be better represented and we have to engage those families and that is the first thing we have to do with that group."

Based on the superintendent and administrative team members' responses to the interview questions, the nature of exceptional superintendent leadership in ethnically and economically diverse school districts is culturally responsive. Exceptional superintendents and all administrative team members identified the superintendent as a leader who makes decisions based exclusively on the culture, strengths and interests of the child. All students receive access to what they need regardless of socio-economic status including educational resources and highquality instruction.

\section{Research Question 2}

Research question two asked, "What leadership traits do each of the identified superintendents possess?" Ten broad leadership traits were identified during the first round of coding. Although this list was later refined by consolidating redundancy and embedding the overarching theme of culturally responsive leadership, the participant's responses to the 
interview questions revealed the following 10 common traits:

- The Superintendent is a Culturally Responsive Leader

- The Superintendent is a Student-Centered Leader

- The Superintendent Maintains a Focus on Instruction

- The Superintendent is Collaborative

- The Superintendent is a Coach

- The Superintendent is a Communicator

- The Superintendent Puts the Right People on the Team

- The Superintendent Builds Relationships

- The Superintendent Focuses on the Vision

- The Superintendent is an Innovator

These 10 traits were common among all of the superintendents and were identified by each of the participants when interviewed about the superintendent's leadership. I determined that for any or all of these traits to have an impact on closing the opportunity gap, the superintendent must be a culturally responsive leader.

\section{Research Question 3}

Research question three asked, "What are the identifiable best practices of exceptional superintendents serving in ethnically and economically diverse school districts?" To answer this question, I applied the best practices of exceptional superintendents serving in ethnically and economically diverse school districts. I identified six common characteristics and one central theme common among the six traits. This theme is culturally responsive leadership. Therefore, the research led to the creation of the Key Characteristics of Culturally Responsive Superintendents Serving in Ethnically and Economically Diverse School Districts. These key 
characteristics were repeatedly identified by superintendents and administrative team members of all three districts during the data collection. The Key Characteristics of Culturally Responsive Superintendents Serving in Ethnically and Economically Diverse School Districts are:

1. The Culturally Responsive Superintendent Recognizes Culture as Paramount to Effective Instruction

2. The Culturally Responsive Superintendent has a Deep Understanding of What Quality Instruction Looks Like

3. The Culturally Responsive Superintendent Effectively Engages The Entire Community

4. The Culturally Responsive Superintendent Hires and Develops Educators Who Understand Culture and Language are Essential to Learning

5. The Culturally Responsive Superintendent Articulates a Vision that Denies DeficitThinking

6. The Culturally Responsive Superintendent Innovates to Ensure Equity and Excellence for Every Child

Those beliefs are organized into the following table which identifies commonly held beliefs identified during interviews with the superintendents and administrative team members. With this knowledge, I created a new model blending the insights from the literature review on CRP with the findings from this study. This table effectively combines what we know about CRP from the literature with the data illuminated collected for this study and provides a new framework for how exceptional superintendents incorporate cultural responsiveness in their daily practice. 
Table 4

The Key Characteristics of Culturally Responsive Superintendents Serving in Ethnically and Economically Diverse School Districts

The Key Characteristics of

Culturally Responsive

Superintendent Leadership

Culturally Responsive Superintendent Beliefs

The Culturally Responsive

Superintendent Recognizes

Culture as Paramount to

Effective Instruction

The Culturally Responsive Superintendent has a Deep Understanding of What Quality Instruction Looks Like

The Culturally Responsive Superintendent Effectively Engages The Entire Community

The Culturally Responsive Superintendent Hires and Develops Educators Who Understand Culture and Language are Essential to Learning

The superintendent rejects a deficit mindset resulting in a narrowing of the opportunity gap through intentional efforts that ensure instruction is student equity-centered. Student culture, strengths and interests are paramount in planning and executing a high-quality instructional program. The child cannot be separated from his or her ethnicity, beliefs, strengths or interests. The superintendent understands the need to personalize instruction and recognizes culture as an asset leading to a narrowing of the opportunity gap.

Exceptional superintendents respect the intellectual potential of students. The superintendent narrows the opportunity gap by maintaining high instructional expectations and ensures educators challenge all students. They do not make negative assumptions about the abilities of children based on family income or culture. Instruction is rigorous as anything less would not be ethical.

The superintendent narrows the opportunity gap by intentionally going out into the community to develop relationships and harvest ideas. The culturally responsive superintendent does not rely on district-organized parent meetings; rather, they go to athletic competition, cultural events, service events, student performances and others. In this way, the superintendent exhibits a belief that schools are an extension of the community. The culturally responsive superintendent also communicates with families and community members in a variety of written formats including electronic and print notifications. The district provides this written communication in the native languages of the community. In soliciting input from the community, the superintendent builds relationships and recognizes the authority of parents as an asset who can provide insight into better teaching and learning.

The superintendent narrows the opportunity gap by hiring, developing and retaining staff trained in culturally responsive pedagogy. Employees understand the expectation to reject deficitthinking. Culturally responsive superintendents often hire educators who share the ethnicity of the community, although this is not an excuse for not teaching to student culture. The superintendent ensures that rich professional development is provided to staff to develop cultural competency. The superintendent is often directly involved in developing the staff as an instructional coach.

Table continued 
The Key Characteristics of

Culturally Responsive

Superintendent Leadership

The Culturally Responsive

Superintendent Articulates a Vision that Denies Deficit-

Thinking

The Culturally Responsive Superintendent Innovates to Ensure Equity and Excellence for Every Child
Culturally Responsive Superintendent Beliefs

The superintendent narrows the opportunity gap by collaborating with students, parents, community leaders, and stakeholders to develop a vision that is culturally responsive. The actions and beliefs of the district leader do not tolerate a watering down of the vision and the superintendent personally assesses the development of the vision as an active participant in schools. The vision guides students to develop a 'critical consciousness' to develop conviction and confidence.

The superintendent narrows the opportunity gap by developing and supporting innovations to help educators differentiate based on culture, knowledge, strengths and interests. Technology is provided to level the playing field and meet the needs of students who do not have home access. Financial resources are not spared to support innovative, culturally responsive solutions to chronic problems in ethnically and economically diverse school districts.

These characteristics are the identified best practices of culturally responsive superintendents serving in ethnically and economically diverse school districts. In Table 5, they are compared to those practices of culturally responsive teachers, which were identified in an analysis of the literature on culturally responsive pedagogy.

\section{Table 5}

Best Practices of Culturally Responsive Teachers

They believe in a personalized learning experience

They believe an understanding of the community is central to achievement

They believe learning requires relationships

They believe in high expectations for students, staff, and community members

They believe family engagement and involvement is paramount

They believe in strong collaboration among faculty and staff

They believe in intentional engagement in culturally responsive practices 
Creating this new model for district-level leadership using CRP will allow district-level leaders to directly impact the opportunity gap by focusing on the assets of a multicultural school district, thus improving the potential to transform the community and the school district. This basic framework provides a new lens to view leadership through empowerment and resiliency.

\section{Implications for Policy and Practice}

This study illuminated several areas that would support and enrich the practice of active school administrators, improve superintendent and principal preparation programs, and inform policy.

\section{Policy}

With respect to policy, the findings produced by this study should have implications on design of superintendent and principal preparation program and/or requirements for serving in a leadership capacity in an economically and ethnically diverse school district. Superintendent and principal leadership preparation programs may use the information provided in this study to improve graduate student outcomes through the implementation of a culturally responsive framework. Furthermore, research could be used to design and provide an evaluation tool for school boards in evaluating superintendent professional practice and student outcomes to identify culturally responsive leadership.

\section{Practice}

I believe that this study has the potential to inform existing and aspiring school superintendents serving in ethnically and economically diverse school districts. The Key Characteristics of Culturally Responsive Superintendents Serving in Ethnically and Economically Diverse School Districts may be interpreted as 'best practices' that should be emulated in any school district, but certainly those with ethnic or economic diversity. 
Additionally, the study provides a framework for superintendents serving in a similar context and may be employed to support school districts struggling to improve achievement and close the opportunity gap.

\section{Epiphany}

Several findings surprised me during the study. First, none of the three superintendents tied their own practice explicitly to the research on culturally responsive pedagogy. My understanding of the framework allowed me to identify the tenets of CRP in the leadership of the identified superintendents. All three superintendents and selected administrative team members were intentional about acknowledging bias, rejecting deficit-thinking and addressing the significance of culture throughout the data collection process. Culturally responsive leadership quickly emerged as an organic function of the school district as administrative team members discussed their own experiences and beliefs. Also, I expected superintendents and administrative team level administrators to discuss 'school business' more often. However, the three identified superintendents' interests, strengths, and formal training were in the area of curriculum and instruction and they directed the expending of district dollars to that end. While the participants spoke occasionally about responsibly allocating the districts' financial resources, the superintendents and administrative team members spoke more often about effective instruction and their role in ensuring an outstanding, culturally-responsive instructional program for all students.

\section{Critique of the Study}

If given the opportunity to begin the study again, I would expand the research beyond the borders of Illinois to see if similar findings emerged in school districts in other states.

Additionally, I would have spent time looking at the size and design of the school districts. It 
would be valuable to study the practices of exceptional superintendents serving in other states that may operate much larger systems. The districts identified for this study were considered small to large by Illinois standards. However, a 'large' district in Illinois where 860 school districts exist may be quite different from a state that operates county-wide schools. Additionally, I would have liked more time to observe the practice of identified superintendents. Unanticipated interruptions and traveling to and from school buildings took additional time that was not built in to my visits. Combined with interviews, this left less time than desired for observation of the exceptional superintendents.

\section{Recommendations for Future Research}

The following areas were identified for further research.

1. The superintendents identified for this study were all from Illinois. It would be valuable to identify if different regions of the country garnered similar results.

2. The literature on Culturally Responsive Leadership at the district-level was almost non-existent. Further qualitative and quantitative research on the positive effects of superintendents who operate from a culturally responsive framework would support a more robust understanding of Culturally Responsive Leadership.

3. Two of the three superintendents were raised in communities other than the district they now serve. One of the superintendents was raised in the community. This warrants further research as one superintendent's deep connection to the community may indicate a better understanding of the district's cultural norms. Research on the benefit of School Boards hiring from within the community would be valuable. 


\section{Conclusions}

Despite a wealth of research and knowledge, the achievement gap, also known as the 'opportunity gap', between white students and non-white, low-income students continues to expand (Illinois Report Card, 2015). It is crucial that researchers spend time investigating the leadership practices and beliefs of exceptional superintendents serving in economically and ethnically diverse school districts to examine the key characteristics of culturally responsive superintendents. This study provides evidence that each and every child deserves high-quality, personalized instruction that recognizes culture as an asset and not a deficit. Superintendents serving in diverse communities will require professional training, mentorship, and policy to support an effective transition to a culturally responsive framework. This study of three exceptional superintendents can serve as a model for district and school level leaders who desire to close the opportunity gap. 


\section{REFERENCES}

Auerbach, S. (2009). Walking the walk: Portraits in leadership for family engagement in urban schools. Journal of School Leadership, 17(6), 699-735.

Baquedano-López, P., Alexander, R., \& Hernandez, S. (2004). Equity issues in parental and community involvement in schools: What educators need to know. Review of Research in Education, 37, 149-182.

Brown, K. M. (2004). Leadership for social justice and equity: Weaving a transformative framework and pedagogy. Educational Administrative Quarterly, 40(1), 79-110.

Bazron, B., Osher, D., \& Fleischman, S. (2005). Research matters: Creating culturally responsive schools. Educational Leadership, 63(1), 83-84.

Beachum, F. (2011). Culturally relevant leadership for complex $21^{\text {st }}$-century school contexts. The sage handbook of educational leadership ( $2^{\text {nd }}$ ed.; pp. 26-35). Thousand Oaks, CA: Sage.

Beachum, F. D., \& McCray, C. R. (2011). Cultural collision and collusion: Reflections on hip-hop culture, values, and schools. New York, NY: Peter Lang Publishing.

Bickman, L., \& Rog, D. J. (2008). Handbook of applied social research methods. Thousand Oaks, CA: Sage.

Bjork, L. G. (2000). The transformative role of the school superintendents: Creating a community of learners. Case studies of the superintendency (pp. 41-60). Lanham, MD: Scarecrow Press, Inc.

Björk, L. G., \& Kowalski, T. J. (2005). The contemporary superintendent. Thousand Oaks, CA: Corwin Press.

Comer, J. P. (2004). Leave no child behind: Preparing today's youth for tomorrow's world. New Haven, CT: Yale University Press.

Cowan, K. T. (2003). The new Title I: The changing landscape of accountability. Tampa, FL: Thompson Publishing Group.

Creswell, J. W. (2009). Research design: Qualitative, quantitative, and mixed methods approaches. Los Angeles, CA: Sage.

Creswell, J.W. (2013). Qualitative inquiry and research design: Choosing among five approaches $\left(2^{\text {nd }}\right.$ ed.). Thousand Oaks, CA: Sage.

DuFour, R., \& Marzano, R. (2011). Leaders of learning: How district, school, and classroom leaders improve student achievement. Bloomington, IN: Solution Tree. 
Eller, J., \& Carlson, H. (2009). So now you're the superintendent. Thousand Oaks, CA: Corwin.

Gay, G. (2010). Culturally responsive teaching: Theory, research, \& practice. New York, NY: Teachers College Press.

Gee, J. P. (2010) How to do discourse analysis: A toolkit. New York, NY: Taylor and Francis.

Glass, T. E., Björk, L., \& Brunner, C. C. (2000). The study of the American school superintendency, 2000: A look at the superintendent of education in the new millennium. Arlington, VA: American Association of School Administrators.

Glesne, C. (2011). Becoming qualitative researchers: An introduction ( $4^{\text {th }}$ ed.). Boston, MA: Pearson.

Guba, E. G., \& Lincoln, Y. S. (1994). Competing paradigms in qualitative research. Handbook of Qualitative Research, 2, 105-117.

Harvey, J., Cambron-McCabe, N., Cunningham, L., \& Koff, R. H. (2013) The Superintendent's Fieldbook ( $3^{\text {rd }}$ ed.). Thousand Oaks, CA: Corwin.

Hatch, J. A. (2002). Doing qualitative research in education settings. Albany, NY: State University of New York Press.

Hatt, B. (2012). Smartness as a cultural practice in schools. American Educational Research Journal, 49(3), 438-460.

Hatt, B. (2007). Street smarts vs. book smarts: The figured world of smartness in the lives of marginalized, urban youth. The Urban Review, 39(2) 145-166.

Illinois School Report Card. Illinois State Board of Education, Division of Data Analysis and Progress Reporting. (2015). Retrieved 20 November, 2015.

Irvine, J., Armento, B., Causey, V., Jones, J., Frasher, R., \& Weinburgh, M. (2000). Culturally responsive teaching: Lesson planning for elementary and middle grades. New York, NY: McGraw-Hill Inc.

Kadner, P. (2015, March 26). Illinois schools have biggest funding gap in nation. Chicago Tribune. Retrieved from http://www.chicagotribune.com/suburbs/ dailysouthtown/opinion/ct-sta-kadner-studies-st-0327-20150326-column.html

Kannapel, P. J., Clements, S. K., Taylor, D., \& Hibpshman, T. (2005). Inside the black box of high-performing high-poverty schools. Lexington, KY: Prichard Committee for Academic Excellence.

Kowalski, T. J. (2013). The school superintendent: Theory, practice, and cases $\left(3^{\text {rd }}\right.$ ed.). Thousand Oaks, CA: Sage Press. 
Ladson-Billings, G. (1995). But that's just good teaching: The case for culturally relevant pedagogy. Theory Into Practice, 34(3), 159-165.

Ladson-Billings, G. (2014). Culturally relevant pedagogy 2.0: Aka the remix. Harvard Educational Review, 84(1), 74-84.

Ladson-Billings, G. (2006). From the achievement gap to the education debt: Understanding achievement in US schools. Educational Researcher, 35(7), 3-12.

Ladson-Billings, G. (2000). Fighting for our lives: Preparing teachers to teach African American students. Journal of Teacher Education, 51(3), 206-214.

Ladson-Billings, G. (2009). The dreamkeepers: Successful teachers for African-American children. San Francisco, CA: Jossey-Bass.

Latham, A. (1997). Responding to cultural learning styles. Educational Leadership, 54(8), 88-89.

Libka, R. J. (2012). The relationship between Illinois school district superintendent longevity and high school student achievement (Doctoral dissertation). Retrieved from ProQuest Dissertations and Theses. (1022504468)

Lincoln, Y. S., \& Guba, E. G. (1985). Naturalistic inquiry. Newbury Park, CA: Sage.

Lindsey, D., Lindsey, R., Nuri-Robins, K., \& Terrell, R. (2011) Culturally proficient instruction: A guide for people who teach. Thousand Oaks, CA: Corwin Press.

Lyman, L. (2000). How do they know you care?: A principal's challenge. New York, NY: Teachers College Press.

Lyman, L., \& Villani, C. (2004). Best leadership practices for high-poverty schools. Lanham, MD: Scarecrow Education.

Marzano, R., \& Waters, T. (2009). District leadership that works. Bloomington, IN: Solution Tree Press.

Maslow, A. H. (1943). A theory of human motivation. Psychological Review, 50(4), 370-96.

Maxwell, J. A. (2005). Qualitative research design: An interactive approach (2 ${ }^{\text {nd }}$ ed.). Thousand Oaks, CA: Sage.

National Commission on Excellence. (1983). A nation at risk: The imperative for educational reform. Washington, DC: Government Printing Office.

No Child Left Behind Act (NCLB), Pub. L. 107-110, § 115, Stat. 1425 (2001). 
Paris, D. (2012). Culturally sustaining pedagogy a needed change in stance, terminology, and practice. Educational Researcher, 41(3), 93-97.

Parrot, W. H., \& Budge, K. M., (2012). Turning high-poverty schools into high performing schools. Alexandria, VA: ASCD.

Pascopella, A. (2011). Superintendent staying power: District Administrator Magazine 47(4). 31-36.

Rost, J. (1991). Leadership for the Twenty-First Century. New York, NY: Praeger.

Saldaña, J. (2016). The Coding Manual for Qualitative Researchers. Thousand Oaks, CA: Sage.

Sergiovanni, T. (1992). Moral leadership. San Francisco, CA: Jossey-Bass.

Smith, J. G. (2006). Parental involvement in education among low income families: A case study. School Community Journal, 16(1), 43-56

The Education Trust. (2015). Funding gaps 2015: Too many states still spend less on educating students who need the most. Washington, DC: The Education Trust.

Valencia, R. R. (1997). The evolution of deficit-thinking: Educational thought and practice. Abingdon, OX: Routledge Falmer.

Wagner, L. (2010). The savvy superintendent: Leading instruction to the top of the class. Lanham, MD: Rowman and Littlefield.

Wright, H., \& Harris, S. (2010). The role of the superintendent in closing the achievement gap in diverse small school districts. Planning and Changing, 41(3/4), 220-233. 
APPENDIX A

INTERVIEW GUIDES 


\section{SUPERINTENDENT INTERVIEW GUIDE}

1. Please share your educational and personal background.

a. Family background

b. Education (degrees earned and where)

c. Current/Previous roles in education

d. How did you end up entering into the superintendency?

i. Did it begin because you were "tapped" and asked to apply or was it a personal interest?

ii. What was your motivation for pursuing a leadership position?

2. Please tell me about your leadership philosophy.

3. Please tell me about your current district.

a. Most positive aspects of the district

b. Greatest challenges.

1. Walk me through a typical work day for you.

2. How do you organize and prioritize your time?

4. I noticed your district has had steadily gains in achievement scores (according to PARCC/ISAT). What do you think are the factors that have led to gains in achievement scores in your district?

1. Are there particular factors that you think are important for improving achievement of students of color?

2. What about low income students - similar strategies or different?

5. How would you describe yourself as a leader?

a. Style?

i. Examples?

b. Strengths vs. areas of needed growth?

i. Example?

c. How do you think you have grown as a leader since you first started?

i. Example?

d. What process do you go through to make difficult decisions?

i. Example?

6. What core beliefs guide you as a leader?

i. Example when you have used them to guide a decision?

b. Where do your core beliefs come from? How did they develop as your core beliefs?

7. What do you believe it means to be an effective superintendent in a diverse school district?

8. What areas do you feel you must improve your leadership as a superintendent serving in an ethnically and economically diverse school district?

9. What are priorities in the district when it comes to change and decision-making?

a. If there is change to be made, how does it get done?

10. How are decisions made in the district? 


\section{SUPERINTENDENT-SELECTED ADMINISTRATIVE TEAM MEMBER}

\section{INTERVIEW GUIDE}

1. Please share your educational and personal background.
a. Family background
b. Education (degrees earned and where)
c. Current/Previous roles in education

2. Please tell me about your leadership philosophy.

3. Please tell me about your current district.

a. Most positive aspects of the district

b. Greatest challenges

3. Walk me through a typical work day for you.

4. How do you organize and prioritize your time?

4. I noticed your district has had steadily gains in achievement scores (according to PARCC/ISAT). What do you think are the factors that have led to gains in achievement scores in your district?

3. Are there particular factors that you think are important for improving achievement of students of color?

4. What about low income students - similar strategies or different?

5. What is the role of the superintendent in the improvement?

5. In your opinion, what are the strengths of the superintendent as a leader?

a. How does the superintendent organize and prioritize time?

b. How does the superintendent run meetings?

c. How is the superintendent connected to the community?

6. Are there any common statements or mantras you hear from the superintendent

a. Why do you think he/she uses that saying so often?

7. What would you identify as the superintendent's core beliefs?

a. Any examples of seeing these core beliefs in action?

8. What reform initiative(s) has the superintendent introduced that have promoted the district's success?

a. What impact have these initiatives had on low income students and families? Students of color?

9. How are decisions made in the district?

10. What are priorities in the district when it comes to change and decision-making?

a. If there is change to be made, how does it get done? 
APPENDIX B

DATA ACCOUNTING LOG

\begin{tabular}{|c|c|c|c|c|c|c|c|c|c|c|}
\hline & Supt 1 & Cab 1 & Cab 2 & Supt 2 & Cab 1 & Cab 2 & Supt 3 & Cab 1 & Cab 2 & Cab 3 \\
\hline Interview & $\begin{array}{l}\text { Early } \\
\text { Nov. } \\
2017\end{array}$ & $\begin{array}{l}\text { Early } \\
\text { Nov. } \\
2017\end{array}$ & $\begin{array}{l}\text { Early } \\
\text { Nov. } \\
2017\end{array}$ & $\begin{array}{l}\text { Mid } \\
\text { Nov. } \\
2017\end{array}$ & $\begin{array}{l}\text { Mid } \\
\text { Nov. } \\
2017\end{array}$ & $\begin{array}{l}\text { Mid } \\
\text { Nov. } \\
2017\end{array}$ & $\begin{array}{l}\text { Late } \\
\text { Nov. } \\
2017\end{array}$ & $\begin{array}{l}\text { Late } \\
\text { Nov. } \\
2017\end{array}$ & $\begin{array}{l}\text { Late } \\
\text { Nov. } \\
2017\end{array}$ & $\begin{array}{l}\text { Late } \\
\text { Nov. } \\
2017\end{array}$ \\
\hline Location & $\begin{array}{l}\text { District } \\
\text { Office }\end{array}$ & $\begin{array}{c}\text { District } \\
\text { Office }\end{array}$ & $\begin{array}{c}\text { District } \\
\text { Office }\end{array}$ & $\begin{array}{c}\text { District } \\
\text { Office }\end{array}$ & $\begin{array}{c}\text { District } \\
\text { Office }\end{array}$ & $\begin{array}{c}\text { District } \\
\text { Office }\end{array}$ & $\begin{array}{c}\text { District } \\
\text { Office }\end{array}$ & $\begin{array}{c}\text { District } \\
\text { Office }\end{array}$ & $\begin{array}{c}\text { District } \\
\text { Office }\end{array}$ & Phone \\
\hline Observation & $\begin{array}{l}\text { Early } \\
\text { Nov. } \\
2017\end{array}$ & N/A & $\mathrm{N} / \mathrm{A}$ & $\begin{array}{l}\text { Mid } \\
\text { Nov. } \\
2017\end{array}$ & $\mathrm{~N} / \mathrm{A}$ & $N / A$ & $\begin{array}{l}\text { Late } \\
\text { Nov. } \\
2017\end{array}$ & $N / A$ & $\mathrm{~N} / \mathrm{A}$ & $\mathrm{N} / \mathrm{A}$ \\
\hline $\begin{array}{l}\text { Document } \\
\text { District } \\
\text { Website } \\
\text { ("X" or N/A) }\end{array}$ & $x$ & N/A & $\mathrm{N} / \mathrm{A}$ & $x$ & $\mathrm{~N} / \mathrm{A}$ & $\mathrm{N} / \mathrm{A}$ & $x$ & $N / A$ & $\mathrm{~N} / \mathrm{A}$ & $\mathrm{N} / \mathrm{A}$ \\
\hline $\begin{array}{l}\text { Document } \\
\text { Assessment } \\
\text { Data - } \\
\text { Illinois } \\
\text { Report Card }\end{array}$ & $x$ & $\mathrm{~N} / \mathrm{A}$ & $\mathrm{N} / \mathrm{A}$ & $x$ & $\mathrm{~N} / \mathrm{A}$ & $\mathrm{N} / \mathrm{A}$ & $x$ & $\mathrm{~N} / \mathrm{A}$ & $\mathrm{N} / \mathrm{A}$ & $\mathrm{N} / \mathrm{A}$ \\
\hline
\end{tabular}




\section{APPENDIX C}

OBSERVATIONAL PROTOCOL

Date:

Time:

Length of activity:

minutes

Site: Participants:

\section{Description:}

*During my fieldwork I will collect information from observation and document on the observation protocol.

\begin{tabular}{|c|c|}
\hline Descriptive Notes & Reflective Notes \\
\hline Physical setting: visual layout of space & $\begin{array}{l}\text { Reflective comments: questions to } \\
\text { self, observations of nonverbal } \\
\text { behavior, my interpretations }\end{array}$ \\
\hline $\begin{array}{l}\text { Description of participants: } \\
\text { - Physical description } \\
\text { - Attire } \\
\text { - Grooming } \\
\text { Descriptions of Interactions: } \\
\text { - How do they treat people? } \\
\circ \text { Handshakes? } \\
\circ \quad \text { Smiles? } \\
\circ \quad \text { Know by name? } \\
\circ \text { How do they treat others? } \\
\text { What do they talk about with others? } \\
\circ \text { Do they discuss class and race? } \\
\circ \quad \text { Are deficits or strengths the focus? } \\
\circ \quad \text { How much do they discuss/participate in }\end{array}$ & \\
\hline
\end{tabular}




\begin{tabular}{|c|c|}
\hline $\begin{array}{l}\text { meeting student outcomes vs. completing } \\
\text { administrative tasks? } \\
\text { Description of activities } \\
\text { - Does CRP come up organically? } \\
\text { - How are meetings run? } \\
\text { - What are the topics discussed through the day? } \\
\text { Description of individuals engaged in activity } \\
\text { - Are interactions positive? } \\
\text { - Do individuals appear to act with purpose? } \\
\text { - Do people seem happy? } \\
\text { - Are people tired or energized? } \\
\text { Description/Sequence of activity over time } \\
\text { - How is time used? } \\
\quad \text { How do they prioritize time? } \\
\quad \text { Where do they spend their time through the } \\
\quad \text { day? Office, schools, etc.? } \\
\text { Unplanned events } \\
\text { - Participants' comments: expressed in quotes }\end{array}$ & \\
\hline The researcher's observation of what seems to be occurring & \\
\hline
\end{tabular}


APPENDIX D

LETTERS OF CONSENT 


\section{LETTER OF CONSENT FOR ADULTS (Administrative team)}

\section{Characterizing Exceptional Superintendent Leadership in Ethnically and Economically Diverse School Districts}

\section{Dear Partner in Research:}

I am a graduate student under the direction of Dr. Beth Hatt in the Department of Educational Administration and Foundations at Illinois State University. I am conducting a research study to identify the leadership styles of effective superintendents serving in racially and economically diverse communities. I am inviting your participation, which will involve one interview lasting approximately one hour.

Your participation in this study is voluntary and all participants must be 18 years of age or older. If you choose not to participate or to withdraw from the study at any time, it will not impact my research and all mention of you in any capacity will be removed from the study. Your responses are confidential. You are able to skip any questions you do not feel comfortable answering.

Although there may be no direct benefit to you, a possible benefit of your participation is a greater understanding of effective practices of superintendents. Participants may become uncomfortable while being interviewed or observed. You are able to refuse to answer any questions, quit the study at any time, and/or ask for particular aspects of their day to not be included as data. An additional risk would be a potential breach in confidentiality. Every effort will be made to maintain confidentiality. All data will be kept in a password protected computer or locked office and administrative team. Names will be replaced with pseudonyms.

If you have any questions concerning the research study, please call me at or e-mail me at or you may contact my faculty advisor, Dr. Beth Hatt, by phone (309-438-7187) or email (hatt.beth@ gmail.com). If you have any questions about your rights as a subject/participant in this research, or if you feel you have been placed at risk, you can contact the Research Ethics \& Compliance Office at Illinois State University at (309) 438-2529.

Sincerely,

Nicholas M. Henkle

Ed.D candidate, Illinois State University

I consent to participating in the above study. I understand that interviews may be recorded by audio for later data analysis.

Signature

Date 


\title{
LETTER OF CONSENT FOR ADULTS (Superintendents)
}

\author{
Characterizing Exceptional Superintendent Leadership in Ethnically and \\ Economically Diverse School Districts
}

Dear Partner in Research:

I am a graduate student under the direction of Dr. Beth Hatt in the Department of Educational Administration and Foundations at Illinois State University. I am conducting a research study to identify the leadership styles of effective superintendents serving in racially and economically diverse communities. I am inviting your participation, which will involve up to three interviews lasting approximately one hour each, three full-day observations and pertinent documents or artifacts. These interviews and observations may include several meetings over a 3-month period. The artifacts may include documents or photos that you believe provide examples of your accomplishments as a leader in your district. The artifacts collected will be determined in collaboration with you. Potential artifacts could include but are not limited to the district strategic plan, pictures of constructed or remodeled buildings, or fliers advertising district events.

Your participation in this study is voluntary and all participants must be 18 years of age or older. If you choose not to participate or to withdraw from the study at any time, it will not impact my research and all mention of you in any capacity will be removed from the study. Your responses are confidential and any information that might allow someone to identify you will not be disclosed. You are able to skip any questions you do not feel comfortable answering.

Although there may be no direct benefit to you, a possible benefit of your participation is a greater understanding of effective practices of superintendents. Participants may become uncomfortable while being interviewed or observed and there are potential risks to reputation and employability. Risks to reputation and employability are minimized by the research focusing solely on your best practices as superintendent. You are able to refuse to answer any questions, quit the study at any time, and/or ask for particular aspects of their day to not be included as data. An additional risk would be a potential breach in confidentiality. Every effort will be made to maintain confidentiality. All data will be kept in a password protected computer or locked office and administrative team. Names will be replaced with pseudonyms.

If you have any questions concerning the research study, please call me at ( $\square) \square$ or e-mail me at $\quad$ or you may contact my faculty advisor, Dr. Beth Hatt, by phone (309-438-7187) or email (hatt.beth@gmail.com). If you have any questions about your rights as a subject/participant in this research, or if you feel you have been placed at risk, you can contact the Research Ethics \& Compliance Office at Illinois State University at (309) 438-2529.

Sincerely,

Nicholas M. Henkle

Ed. D candidate, Illinois State University

I consent to participating in the above study. I understand that interviews may be recorded by audio for later data analysis.

Signature

Date 


\section{APPENDIX E}

\section{SUPERINTENDENT IDENTIFICATION TOOL}

(Identified by Regional Superintendents as 'Exemplary')

\begin{tabular}{|c|c|c|c|c|c|c|c|}
\hline $\begin{array}{l}\text { Superintendent } \\
\text { Name } \\
\text { (organized by } \\
\text { county) }\end{array}$ & $\begin{array}{l}\text { DISTRICT } \\
\text { Name }\end{array}$ & $\begin{array}{c}5 \\
\text { years sup. } \\
\text { Experience }\end{array}$ & $\begin{array}{l}3 \text { years } \\
\text { in } \\
\text { current } \\
\text { position }\end{array}$ & $\begin{array}{c}\text { District } \\
40 \% \\
\text { low } \\
\text { income }\end{array}$ & $\begin{array}{c}\text { District } \\
40 \% \\
\text { non- } \\
\text { white }\end{array}$ & $\begin{array}{l}\text { Achievement } \\
\text { Gap? }\end{array}$ & $\begin{array}{c}\text { Identified } \\
\text { as } \\
\text { Exemplary } \\
\text { by ROE? }\end{array}$ \\
\hline \multicolumn{8}{|l|}{ County } \\
\hline & & & & & & & \\
\hline & & & & & & & \\
\hline \multicolumn{8}{|l|}{ County } \\
\hline & & & & & & & \\
\hline & & & & & & & \\
\hline \multicolumn{8}{|l|}{ County } \\
\hline & & & & & & & \\
\hline & & & & & & & \\
\hline \multicolumn{8}{|l|}{ County } \\
\hline & & & & & & & \\
\hline & & & & & & & \\
\hline \multicolumn{8}{|l|}{ County } \\
\hline & & & & & & & \\
\hline & & & & & & & \\
\hline
\end{tabular}




\section{APPENDIX F}

\section{CODING SPREADSHEET}

\begin{tabular}{|c|c|c|c|c|c|c|c|c|}
\hline QUESTIONS & $\begin{array}{l}\text { LEADERSHIP } \\
\text { PHILOSOPPHY }\end{array}$ & STRENGTHS & ACTIONS & $\begin{array}{l}\text { LEADERSHIP } \\
\text { STYLE }\end{array}$ & $\begin{array}{l}\text { CORE } \\
\text { BELIEFS }\end{array}$ & $\begin{array}{l}\text { IMPACT } \\
\text { ON } \\
\text { STUDENTS }\end{array}$ & $\begin{array}{l}\text { DECISION- } \\
\text { MAKING } \\
\text { PROCESS }\end{array}$ & FREQUENCY \\
\hline \multicolumn{9}{|l|}{ THEMES } \\
\hline COMMUNICATOR & & & & & & & & $\begin{array}{l}\text { Communicator: } \\
16\end{array}$ \\
\hline district 1 & & & C1B & $\mathrm{C} 1 \mathrm{~A}$ & & & & \\
\hline district 2 & & & S2 & $\mathrm{C} 2 \mathrm{~A}$ & & & $\begin{array}{l}\text { S2, } \\
\text { C2A, } \\
\text { C2B }\end{array}$ & \\
\hline district 3 & S3 & & & $\begin{array}{l}\text { S3, C3A, } \\
\text { C3B, } \\
\text { C3C }\end{array}$ & $\begin{array}{l}\text { S3, } \\
\text { C3B }\end{array}$ & C3C & S3 & \\
\hline $\begin{array}{l}\text { STUDENT } \\
\text { CENTERED }\end{array}$ & & & & & & & & $\begin{array}{l}\text { Student } \\
\text { Centered: } 32\end{array}$ \\
\hline district 1 & & $\begin{array}{l}\text { S1, C1A, } \\
\text { C1B }\end{array}$ & C1A, C1B & C1A, C1B & $\begin{array}{l}\text { S1, } \\
\text { C1A, } \\
\text { C1B }\end{array}$ & C1A & & \\
\hline district 2 & S2 & $\mathrm{S} 2, \mathrm{C} 2 \mathrm{~A}$ & S2 & $\begin{array}{l}\text { S2, C2A, } \\
\text { C2B }\end{array}$ & $\begin{array}{l}\text { S2, } \\
\text { C2A, } \\
\text { C2B }\end{array}$ & & & \\
\hline district 3 & S3 & S3 & C3B & C3A & $\begin{array}{l}\text { S3, } \\
\text { C3A, } \\
\text { C3B, } \\
\text { C3C }\end{array}$ & $\begin{array}{l}\text { S3, } \\
\text { C3A, } \\
\text { C3C }\end{array}$ & & \\
\hline $\begin{array}{l}\text { BUILDS } \\
\text { RELATIONSHIPS }\end{array}$ & & & & & & & & $\begin{array}{l}\text { Relationships: } \\
12\end{array}$ \\
\hline district 1 & & S1 & & & $\mathrm{C} 1 \mathrm{~A}$ & & & \\
\hline district 2 & & & & $\begin{array}{l}\text { S2, C2A, } \\
\text { C2B }\end{array}$ & $\mathrm{C} 2 \mathrm{~A}$ & & & \\
\hline district 3 & & S3, C3A & С3A, С3B & C3A & & $\mathrm{C} 3 \mathrm{C}$ & & \\
\hline $\begin{array}{l}\text { CULTURALLY } \\
\text { RESPONSIVE }\end{array}$ & & & & & & & & CRP: 33 \\
\hline district 1 & & $\begin{array}{l}\text { C1A, } \\
\text { C1B }\end{array}$ & $\begin{array}{l}\text { S1, C1A, } \\
\text { C1B }\end{array}$ & $\begin{array}{l}\text { S1, C1A, } \\
\text { C1B }\end{array}$ & $\begin{array}{l}\text { S1, } \\
\text { C1A }\end{array}$ & $\begin{array}{l}\text { S1, } \\
\text { C1A, } \\
\text { C1B }\end{array}$ & $\begin{array}{l}\text { C1A } \\
\text { C1B }\end{array}$ & \\
\hline district 2 & & S2 & $\begin{array}{l}\text { S2, C2A, } \\
\text { C2B }\end{array}$ & S2, C2A & & $\begin{array}{l}\text { S2, } \\
\text { C2A, } \\
\text { C2B }\end{array}$ & & \\
\hline district 3 & & S3 & $\begin{array}{l}\text { S3, C3A, } \\
\text { C3B }\end{array}$ & S3, C3C & $\begin{array}{l}\text { S3, } \\
\text { C3A, } \\
\text { C3C, }\end{array}$ & S3, C3B & & \\
\hline
\end{tabular}




\begin{tabular}{|c|c|c|c|c|c|c|c|c|}
\hline COLLABORATIVE & & & & & & & & Collaborative: 20 \\
\hline district 1 & S1 & & & & & & $\begin{array}{l}\text { S1 } \\
\text { C1A, } \\
\text { C1B }\end{array}$ & \\
\hline district 2 & S2 & $\mathrm{C} 2 \mathrm{~A}$ & & $\begin{array}{l}\text { S2,C2A, } \\
\text { C2B }\end{array}$ & $\mathrm{C} 2 \mathrm{~A}$ & & $\begin{array}{l}\mathrm{S} 2, \\
\mathrm{C} 2 \mathrm{~A}, \\
\mathrm{C} 2 \mathrm{~B}\end{array}$ & \\
\hline district 3 & & S3 & & & & $\begin{array}{l}\text { C3A, } \\
\text { C3C }\end{array}$ & $\begin{array}{l}\text { S3, } \\
\text { C3A, } \\
\text { C3B, } \\
\text { C3C }\end{array}$ & \\
\hline INNOVATIVE & & & & & & & & Innovative: 10 \\
\hline district 1 & & S1 & & C1B & C1B & & & \\
\hline district 2 & S2 & & & & & $\mathrm{C} 2 \mathrm{~A}$ & & \\
\hline district 3 & & & S3 & S3, C3B & & S3, C3A & & \\
\hline $\begin{array}{l}\text { RIGHT PEOPLE } \\
\text { ON TEAM }\end{array}$ & & & & & & & & $\begin{array}{l}\text { People on Team: } \\
14\end{array}$ \\
\hline district 1 & S1 & & C1A & S1 & & & & \\
\hline district 2 & & & S2 & & & S2 & & \\
\hline district 3 & & S3 & С3A, С3В & $\begin{array}{l}\text { C3A,C3B, } \\
\text { C3C }\end{array}$ & $\begin{array}{l}\text { S3, } \\
\text { C3A }\end{array}$ & C3A & & \\
\hline $\begin{array}{l}\text { INSTRUCTIONAL } \\
\text { FOCUS }\end{array}$ & & & & & & & & $\begin{array}{l}\text { Instructional } \\
\text { Focus: } 21\end{array}$ \\
\hline district 1 & & $\begin{array}{l}\text { S1, C1A, } \\
\text { C1B }\end{array}$ & & $\begin{array}{l}\text { S1, C1A, } \\
\text { C1B }\end{array}$ & & & $\begin{array}{l}\text { S1 } \\
\text { C1A }\end{array}$ & \\
\hline district 2 & & S2 & $\begin{array}{l}\text { S2, C2A, } \\
\text { C2B }\end{array}$ & & & $\mathrm{C} 2 \mathrm{~A}$ & & \\
\hline district 3 & & S3, C3A & $\begin{array}{l}\text { S3, C3A, } \\
\text { C3C }\end{array}$ & C3C & S3 & S3 & & \\
\hline FOCUSED VISION & & & & & & & & $\begin{array}{l}\text { Focused Vision: } \\
11\end{array}$ \\
\hline district 1 & & & C1B & $\begin{array}{l}\text { S1, C1A, } \\
\text { C1B }\end{array}$ & C1B & & & \\
\hline district 2 & & & & S2, C2A & & & & \\
\hline district 3 & S3 & $\mathrm{C} 3 \mathrm{C}$ & C3B & & & C3A & & \\
\hline $\mathrm{COACH} / \mathrm{PD}$ & & & & & & & & Coach/PD: 20 \\
\hline district 1 & S1 & & $\begin{array}{l}\text { MS. } \\
\text { ANDREWS }\end{array}$ & $\begin{array}{l}\text { S1, C1A } \\
\text { C1B }\end{array}$ & C1B & & S1 & \\
\hline district 2 & & & $\begin{array}{l}\text { S2, } \\
\text { C2A }\end{array}$ & $\begin{array}{l}\text { S2, } \\
\text { C2A }\end{array}$ & & $\begin{array}{l}\text { S2,C2A, } \\
\text { C2B }\end{array}$ & & \\
\hline district 3 & S3 & S3 & & $\begin{array}{l}\text { S3, C3A, } \\
\text { C3B }\end{array}$ & C3A & & & \\
\hline
\end{tabular}

